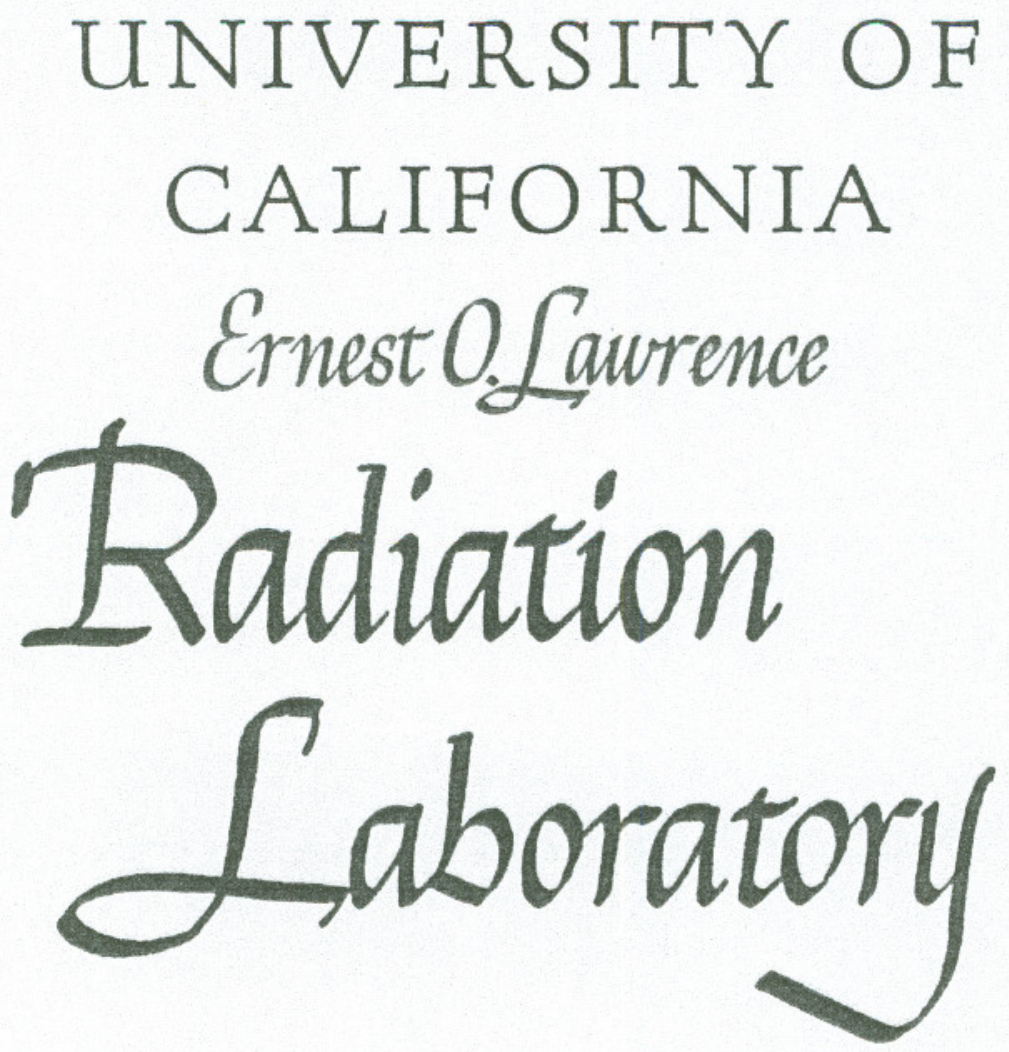

\title{
CHEMISTRY DIVISION SEMIANNUAL REPORT June through November 1959
}

TWO-WEEK LOAN COPY

This is a Library Circulating Copy which may be borrowed for two weeks.

For a personal retention copy, call

Tech. Info. Division, Ext. 5545 
UCRL-9093

Chemistry-General UC-4

TID-4500 (15th Ed.)

UNIVERSITY OF CALIFORNIA

Lawrence Radiation Laboratory

University of California

Contract No. W-7405-eng-48

\section{CHEMISTRY DIVISION SEMIANNUAL REPORT}

June through November 1959

February 8, 1960 


\section{Printed in USA. Price $\$ 2.50$. Available from the office of Technical Services \\ U. S. Department of Commerce Washingt on 25 , D.C.}




\section{CHEMISTR Y DIVISION SEMIANNUAL REPORT}

June through November 1959

$\underline{\text { Gontents }}$

\section{NUCLEAR CHEMISTRY}

\section{NUCLEAR REACTION STUDIES}

Nuclear Reactions Induced by High-Energy Protons and Mesons . . . . . . . . . . . . 6

Interaction of High-Energy Protons with Indium . . . . 8

Interaction of High-Energy Protons and Alpha

Particles with Iodine-127 . . . . . . 9

Elastic Scattering of Heavy Ions . . . . . . . . . . 10

Elastic Scattering of 31-Mev He${ }^{3}$ Ions by $\mathrm{Cu}$ and $\mathrm{Bi}$. . . . 12

Nuclear Reactions in Carbon and Nitrogen . . . . . . . 15

Polarized-Proton Beam from p-He $\mathrm{H}^{4}$ Elastic Scattering . . 18

$(p, a)$ Reactions . . . . . . . . . . . . . . . . 19

fa,t) Reactions . . . . . . . . . . . . . 21

Heavy-Ion Coulomb Excitation . . . . . . . . . . 25

\section{NUCLEAR FISSION}

Fission of Gold With 120-Mev Carbon Ions . . . . . . . 26

Angular-Momentum Effects in Heavy-Ion-Induced Fission . . 27

The Angular Distribution of Fission Fragments . . . . . 27

Mass Spectrometric Study of Charged-Particle-Induced

Fission.......... . . . . 28

\section{RADIOACTIVITY AND NUCLEAR PROPERTIES}

Multiple Fission by $\mathrm{C}^{12}$ Interactions with $\mathrm{U}^{238}$. . . . . 34

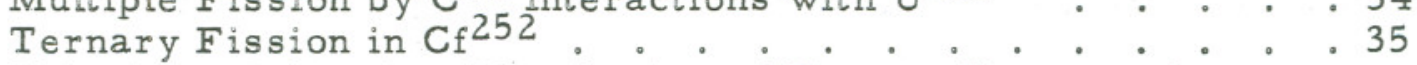

Velocity and Angular Distribution of Prompt Neutrons from

Spontaneous Fission of $\mathrm{Cf}_{\mathrm{f}} 252$. . . . . . . 36

Self-Transfer of $\mathrm{Cf}^{252}$. . . . . . . . . . . . . . . . . . 38

Production and Purification of Heavy Isotopes . . . . . . 39

On the $\mathrm{Am}^{242}$ Is omeric Pair . . . . . . . . . . . 39

Measurement of the Half-Lives of the 74.6-kev Excited

State of $\mathrm{Np}^{239}$ and the 68-kev Excited State of Ra226 . 41

Analysis of Delayed-Coincidence Curves . . . . . . . 42

Gamma-Gamma Angular-Distribution Studies in the Beta

Decay of $\mathrm{U}^{237}$. . . . . . . . . . . . 44 44

$\mathrm{Np}^{234}$ Conversion-Electron Spectrum

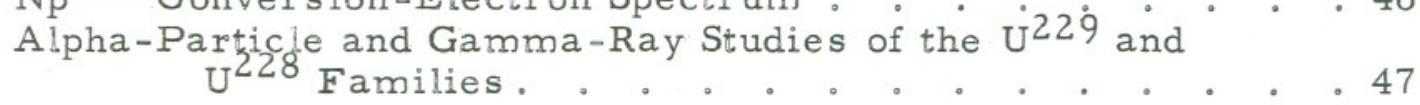

New Neutron-Deficient Is otopes of Antimony and

Tellurium . . . . . . . . . . . 53

Freceding Semiannual Reports: UCRL-8867, UCRL-8618 
Magnetic Moment of Cerium-137m . . . . . . . . . 58

Nuclear Alignment of Rare Earth Isotopes . . . . . . . 59

Electric Hyperfine-Structure Alignment of Iodine . . . . . 60

Atomic Beams . . . . . . . . . . . . . . . 61

Calculation of Gyromagnetic Ratio for Rotation of

Even-Even Nüclei . . . . . . . . . 63

Intrinsic Quadrupole Moments of Deformed Nuclei . . . . 64

\section{CHEMICAL AND PHYSICAL PROPERTIES}

Paramagnetic Resonance in Tetravalent $\mathrm{Pa}^{231} . .^{2}$. . 66

Energy Levels of Tm IV . . . . . . . . . . 67

Spectra of $\mathrm{Pm} \mathrm{Cl}_{3}$. . . . . . . . . . . . 67

The Near Infrared Absorption Spectrum of $\mathrm{CeCl}_{3}$. . . . 67

Mass Spectroscopy . . . . . . . . . . . 68

Radiation Chemistry Group . . . . . . . . . . . 70

Hot-Atom Chemistry of Sulfur-35 . . . . . . . . 71

Preparation and Properties of Curium Metal. . . . . . . 74

Preparation of $\mathrm{AmO}$ and $\mathrm{PuO}$. . . . . . . . . . 74

Americium Metal: Preparation and Crystal Structure . . . 75

Structures of Organic Compounds . . . . . . . . . . 77

Polarized Octahedra in Barium Tetratitanate . . . . . . 77

Least Squares and Choice of Origin in Polar Space Groups . . 78

\section{INSTRUMENT ATION}

A New Permanent-Magnet $\beta$ Spectrograph . . . . . . . 79 Modification of $25-\mathrm{cm}$ Double-Focusing $\beta$ Spectrometer . . . 81

Absolute Beta Counting . . . . . . . . . . . . . 82

Solid-State Particle Detectors . . . . . . . . . . 83

A Precision High-Geometry Alpha Chamber . . . . . . . 84

\section{GENERAL CHEMISTRY}

METALS AND HIGH-TEMPERATURE THERMODYNAMICS

Absolute-Lifetime Apparatus . . . . . . . . . . . 86

Magnesium Oxide and Hydroxide Gaseous Species . . . . 86

Absolute Absorption Coefficient of $\mathrm{C}_{2}$ and $\mathrm{CN}$. . . . . . 86

Thermodynamic Compilations . . . . . . . . . 86

\section{THEORETICAL ST UDIES}

Theory of Bonding of Gaseous Halides and Oxides of

Transition Metals . . . . . . . . 87

Low Excited States in $\mathrm{C}_{2}$ Molecule . . . . . . . . . 87

Calculation of the "f Numbers" for Allowed Transitions
in $\mathrm{C}_{2}$ Molecules . . . . . . . . . 87

Abundance of ${ }^{2} C_{2}$ Molecule in the Solar Reversal Layer . . . 87

Probability of the ${ }^{3} \prod_{\mathrm{u}} \rightarrow{ }^{1} \Sigma_{\mathrm{g}}^{+}$Forbidden Transition in

$\mathrm{C}_{2}$ Molecule . . . . . . . . . . 87

Electronic States of $\mathrm{C}_{3}$ Molecule. . . . . . . . . . 88 
General Theory of "Core Polarization" and Inter-and Intra-Atomic "Van der Waals" Forces . . . . . . . . . 88

"Core Polarization" in Alkali Molecule-Ions . . . . . 88

\section{SPECTROSCOPY}

Infrared Spectra of Marginally Metallic Systems . . . . . 89

Microwave Spectroscopy at Elevated Temperatures . . . . 89

Nuclear-Magnetic-Resonance Spectra of Some

Molecular Complexes . . . . . . . . 90

NMR Studies of Hydrogen Bonding . . . . . . . . . . 90

Hydrogen F luoride Systems 。 . . . . . . . . . . . 90

NMR: Knight Shift in Solutions of Calcium in 3 Liquid Ammonia . . . . . 90

Electron-Spin Resonance: Paramagnetic Resonance . . . . 91

Ultraviolet: Matrix-Isolation Studies of Carbon Japor . . . 91

\section{STATISTICAL THERMODYNAMICS}

Second Virial Coefficient . . . . . . . . . . 92

SOLID-STATE AND LOW-TEMPERATURE THERMODYNAMICS

Interactions Between Molecules Adsorbed on a

Surface .. . . . . . . . . . . . 93

Studies in the Solid-State Chemistry of Silver Oxide . . . . 93

Heat Capacity of Solid Hydrogen Under Pressure . . , . . 93

Heat Capacity of Bismuth . . . . . . . . . . 93

Heat Capacity of the Alkali Metals at

Temperatures Below $1^{\circ} \mathrm{K}$. . . . . . . . . 94

Heat Capacity of Gallium . . . . . . . . . . . . . 94

Heat Capacity of Small Particles of MgO . . . . . . . 94

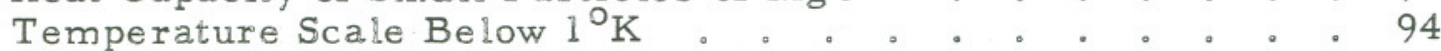

Heat Capacity of La-Gd Alloys . . . . . . . . . . 95

\section{INORGANIC CHEMISTRY}

Biarsine . . . . . . . . . . . . . . . . 96

Stibine . . . . . . . . . . . . . . . . . 96

Hydrolysis of Potassium Borohydride . . . . . . . . . 96

Spectra of Metal-Ammonia Solutions . . . . . . . . 96

Species in Refluxed Chromic Perchlorate Solutions . . . . 97

Ruthenium Studies 。 . . . . . . . . . . . 97

The Effect of Salts on the Nuclear Magnetic

Resonance of $\mathrm{F}^{19}$. . . . . . . . . . . . . . 97

NMR Studies of the Rate of Exchange of Water Molecules

in the First Coordination Sphere of Metal Ions

with Bulk Water Molecules . . . . . . . . 97

Mechanism of Electrode Reactions . . . . . . . . 98 
UCR L-9093

MOLEC ULAR-BEAM STUDIES

Study of Reactive Collisions in Crossed Molecular Beams . . . . . . . . . . . . . 99

HIGH-PRESSURE ST UDIES

Pressure Sintering of Inorganic Oxides . . . . . 100

Phase Diagram of $\mathrm{Pu}$ and Np . . . . . . . . . . 100

The Gap in Iodine . . . . . . . . . . . . 100

A Pressure Scale to $400,000 \mathrm{~atm}$. . . . . . . 100

\section{CHEMICAL ENGINEERING (PROCESS CHEMISTRY)}

Fractional Crystallization from Melts . . . . . . 101

Settling Characteristics of an Immiscible-Liquid

System . . . . . . . . . . . . 101

Partial Coalescence of a Liquid Drop at a Liquid-

Liquid Interface . . . . . . . . . . . 102

Forced-Convection Boiling in Tubes . . . . . . 102

Liquid-Liquid Extraction and Agitation: Performance

of Packed Extraction Columns . . . . . . 102

Coalescence Rates in Agitated Immiscible Mixtures . . . 102

Rate Processes at Fluid Interfaces . . . . . . . . 103

Liquid Diffusion . . . . . . . . . . . . . 103

Longitudinal Dispersion in Beds of Finely Divided

Solids . . . . . . . . . . 103 


\section{CHEMISTRY DIVISION SEMIANNUAL REPORT June through November 1959 \\ Lawrence Radiation Laboratory and Department of Chemistry University of California, Berkeley, California \\ February 8, 1960}

\section{NUCLEAR CHEMISTRY}

Glenn T. Seaborg and Isadore Perlman in charge

Nuclear Reaction Studies

\section{NUCLEAR REACTIONS INDUCED BY HIGH-ENERGY PROTONS AND MESONS}

Paul L. Reeder and Samuel S. Markowitz

High-energy studies of the $(\mathrm{p}, 2 \mathrm{p})$ reaction in $\mathrm{Zn}^{68}$ and $\mathrm{Fe}^{57}$ are being carried out. The excitation functions for the reactions $\mathrm{Zn}^{68}(\mathrm{p}, 2 \mathrm{p}) \mathrm{Cu}^{67}$ and $\mathrm{Fe}^{57}$ (p, 2p) Mn 56 are being measured from $400 \mathrm{Mev}$ to $6.2 \mathrm{Bev}$. Preliminary results are shown in Table I. The cross sections are calculated on the basis of a $10.7-\mathrm{mb}$ cross section for the $\mathrm{Al}^{27}$ ( $\mathrm{p}, 3 \mathrm{pn}$ ) Na24 reaction used to monitor the proton beam.

The yield of $\mathrm{Mn}^{52}$ from proton bombardments of natural iron is found to be approximately constant at $7 \mathrm{mb}$ over the energy region $400 \mathrm{Mev}$ to 4.0 Bev. Similarly, the yields of $\mathrm{Cu}^{61}$ and $\mathrm{Cu}^{64}$ from proton bombardment of natural zinc are constant at $17 \mathrm{mb}$ and $13 \mathrm{mb}$, respectively, over the same energy region.

Experiments are being carried out in an attempt to measure the cross section for the reaction $\mathrm{Zn}^{68}\left(\pi^{+}, \pi^{+} \mathrm{p}\right) \mathrm{Cu}^{67}$, using $310-\mathrm{Mev} \pi^{+}$produced at the 184-inch cyclotron. The meson beam, which is produced by $720-\mathrm{Mev}$ protons incident on copper, has an intensity of about $10^{6} \pi^{\pi^{4}}$ per min over a 3 -in.-diameter circle. The total induced activity of $\mathrm{Cu}^{67}$ from zinc of natural isotopic composition is about $100 \mathrm{cpm}$ as detected by an end-window gas-flow proportional counter. The target thickness is $600 \mathrm{mg} / \mathrm{cm}^{2}$, so that the mesons lose only about $5 \mathrm{Mev}$ in passing through the target. Bombardment time is from 8 to 20 hours. Copper -67 , half-life 61 hours, has been radiochemically detected, and experiments are being carried out to determine what part of the observed activity is due to the $\mathrm{Zn}^{68}\left(\pi^{+}, \pi^{+} \mathrm{p}\right) \mathrm{Cu} 67$ reaction and what part is due to the interaction of stray or secondary fast neutrons with $\mathrm{Zn}_{\mathrm{n}} 67(4.1 \%$ abundant) to produce the $(\mathrm{n}, \mathrm{p})$ reaction or with $\mathrm{Zn}^{68}(18.6 \%$ abundant) to produce $\mathrm{Cu} 67$ via the $(\mathrm{n}, \mathrm{pn})$ reaction. 
Table I

\begin{tabular}{|c|c|c|}
\hline \multicolumn{3}{|c|}{ Cross sections for $(\mathrm{p}, 2 \mathrm{p})$ reactions } \\
\hline \multirow{2}{*}{$\begin{array}{l}\text { Proton energy } \\
(\mathrm{Bev})\end{array}$} & \multicolumn{2}{|c|}{ Reaction $^{a}$} \\
\hline & $\mathrm{Zn}^{68}(\mathrm{p}, 2 \mathrm{p}) \mathrm{Cu}^{67}$ & $\mathrm{Fe}^{57}(\mathrm{p}, 2 \mathrm{p}) \mathrm{Mn}^{56}$ \\
\hline 0.40 & $21,19,25$ & $35,41,48$ \\
\hline 0.56 & $21,25,23$ & 44,55 \\
\hline 0.72 & $24,27,31$ & 57,58 \\
\hline 2.0 & 20 & -- \\
\hline 4.0 & 19 & 58 \\
\hline 5.7 & 19 & -- \\
\hline 6.2 & 19,18 & -- \\
\hline
\end{tabular}

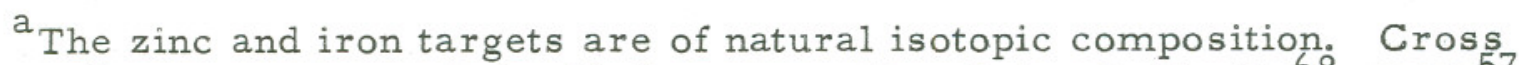
sections were computed with the assumption that only the $\mathrm{Zn}^{68}$ or $\mathrm{Fe}^{57}$ contributed to formation of the observed products. 


\section{INTERACTION OF HIGH-ENERGY PROTONS WITH INDIUM \\ David R. Nethaway ${ }^{*}$ and Lester Winsberg}

Indium was bombarded with protons ranging in energy from 1.0 to $6.2 \mathrm{Bev}$. Reactions of the type $(\mathrm{p}, \mathrm{pxn}),(\mathrm{p}, 2 \mathrm{pxn}),\left(\mathrm{p}, \mathrm{p}^{\prime}\right)$, and $\left(\mathrm{p}, \mathrm{p} \pi^{+}\right)$that produce isotopes of indium and cadmium were investigated. The excitation functions are constant within experimental error in this energy region with possible exceptions for Cd 115 and In $115 \mathrm{~m}$ at $1.0 \mathrm{Bev}$. These results are compared with two types of calculation. In one treatment, the nucleus is considered to be a degenerate Fermi gas of nucleons. The cross sections that were calculated with this nuclear model at $2 \mathrm{Bev}$ are much smaller than the experimental values. The second treatment takes into account the shell structure of In 115. The latter calculation was made for the ( $\mathrm{p}, \mathrm{pn})$, $\left(p, p^{\prime}\right)$, and $\left(p, p \pi^{+}\right)$reactions. Good agreement with the experimental results was found for the $(\mathrm{p}, \mathrm{pn})$ reaction at 4.1 and $6.2 \mathrm{Bev}$. The calculated values for the $\left(\mathrm{p}, \mathrm{p} \pi^{+}\right)$reaction at 2,4 , or 6 Bev were too small by a factor of 5 to 100. The low values may be the result of an inadequate analysis of inelastic p-p scattering. The calculated value of the total cross section of the $\left(\mathrm{p}, \mathrm{p}^{0}\right)$ reaction is larger than the measured value for $\mathrm{In}^{115 \mathrm{~m}}$ at $1 \mathrm{Bev}$ and is smaller at 4 and $6 \mathrm{Bev}$. The comparison of the experimental results with the calculated values is discussed in terms of the adequacy of the calculations.

A detailed report of this title by these authors was recently submitted to Physical Review.

\footnotetext{
Now at the Livermore site of Lawrence Radiation Laboratory.
} 


\section{INTERACTION OF HIGH-ENERGY PROTONS AND ALPHA PARTICLES WITH IODINE-127 \\ Inge-Maria Ladenbauer* and Lester Winsberg}

Iodine was bombarded with protons ranging in energy from 0.25 to $6.2 \mathrm{Bev}$ and with $0.25-, 0.50_{-}$, and $0.72-\mathrm{Bev}$ alpha particles. Reactions of the type $(p, p \times n),(p, 2 p x n),\left(p, p \pi^{+}\right),\left(p, p 2 \pi^{+}\right),\left(p, n \pi^{-}\right)$, and $(a, a x n)$ to produce iodine, tellurium, antimony, and cesium isotopes were investigated. Upper limits in the range 0.01 to $0.1 \mathrm{mb}$ were found for cross sections of reactions to produce ${ }_{51} \mathrm{Sb}^{127}$ and ${ }_{55} \mathrm{Cs}^{127}$. For $52 \mathrm{Te}{ }^{127}$, upper limits in the range of 1 to $2 \mathrm{mb}$ were found. This and other studies of reactions in which the product has the same mass number as that of the target are discussed in terms of the initial interaction. At all incident energies studied, the cross section for the formation of ${ }_{53} I^{126}$ via the $(p, p n)$ or $(a, a n)$ reaction is significantly higher than that of the other ( $p, p \times n)$ or $(\alpha, a \times n)$ reactions, with the possible exception of $(a, a 4 n)$.

The (p, pn) and probably the ( $a$, an) reactions appear to be due primarily to knock-on 'collisions with surface neutrons. The excitation functions for the production of iodine isotopes by proton bombardment decrease between 0.25 and $0.72 \mathrm{Bev}$ but remain relatively constant for higher energies. The (p, 2pxn) reactions show a similar effect, but with the excitation functions becoming constant at about $2 \mathrm{Bev}$. These results are compared with Monte Carlo calculations of the proton-initiated nucleon cascade and of the subsequent evaporation of light particles.

A further detailed report of this title by these authors was recently submitted to Physical Review.

Present address: Sloane Physics Laboratory, Yale University, New Haven, Connecticut. 


\section{ELASTIC SCAT TERING OF HEAVY IONS}

\section{Jonas Alster and Homer E. Conzett}

The measurements of the angular distribution of elastically scattered heavy ions can be interpreted with the Blair sharp-cutoff model. 1 This interpretation allows a unique determination of an interaction radius $R$ of the heavy ion and the target nucleus. Since the large-cutoff $\ell$ value ( 100) can be found with a precision of \pm 1 , the precision of the calculated $R$ is limited only by the accuracy with which the energy of the projectile is known, according to the formula

$$
E=\frac{Z_{1} Z_{2} e^{2}}{R}+\frac{\ell^{\prime}\left(\ell^{\prime}+1\right) \hbar^{2}}{2 \mu R^{2}} .
$$

Following a suggestion by Blair, ${ }^{2}$ a program has been started to measure the interaction radii, with a precision of 1 to $2 \%$, throughout the periodic table in order to find even-odd and shell effects.

The angular distribution of $\mathrm{C}^{12}$ scattered from $\mathrm{Au}^{197}$ has been measured in order to check the equipment and to compare the results with those obtained by Goldberg and Reynolds. 3 Preliminary results of $\mathrm{C}^{12}$ scattered from In 115 and Ta181 are shown in Fig. 1.

Since then, improvements have been made in the energy resolution of the CsI crystal counter, because at large scattering angles it was difficult to distinguish between elastically and inelastically scattered ions. An energy resolution of $2.5 \%$ is now possible. The angular resolution is \pm 0.7 degree.

Final data have been obtained for $\mathrm{C}^{12}$ on $\mathrm{Ag}^{107}$, In ${ }^{115}$, and $\mathrm{Ta}^{181}$. We were able to follow the angular distribution for elastic scattering down to

$$
\frac{\sigma_{\text {elas }}}{\sigma_{\text {coul }}} \approx \frac{1}{60}, \quad \text { thanks to the improved energy resolution. }
$$

Additional unsupported targets of $\sim 1 \mathrm{mg} / \mathrm{cm}^{2}$ of $\mathrm{Al}_{6}^{27}, \mathrm{Fe}, \mathrm{Cu}^{63}$, $\mathrm{Ni} 58, \mathrm{Ni}^{60}$, Cd ${ }^{14}$ are already made, and $\mathrm{Ca}^{40}$ and $\mathrm{Ho}^{165}$ targets are planned.

An IBM 650 program for the Blair-model analysis was kindly given to us by Goldberg and Reynolds, and attempts will be made to use an opticalmodel analysis.

I. S. Blair, Phys. Rev. 95, 1218 (1954)。

${ }^{2}$ Proceedings of the Conference on Reactions Between Complex Nuclei, Gatlinburg, Tennessee, 1958, p. 205.

${ }^{3}$ E. Goldberg and H. L. Reynolds, Phys。Rev. 112, 1981 (1958). 


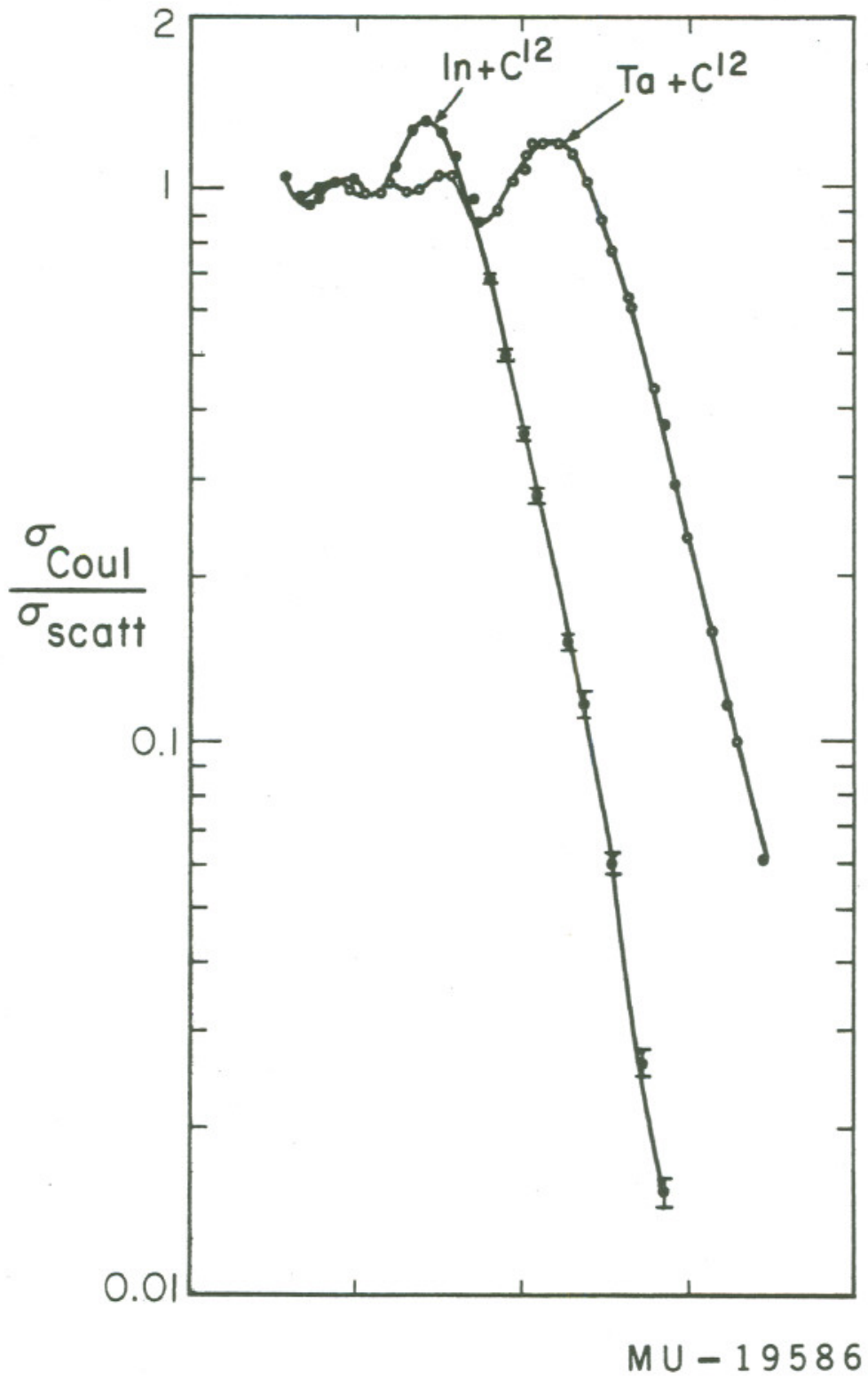

Fig. 1. Angular distribution of $\mathrm{C}^{12}$ scattered from $\mathrm{In}^{115}$ and $\mathrm{Ta}^{181}$. 


\section{ELASTIC SCATTERING OF $31-\mathrm{Mev} \mathrm{He}^{3}$ IONS $\mathrm{BY} \mathrm{Cu}$ AND Bi}

George Igo, Samuel S. Markowitz, and Jose Gonzalez-Vidal

As a part of a survey of $\mathrm{He}^{3}$ elastic scattering, the angular distribution of 31-Mev $\mathrm{He}^{3}$ ions elastically scattered from $\mathrm{Cu}$ and $\mathrm{Bi}$ in the angular range 20 to $65 \mathrm{deg}$ has been measured. The purpose of these measurements, as well as those planned to follow, is to compare the opticalmodel potential necessary to fit the $\mathrm{He}^{3}$ and $\mathrm{He}^{4}$ data. The data on $\mathrm{He}^{3}$ reactions will presumably reflect effects of nonzero spin and small binding energy. Figure 2 shows the copper and bismuth data. The solid curves are the Rutherford cross section, $\sigma_{c}\left(\theta_{c}, \mathrm{~m}\right)$, for $\mathrm{Cu}$ and $\mathrm{Bi}$. The significant features are the rise of the experimental cross section, $\sigma\left(\theta_{c}, \mathrm{~m}\right.$, ), above $\sigma_{\mathrm{C}}\left(\theta_{\mathrm{c}, \mathrm{m}}\right)$ in the angular interval 30 to $45 \mathrm{deg}$, followed by a drop below $\sigma_{c}\left(\theta_{c \cdot m}\right)$ at larger angles for $\mathrm{Bi}$. The Cucross section shows the diffraction effects, and is below the corresponding Rutherford cross section in the ảngular range measured.

Table II is a summary of the results obtained to date.

Further measurements are now being made on $\mathrm{Cu}, \mathrm{Bi}, \mathrm{Be}, \mathrm{Al}$, and Sn120. These elements have been chosen because they span the parameter $\mathrm{A}^{1 / 3}$ (where $\mathrm{A}$ is the atomic mass number), which is significant in optical model theory; also, elastic scattering can be resolved from inelastic scattering to the first excited state.in these targets. 


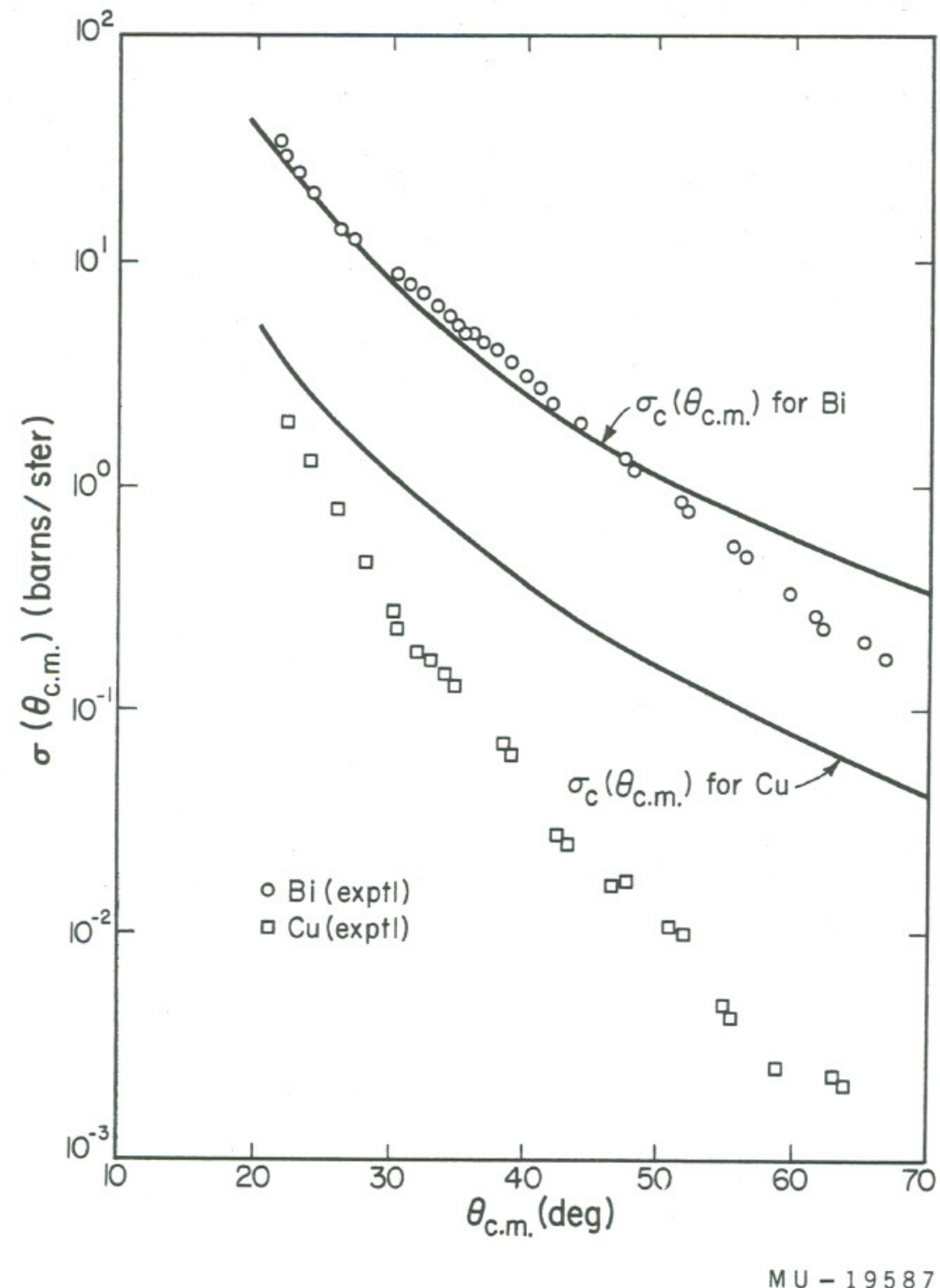

Fig. 2. The elastic scattering of $31 \pm 1-\mathrm{Mev} \mathrm{He}^{3}$ by $\mathrm{Cu}$ and $\mathrm{Bi}$. The points $\square$ and $\bigodot$ are the experimental differential cross sections in the center-of-mass system for $\mathrm{Cu}$ and $\mathrm{Bi}$, respectively. The statistical errors are less than the vertical size of the dot and the angular resolution is $1 \mathrm{deg}$. The solid curves are the Rutherford differential cross sections $\sigma_{\mathrm{c}}\left(\theta_{\mathrm{cm}}\right) \cdot$ 
Nuclear Reactions

$-14-$

UCRL-9093

Table I I

The differential cross section, $\sigma\left(\theta_{\mathrm{c}} . \mathrm{m}\right.$. $)$, for elastic scattering of $31 \pm 1-\mathrm{Mev}$ (incident energy) $\mathrm{He}^{3}$ ions from $\mathrm{Cu}$ and $\mathrm{Bi}$. The statistical errors of the individual points are less than $2 \%$. The angles are measured in the centerof-mass system.

\begin{tabular}{|c|c|c|c|}
\hline \multicolumn{2}{|c|}{$\mathrm{Cu}$} & \multicolumn{2}{|c|}{$\mathrm{Bi}$} \\
\hline $\begin{array}{l}\theta_{c . m} . \\
(\operatorname{deg})\end{array}$ & $\begin{array}{c}\sigma\left(\theta_{\mathrm{c} \cdot \mathrm{m}_{0}}\right) \\
(\text { barns/ster })\end{array}$ & $\begin{array}{l}\theta_{\text {c.m. }} . \\
\text { (deg) } \\
\end{array}$ & $\begin{array}{c}\sigma\left(\theta_{\mathrm{c} . \mathrm{m} .}\right) \\
\text { (barns/ster) } \\
\end{array}$ \\
\hline $\begin{array}{l}22.3 \\
23.8 \\
25.9 \\
27.9 \\
30.0 \\
30.3 \\
32.1 \\
32.6 \\
34.2 \\
34.7 \\
38.3 \\
38.9 \\
42.5 \\
43.0 \\
46.6 \\
47.6 \\
50.8 \\
51.9 \\
54.9 \\
55.4 \\
59.0 \\
59.5 \\
63.1 \\
63.6\end{array}$ & $\begin{array}{l}1.98 \times 10^{0} \\
1.29 \times 10^{0} \\
7.97 \times 10^{-1} \\
4.60 \times 10^{-1} \\
2.78 \times 10^{-1} \\
2.35 \times 10^{-1} \\
1.80 \times 10^{-1} \\
1.78 \times 10^{-1} \\
1.44 \times 10^{-1} \\
1.32 \times 10^{-1} \\
7.33 \times 10^{-2} \\
6.44 \times 10^{-2} \\
2.88 \times 10^{-2} \\
2.57 \times 10^{-2} \\
1.72 \times 10^{-2} \\
1.77 \times 10^{-2} \\
1.13 \times 10^{-2} \\
1.03 \times 10^{-2} \\
5.09 \times 10^{-3} \\
4.40 \times 10^{-3} \\
2.72 \times 10^{-3} \\
2.63 \times 10^{-3} \\
2.43 \times 10^{-3} \\
2.24 \times 10^{-3}\end{array}$ & $\begin{array}{l}21.5 \\
22.1 \\
23.1 \\
24.1 \\
26.1 \\
27.1 \\
30.2 \\
31.2 \\
32.2 \\
33.2 \\
34.2 \\
34.7 \\
35.2 \\
35.7 \\
36.7 \\
37.7 \\
38.8 \\
39.8 \\
40.8 \\
41.8 \\
43.8 \\
47.4 \\
47.9 \\
51.4 \\
51.9 \\
55.4 \\
56.4 \\
59.5 \\
61.5 \\
62.0 \\
65.0 \\
66.5\end{array}$ & $\begin{array}{l}3.44 \times 10^{1} \\
3.06 \times 10^{1} \\
2.54 \times 10^{1} \\
2.06 \times 10^{1} \\
1.43 \times 10^{1} \\
1.29 \times 10^{1} \\
8.86 \times 10^{0} \\
8.25 \times 10^{0} \\
7.42 \times 10^{0} \\
6.66 \times 10^{0} \\
5.90 \times 10^{0} \\
5.43 \times 10^{0} \\
5.15 \times 10^{0} \\
5.05 \times 10^{0} \\
4.48 \times 10^{0} \\
4.22 \times 10^{0} \\
3.74 \times 10^{0} \\
3.19 \times 10^{0} \\
2.79 \times 10^{0} \\
2.39 \times 10^{0} \\
1.99 \times 10^{0} \\
1.34 \times 10^{0} \\
1.23 \times 10^{0} \\
8.87 \times 10^{-1} \\
8.05 \times 10^{-1} \\
5.69 \times 10^{-1} \\
5.09 \times 10^{-1} \\
3.55 \times 10^{-1} \\
2.78 \times 10^{-1} \\
2.44 \times 10^{-1} \\
2.13 \times 10^{-1} \\
1.78 \times 10^{-1}\end{array}$ \\
\hline
\end{tabular}




\title{
NUCLEAR REACTIONS IN CARBON AND NITROGEN
}

\author{
Bernard G. Harvey and Joseph Cerny III
}

The energy spectra and angular distributions of deuterons from the reaction $\mathrm{C}^{12}(\mathrm{a}, \mathrm{d}) \mathrm{N}^{14}$ have been studied, by using $48-\mathrm{Mev}$ incident helium ions. Deuteron groups corresponding to the formation of six different energy levels of $\mathrm{N}^{14}$ were observed with the $\mathrm{E}-\mathrm{dE} / \mathrm{dx}$ particle-identifying system. Since $\mathrm{C}^{12}$, helium ions, and deuterons all have zero isotopic spin, it is not expected that isotopic spin 1 states of $\mathrm{N}^{14}$ will be formed. The intensity of the isotopic spin 1 level at $3.95 \mathrm{Mev}$ was in fact less than $3 \%$ of the intensity of the $\mathrm{N}^{14}$ ground state.

Several well-established levels of $\mathrm{N}^{14}$ were not observed. The $(\mathbf{a}, \mathrm{d})$ reaction appears to operate very selectively. In the stripping $(a, d)$ reaction, the incident helium ions lose two nucleons to the target nucleus. If the helium ion breaks up into two deuterons, one of which is captured by the target, then the captured nucleons are in a ${ }^{3} \mathrm{~S}$ state. The states of the final nucleus most likely to be formed are perhaps those in which the captured proton and neutron have the same angular momentum. If the captured nucleons cannot enter equivalent states (for example, if the target is a heavy nucleus with widely different proton and neutron numbers), then the cross section for the $(a, d)$ reaction may be small. This hypothesis will be tested by comparison of the reactions $\mathrm{N}^{14}(\mathrm{a}, \mathrm{d}) \mathrm{O}^{16}$ and $\mathrm{N}^{15}(\mathrm{a}, \mathrm{d}) \mathrm{O}$. In the ground-state transitions, the proton and neutron are both added to the $\mathrm{p}_{1 / 2}$ shell in the former reaction, and to the $\mathrm{p}_{1 / 2}$ and $\mathrm{d}_{5 / 2}$ shells for the latter.

The angular distribution of the deuterons corresponding to the formation of the ground state of $\mathrm{N}^{14}$ in the reaction $\mathrm{C}^{12}(\mathrm{a}, \mathrm{d}) \mathrm{N}^{14}$ is shown in Fig. 3. Attempts will be made to fit the angular distribution to the formula of El Nadi. 1 In the meantime, it appears that the angular dependence can be fitted approximately with a simple squared spherical Bessel function, using a value of 2 for the angular momentum $l_{c}$ of the captured nucleons. No fit could be obtained for $\ell_{c}=0$, although the selection rules permit this value. If the captured particles enter the nucleus in a triplet state, as suggested above, then their spins are parallel. If they both enter the $\mathrm{p}_{1 / 2}$ state, as predicted by the shell model, then their orbital angular momenta must also be parallel, so that it is not surprising that $\ell_{c}=2$ is preferred to $\ell_{c}=0$, which could correspond to antiparallel angular momenta.

$$
\text { Preliminary studies of the reaction } \mathrm{N}^{14}(\mathrm{a}, \mathrm{d}) \mathrm{O}^{16} \text { using } \mathrm{N}^{14} \text { gas as }
$$

target again showed that several levels of the product nucleus were formed, but that several other well-known levels are conspicuously absent. A typical deuteron energy spectrum is shown in Fig。 4.

$\overline{1_{M} . ~ E l ~ N a d i, ~ P r o c . ~ P h y s . ~ S o c . ~ A 70, ~} 62$ (1957). 


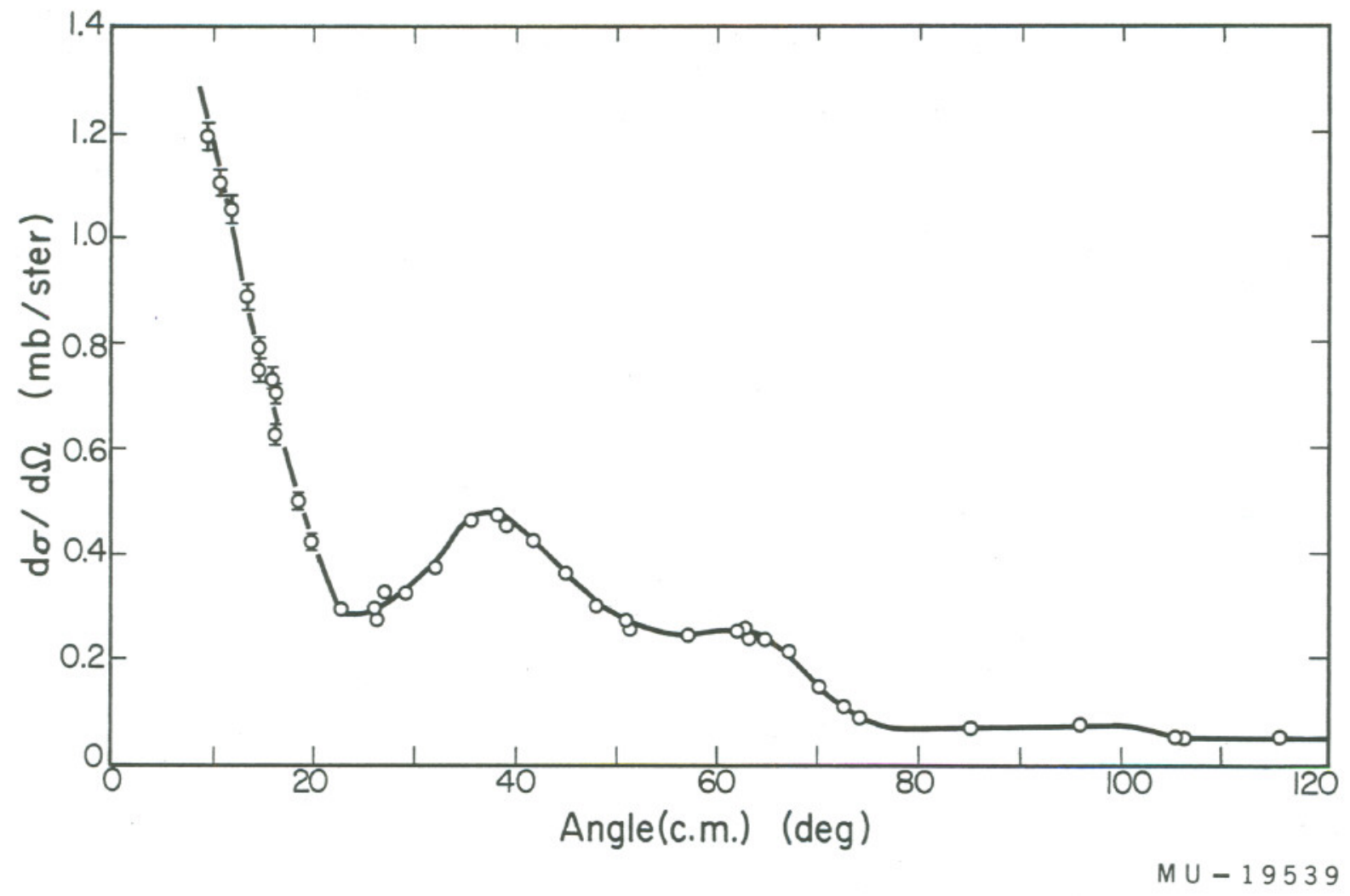

Fig. 3. Angular distribution of deuterons from $\mathrm{C}^{12}(\mathrm{a}, \mathrm{d}) \mathrm{N}^{14}$ (ground state). 


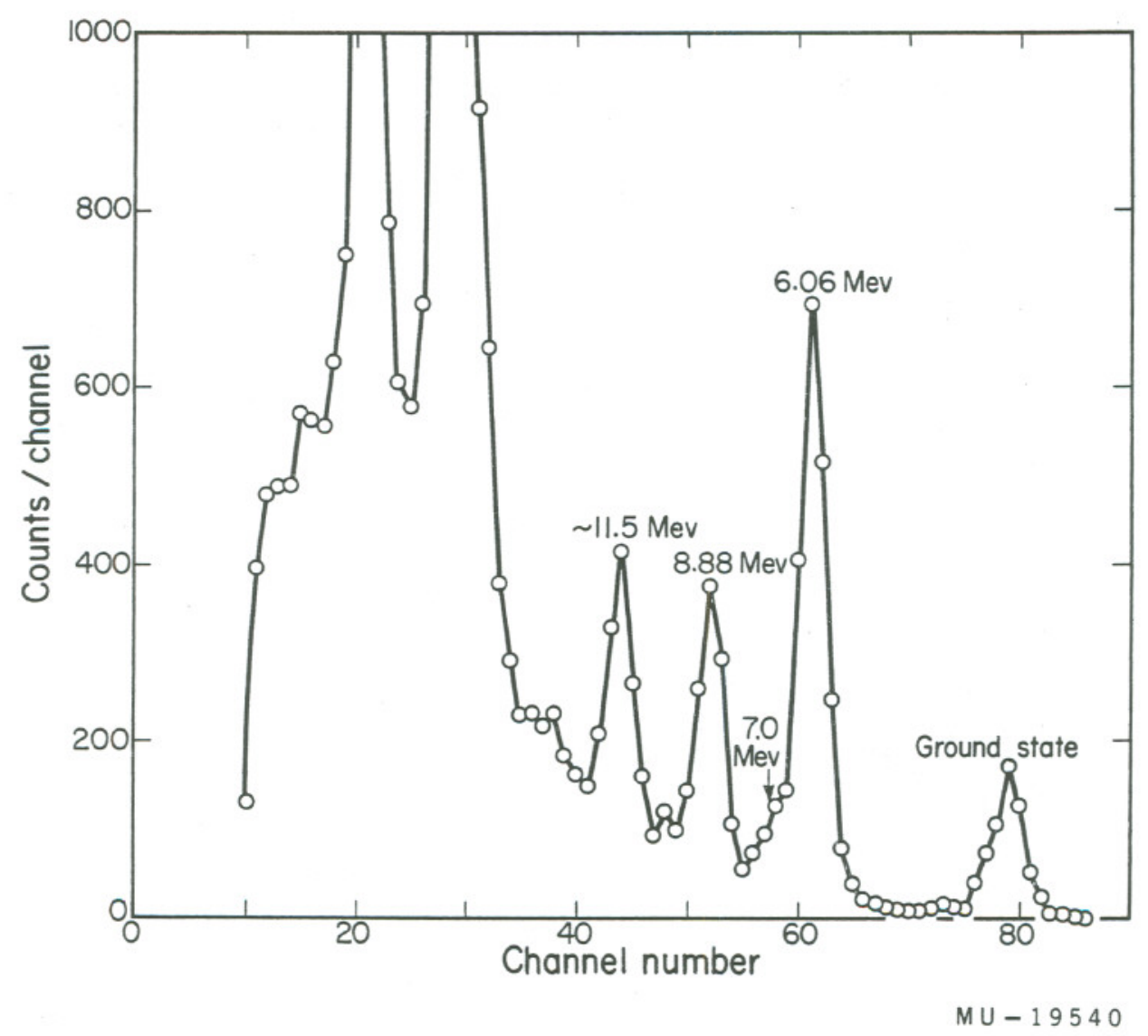

Fig. 4. Energy spectrum of deuterons from $\mathrm{N}^{14}(\mathrm{a}, \mathrm{d}) \mathrm{O}^{16}$ at $11^{\circ}$ (lab. system). 


\section{POLARIZED-PROTON BEAM FROM p-He ${ }^{4}$ ELASTIC SCATTERING} Homer E. Conzett, George Igo, and Aharon Nir*

We are developing a beam of 25-Mev polarized protons, using a method due to Rosen and Brolley. 1 The 48-Mev alpha-particle beam of the 60-inch cyclotron strikes a target chamber containing several atmospheres of $\mathrm{H}_{2}$. The protons knocked on at $25 \mathrm{deg}$ (130 deg c. m. for protons on $\mathrm{He}^{4}$ ) to the incident alpha-particle beam are essentially $100 \%$ polarized and have an energy of about $25 \mathrm{Mev}$ in the laboratory system. A second scattering of these protons in 5 atmospheres of $\mathrm{He}^{4}$ is performed, and the left-right asymmetry is measured as a function of the second-scattering angle. These measurements will enable us to determine the angular distribution of the proton polarization in $\mathrm{p}-\mathrm{He}^{4}$ scattering below $25 \mathrm{Mev}$. In addition, a completely polarized beam of protons will be available for use in further polarization experiments.

* On leave from Weizmann Institute of Science, Rehovoth, Israel. ${ }^{1}$ L. Rosen and J. E. Brolley, Jr., Phys, Rev。107, 1454 (1957). 


\section{(p, a) REACTIONS}

\section{Jonas Alster and Jose Gonzalez-Vidal}

The study of the $(p, a)$ reaction in $\mathrm{Li}^{7}$ and $\mathrm{Li}^{6}$ has been started recently. The $\mathrm{Li}^{7}(\mathrm{p}, \mathrm{a}) \mathrm{He}^{4}$ is of interest for several reasons. Because of the structure of $\mathrm{Li}^{7}$ it is expected that there should be a strong pickup component in the direct-interaction part of the reaction. The investigation of such a mechanism should help to understand the knock-on portion of the $\mathrm{Li}^{7}(\mathrm{a}, \mathrm{t}) \mathrm{Be}^{8}$ reaction, since both reactions depend on the same structure of the $\mathrm{Li}^{7}$ nucleus. Secondly, this reaction has been extensively investigated up to energies around $3 \mathrm{Mev}$, but almost no work at all has been done above that energy. Since $\mathrm{Li}^{7}(\mathrm{p}, \mathrm{a}) \mathrm{He}^{4}$ has become a classic among nuclear reactions it appears of interest to investigate its behavior between 3 and $12 \mathrm{Mev}$.

The experimental arrangement consists of a CsI crystal, thick enough to stop the a particles from the reaction but not the elastically scattered protons, followed by a NaI crystal. The pulses from the NaI crystal are set in anticoincidence with those of the CsI crystal so that only particles stopping in the CsI crystal are counted. The a particles are identified both by their range and by the fact that they are the highest-energy particles produced by protons in $\mathrm{Li}^{7}$.

A Butler fit to the $\mathrm{Li}^{7}(\mathrm{p}, \mathrm{a}) \mathrm{He}^{4}$ so far obtained using $12-\mathrm{Mev}$ incidentenergy protons shows good agreement with a pickup mechanism. A radius of 5.55 fermis was used. For this treatment only minor Coulomb corrections were applied. The experimental data show peaks around 40 and 140 deg (c. m.). The angular distribution is symmetric around $90 \mathrm{deg}$ (c. m.) owing to the identity of the products. See Fig. 5. This symmetry may give rise to difficulties in distinguishing between direct-interaction and compound-nucleus mechanisms, especially at lower energies. Crude theoretical calculations seem to indicate that the direct-interaction contribution to the cross section at the lower energies may be more important than has been previously suspected.

Because of the symmetry around $90 \mathrm{deg}$ (c. $\mathrm{m}_{*}$ ) , $\mathrm{Li}^{7}\left(\mathrm{p}_{3} \mathrm{a}\right) \mathrm{He}^{4}$ presents some unique difficulties. However, the study of $\mathrm{Li}^{6}(\mathrm{p}, \mathrm{a}) \mathrm{He}^{3}$ offers a way of getting insight into both the $\mathrm{Li}^{7}(\mathrm{p}, \mathrm{a})$ and $(\mathrm{a}, \mathrm{t})$ reactions. In the $\mathrm{Li}^{6}(\mathrm{p}, \mathrm{a}) \mathrm{He}^{3}$ reaction the distinction between pure knock-on and pure pickup mechanism is easily made, for in the first case the a particles should show forward peaking and the $\mathrm{He}^{3}$ should be peaked backwards. The reverse should be true in the case of pickup. Thus the investigations of the differential cross section at several energies should give information as to the competition between these two mechanisms and between them and the compound-nucleus reaction.

Unfortunately, preliminary trials have shown that because of the nonlinear response of CsI to charged particles, the experimental equipment, as it stands, is not adequate for the study of this reaction. Appropriate modified equipment is now being developed and tested. At present a proportional counter has been constructed to act as the $\Delta \mathrm{E}_{r}$ part of a particle-identifier 


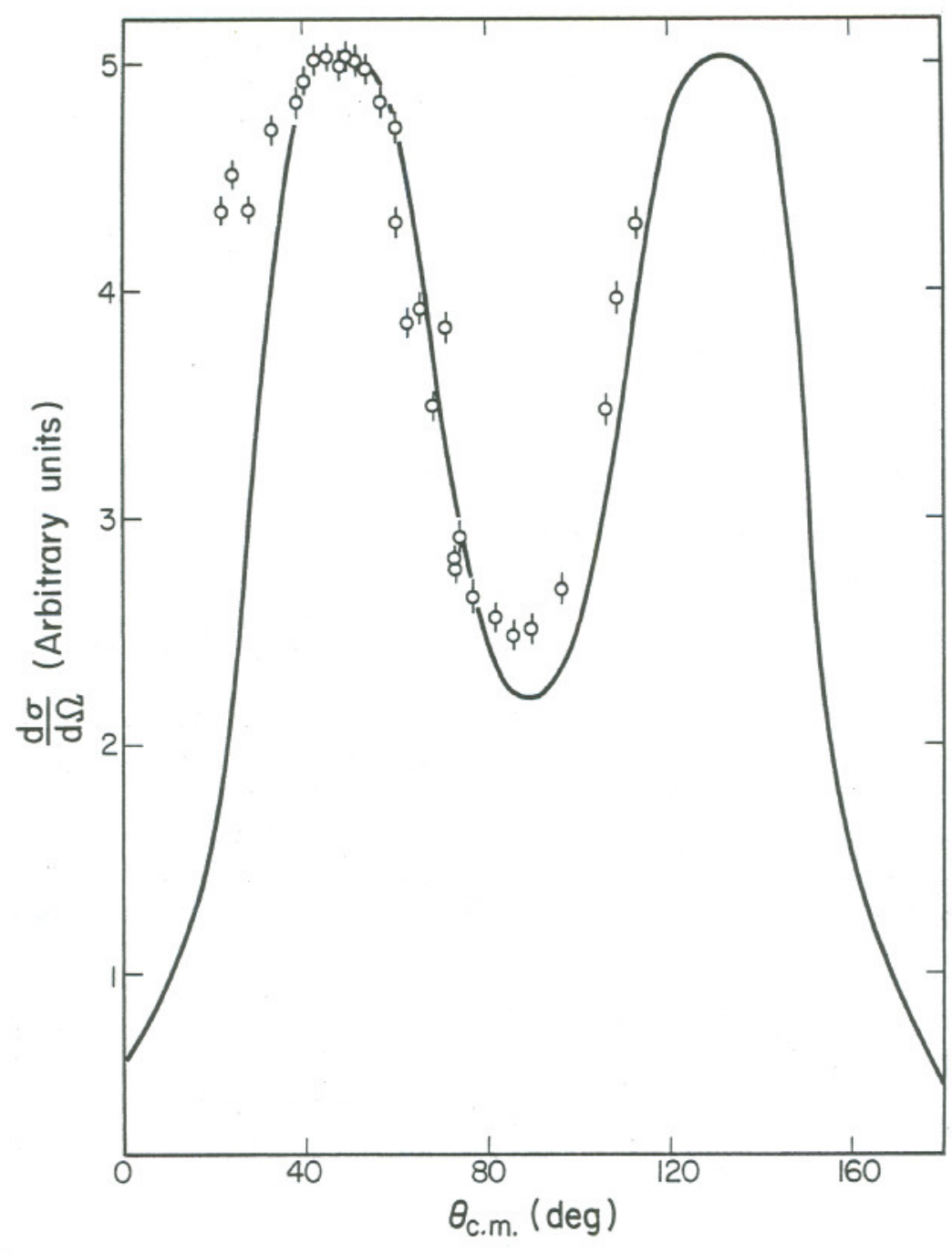

$M U-19541$

Fig. 5. $\mathrm{Li}^{7}(\mathrm{p}, \mathrm{a}) \mathrm{He}^{4}$ Differential cross-section. Solid line represents a Butler fit for a pick-up mechanism. $\gamma=5.55$ fermis. $\ell=1$. Incident proton energy: $12 \mathrm{Mev}$. 
system. Such a system will not only allow research on the $\mathrm{Li}^{6}(\mathrm{p}, \mathrm{a}) \mathrm{He}^{3}$ reaction but also on $\mathrm{Li}^{7}(\mathrm{p}, \mathrm{t}) \mathrm{Li}^{5}$, which is of interest for similar reasons to the other lithium reactions.

Theoretical treatments of the above reactions along the same lines as those for the $(a, t)$ reactions are now in progress.

\section{(a, t) REACTIONS}

Homer E. Conzett and Jose Gonzalez-Vidal

The previously reported work ${ }^{1}$ on $(a, t)$ reactions has been continued. The experimental setup remains essentially unaltered. A particle-identification system based on the multiplication of $E$ and $\Delta E$ of the light product of the reaction is used to choose the desired particle, whose energy spectrum is measured with a Penco pulse-height analyzer. The incident alpha-particle energy was $48 \mathrm{Mev}$.

The tritons from the $\mathrm{Al}^{27}(\mathrm{a}, \mathrm{t}) \mathrm{Si}^{28}$ show that part of the reaction, leading to low excited states of $\mathrm{Si}^{28}$, goes by a direct-interaction mechanism. The peaks in the differential cross section correspond to the spherical Bessel function of order 2, as predicted by Butler's theory. However, the assignment of a given mechanism such as stripping or knock-on becomes difficult because of the inherent limitations of the theory.

Previous work ${ }^{2}$ on integrated $(a, t)$ cross sections shows that in light elements the cross section is larger for odd-Z nuclides than for the neighboring even $-Z$ elements. This effect appears to vanish for large $Z$. This trend suggests that for light elements for which the single-particle picture suggests a strong triton structure, the reaction may go primarily by knockon. Where the triton substructures are not so probable, the stripping mechanism may be more favored; such would be the case for light elements of even atomic number and for heavy elements.

IB. G. Harvey and J. Gonzalez-Vidal in Chemistry Division Semiannual Report, Jan: 1959, p. 16.

2 J. Gonzalez-Vidal, Survey of Tritium-Producing Nuclear Reactions, UCRL-8330, June 1958. 
The study of the $(a, t)$ reaction in $\mathrm{Li}^{6}$ and $\mathrm{Li}^{7}$ should throw some light on this question. The single-particle model for $\mathrm{Li}^{7}$ indicates that for this nucleus a structure consisting of a quasi alpha particle and a quasi triton should be quite probable. Likewise a quasi-deuteron-quasi-alpha-particle structure would be an appreciable component of the $\mathrm{Li}^{6}$ wave function. If the $(a, t)$ reaction has a greater probability of occurring by knock-on than by stripping there should be a striking difference between the cross sections for these two elements. It should be reasonable to expect the $(a, t)$ reaction in $\mathrm{Li}^{7}$ to go mainly as knock-on, whereas for $\mathrm{Li}^{6}$ the $a$-particle stripping would seem more probable. It has been found experimentally that the cross section for $\mathrm{Li}^{7}(a, t) \mathrm{Be}^{8}$ is very large (the largest of all the elements studied), while the same cross-section for $\mathrm{Li}^{6}(a, t) \mathrm{Be}^{7}$ is a few orders of magnitude smaller. See Fig. 6. In both cases the differential cross sections are strongly peaked forward.

The energy spectrum of the tritons from $\mathrm{Li}^{7}$ show two well-resolved peaks corresponding to the ground state and first excited state of $\mathrm{Be}^{8}$, together with a large triton background ascribed to three-body breakup. See Fig. 7.

Two lines of approach are being taken for the theoretical interpretation of these reactions: first a modification of Butler theory to take into account that in $\mathrm{Li}^{7}(a, t) \mathrm{Be}^{8}$ the residual nucleus is only virtually bound, and also to consider the effect of using distorted waves instead of plane waves; secondly a treatment of the differential cross section in terms of explicit wave functions for the entities involved, which treatment may yield useful information on the values of various nuclear parameters involved in nuclear reactions.

Another reaction amenable to this sort of treatment is $B e^{9}(a, t) B^{10}$, which has also been studied. The tritons are strongly peaked in the forward direction.

For $\mathrm{Al}^{27}(\mathrm{a}, \mathrm{t}) \mathrm{Si}^{28}$ the complexity of the nuclei involved makes the second theoretical treatment mentioned above prohibitive, so that only a simple Butler interpretation is planned. However, parity and spin assignments for several unclassified $\mathrm{Si}^{28}$ levels appears possible at present.

In most of the preceding cases, as well as the $F e^{56}(a, t) C o 57$ reaction, there is evidence to support the view that only certain selected levels of the residual nucleus are excited. An interpretation of this phenomenon on the basis of a single-particle model is under way. 


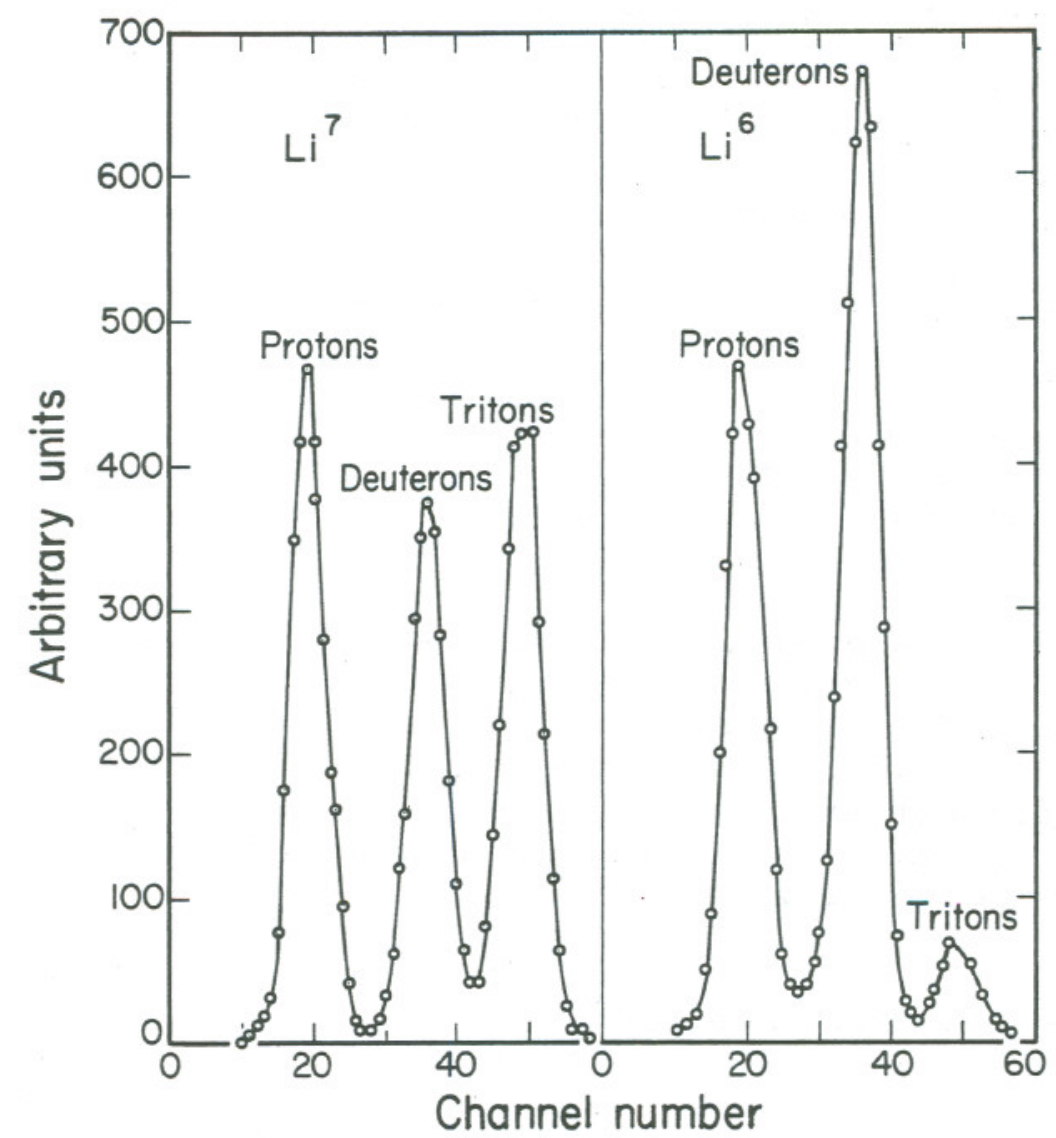

$M U-19542$

Fig. 6. Particle spectra for the reaction products of $48-\mathrm{Mev}$ a particles incident on $\mathrm{Li}^{7}$ and $\mathrm{Li}^{6}$, at $30 \mathrm{deg}$ in the laboratory system. Spectra have been normalized to the proton peak. 


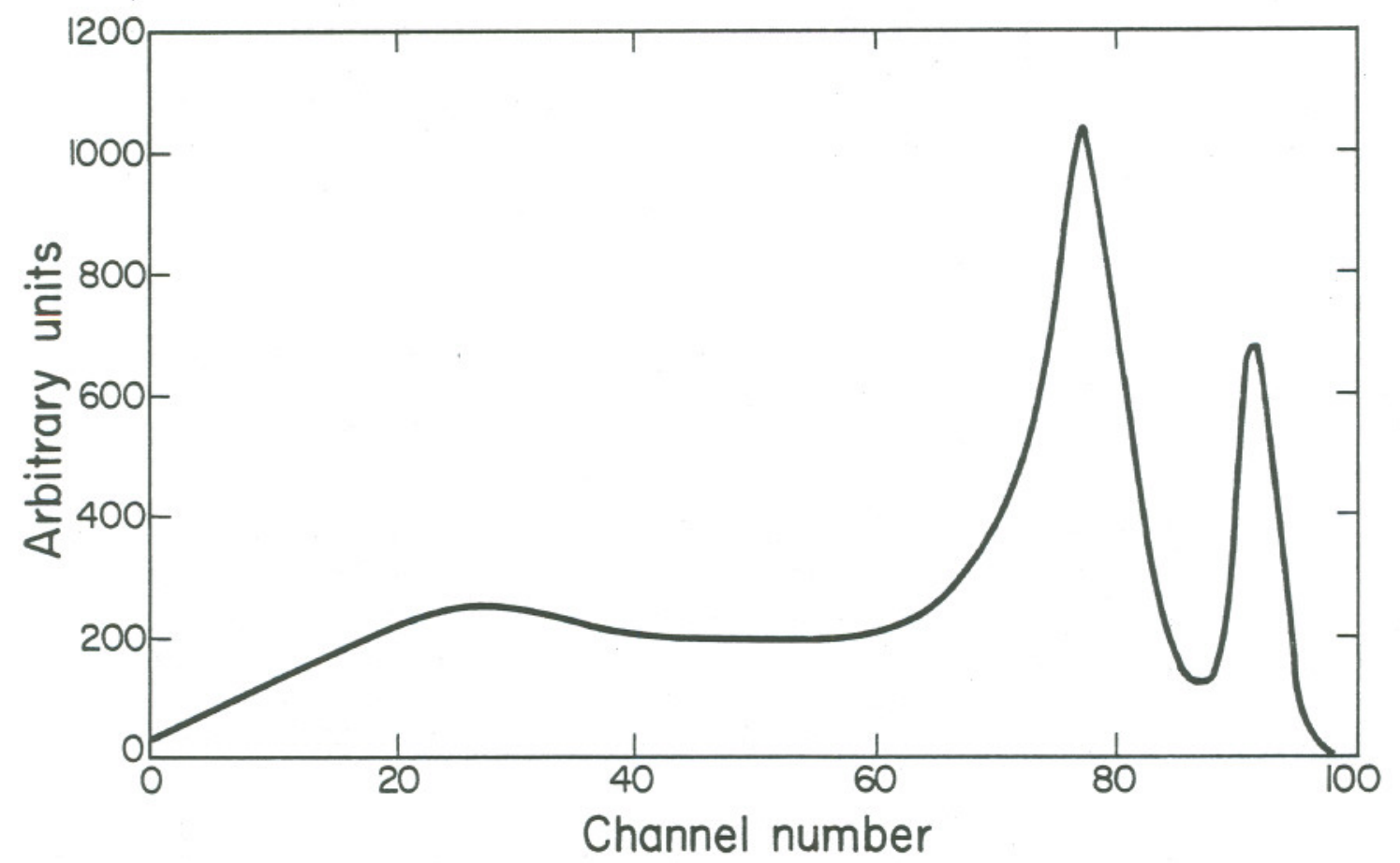

$M U-19543$

Fig. 7. Energy spectrum of tritons from 48-Mev a particles incident on $\mathrm{Li}^{4}$, at an angle of $22.5 \mathrm{deg}$ (lab). 


\section{HEAVY-ION COULOMB EXCITATION}

\section{Bent Elbek, George Igo, Richard Brower, and Richard Diamond}

Work on Coulomb excitation by heavy ions has been hindered by the troubles in the operation of the Hilac. Absolute cross-section measurements of the multiple excitations in $\mathrm{U}^{238}$ and $\mathrm{Th}^{232}$ have not been obtained yet, but $\mathrm{A}^{40}$-produced multiple excitations in $\mathrm{Ta}{ }^{181}$ and $\mathrm{W}^{182}$ have also been observed. In $\mathrm{Ta} 181$ the well-known $9 / 2+$ and $11 / 2+$ levels at 136 and $301 \mathrm{kev}$ were excited, as well as new levels at 500 and $720 \mathrm{kev}$. These new levels are most probably the $13 / 2+$ and $15 / 2+$ levels of the ground-state rotational band; the energies agree with those calculated from the expression $E_{I}=A\left[I(I+1)-I_{0}\left(I_{0}+1\right)\right]+B\left[I^{2}(I+1)^{2}-I_{0}^{2}\left(I_{0}+1\right)^{2}\right]$ to $2 \%$.

In $\mathrm{W}^{182}$, the known levels at 100 and $329 \mathrm{kev}$ were excited, as well as a new level at $680 \mathrm{kev}$. These constitute the $2+, 4+, 6+1$ levels of the groundstate rotational band. It is hoped to determine the absolute cross section for the excitations of these levels and to compare them with the theoretical predictions of Alder and Winther for multiple excitations.

232 An earlier project of looking at the higher-lying levels in $\mathrm{U}^{238}$ and $\mathrm{Th}^{232}$ has been revived, employing $\mathrm{O}^{16}$ beams. New transitions have been observed in both nuclei. In $\mathrm{U}^{238}$, two main groups of de-exciting gamma rays have been found, one around $0.66 \mathrm{Mev}$ and the other at $1.02 \mathrm{Mev}$. In $\mathrm{Th}^{232}$, two groups of gamma rays have also been seen. One group corresponds to the known transitions from a $2+$ level at about $780 \mathrm{kev}$ to the $0+$, $2+$, and $4+$ levels of the ground-state rotational band, and the other consists mainly of a pair of transitions of $1.06 \mathrm{Mev}$. Work to identify the nature of the levels excited is continuing, but is complicated by the occurrence of multiple excitation in the higher bands. To help in these studies, a wedge electron spectrometer is currently being built by Dr. Elbek. 
Nuclear fission

\section{FISSION OF GOLD WITH 120-Mev CARBON IONS}

\section{H. Marshall Blann and T. Darrah Thomas*}

The fission mass-yield curve for the system Au ${ }^{197}+\mathrm{C}^{12}$ (120 Mev) may now be estimated from our radiochemical data. A $1300 \pm 200-\mathrm{mb}$ cross section in a "symmetrical" or very nearly symmetrical peak having its maximum at $A=101$ and being $15 \pm 1$ mass units wide at half maximum (full width) is the result.

Measuring independent yields across various $Z^{\prime}$ 's from $Z=28$ to $Z=53$ (peak $Z=42.5$ ) gives a peak of nearly parabolic shape having a full width at half maximum of 4 to 5 mass units. The most striking feature is that all these curves seem to have a maximum at an $\mathrm{n} / \mathrm{p}$ of $1.36-\mathrm{a}$ surprisingly close similarity to the results of Goeckermann and Perlman on $\mathrm{Bi}^{209}+200-\mathrm{Mev}$ deuterons. 1

Work is in progress on 1 - to 5-minute irradiations, with chemistry being done at the Hilac, in order to get independent yields of short-lived $Y$, $\mathrm{Nb}$, and $\mathrm{Br}$ isotopes.

Final verification of the above results as well as discussion of chargedistribution characteristics is awaiting last refinements in the end-window proportional-counter calibration work.

*Present address: Chemistry Division, Brookhaven National Laboratory, Upton, Long Island, New York.

${ }^{1}$ R. H. Goeckermann and I. Perlman, "Characteristics of Bismuth Fission with High-Energy Particles, " Phys. Rev. 73, 1127-1128 (1948). 


\title{
ANGULAR-MOMENTUM EFFECTS IN HEAVY-ION-INDUCED FISSION John Gilmore
}

Work on the determination of cross sections for heavy-ion-induced fission of $\mathrm{Re}^{185}, \mathrm{Re}^{187}$, and $\mathrm{Ta}{ }^{181}$ was continued, and the resulting data were analyzed to determine the role of angular momentum in the fission process. Targets of $\mathrm{Re}^{185}$ and $\mathrm{Ta} 181$ were bombarded with carbon and oxygen ions, respectively, to give compound nuclei of $\mathrm{Tl} 197$. The bombarding energies were chosen to give the same excitation energy in $\mathrm{Tl} 197$ in the different bombardments, but the angular momentum was, in general, greater in the bombardment with $\mathrm{O}^{\mathrm{P}}$. Comparison of fission cross sections (corrected for differences in compound-nucleus-formation probabilities) shows that the higher angular momentum of the system Ta ${ }^{181}$ plus $\mathrm{O}^{16}$ increases the fission probability relative to the case in which $\mathrm{Re}^{185}$ is bombarded with $\mathrm{C}^{12}$ to give the same excitation energy. This result is in agreement with theoretical considerations, which predict that increasing rotational angular momentum of a nucleus lowers the fission threshold significantly.

A second series of experiments will be carried out to determine the magnitude of the angular-momentum effect in fission of the systems Tm 169 plus $\mathrm{C}^{12}$ ions and Hol65 plus $\mathrm{O}^{16}$.

\section{THE ANGULAR DISTRIBUTION OF FISSION FRAGMENTS}

\author{
Victor E. Viola, Jr.
}

Compound-nucleus states of high angular momentum can be reached in nuclear reactions between heavy elements and heavy ions from the Hilac. Consequently, the study of the angular distribution of fission fragments from these states should provide a test of the Bohr model of fission at moderately high energies. The current studies make use of the recoil collection technique for determining gross fragment distribution as well as for separating specific fragments radiochemically.

The reactions that have been examined so far have used $\mathrm{Au}^{197}$ as a target and the following projectiles: $C^{12}(E=125 \mathrm{Mev}, \bar{l}=46 ; E=109 \mathrm{Mev}$, $\bar{l}=40) ; \mathrm{N}^{14}(\mathrm{E}=146 \mathrm{Mev}, \bar{l}=54)$, and $O^{16}(\mathrm{E}=167 \mathrm{Mev}, \bar{l}=62)$, where $\bar{l}$ is the average angular momentum calculated by using a square-well potential with $r_{0}=1.5$ fermis. The $125-\mathrm{Mev} C^{12}$ angular distribution has been most thoroughly investigated. For this reaction the assumption of a symmetric distribution in the center-of-mass system gives a value of the ratio of the differential cross section at 0 deg to that at $90 \mathrm{deg}$ of $W(0) / W(90)=5.0 \pm 0.2$, with $\bar{\eta}=0.232$ where

$$
\eta=\frac{\text { velocity of center of mass }}{\text { velocity of fission fragment }} .
$$

\footnotetext{
IA. Bohr, in Proceedings of International Conference on Peaceful Uses of Atomic Energy, Geneva, 1955 (United Nations, New York, 1956) Vol. 2, p. 151.
} 
Measurements are made to within 3 to 8 deg of the beam in both directions so that $\eta$ can be estimated fairly accurately from forward-to-backward ratios. Other data at present are:
(a) $\mathrm{N}^{14}-\mathrm{W}(0) / \mathrm{W}(90)=5.9 \pm 0.4 ; \bar{\eta} \cong 0.253$, and
(b) $\mathrm{O}^{16}-\mathrm{W}(0) / \mathrm{W}(90)=5.30 \pm 0.4 ; \bar{\eta} \cong 0.272$.

Only preliminary data are available for the $109-\mathrm{Mev} \mathrm{C}^{12}$ experiment, but these data indicate a lower value of $\mathrm{W}(0) / \mathrm{W}(90)$.

Radiochemical analysis near the beam has been done for $\mathrm{Mo}^{99}$ and $\mathrm{Br} 80, \mathrm{Br} 82$, and $\mathrm{Br} 83$. Present results give $\eta \cong 0.21$ for Mo 99 and $\eta \cong 0.17$ for the $\mathrm{Br}$ fragments.

\section{MASS SPECTROMETRIC STUDY OF CHARGED-PARTICLE-INDUCED FISSION}

\section{Maynard C. Michel and Yung-Yee Chu*}

The mass-spectrometric chain-yield measurements have been completed over the mass region studied (140 $\leqslant A \leqslant 155)$ for the fission of $U^{2} 38$ induced by 24 - and $45.7-\mathrm{Mev}$ helium ions, and the fission of $\mathrm{U}^{235}$ induced by 45.7-Mev helium ions. Preliminary work has also been done on the chain yields in the fission of $\mathrm{U}^{238}$ induced by $730 \mathrm{Mev}$ protons.

The yield-mass plot for the fission of $\mathrm{U}^{235}$ by $45.7-\mathrm{Mev}$ helium ions is shown in Fig. 8. Similar data for the fission of $\mathrm{U}^{238}$ induced by $24-\mathrm{Mev}$ helium ions are shown in Fig, 9.' These curves continue the regularity observed in the fission of $\mathrm{U}^{238}$ by $45.7 \mathrm{-Mev}$ helium ions reported previously, 1 and reinforce our belief that there is no easily observable structure to the yield-mass curves in this mass region. The observed differences in slope are easily related to the changes in target and excitation energy.

A study has been made of the distribution of charge in the fission of $\mathrm{U}^{235}$ and $\mathrm{U}^{238}$ at the moderate excitation quoted above, with fractional chain yields of several shielded isotopes measured with the mass spectrometer. Attempts to fit the data by the equal-charge-displacement rule suggested by Glendenin, Coryell, and.Edwards ${ }^{2}$ or the equal-charge-to-mass-ratio treatment of Goeckermann and Perlman ${ }^{3}$ resulted in rather poor correlations

\footnotetext{
*Present address: Brookhaven National Laboratory, Upton, Long Island, N. Y. ${ }^{1}$ M. C. Michel and Yung-Yee Chu, in Chemistry Division Semiannual Report, UCRL-8867, July 1959, p. 25.

${ }^{2}$ Glendenin, Coryell, and Edwards, in National Nuclear Energy Series Div. IV (McGraw-Hill Book Co., New. York, 1951), Vol. 9, Paper 52.

${ }^{3}$ R. H. Goeckerman and I. Perlman, Phys, Rev。 76, 628 (1949).
} 


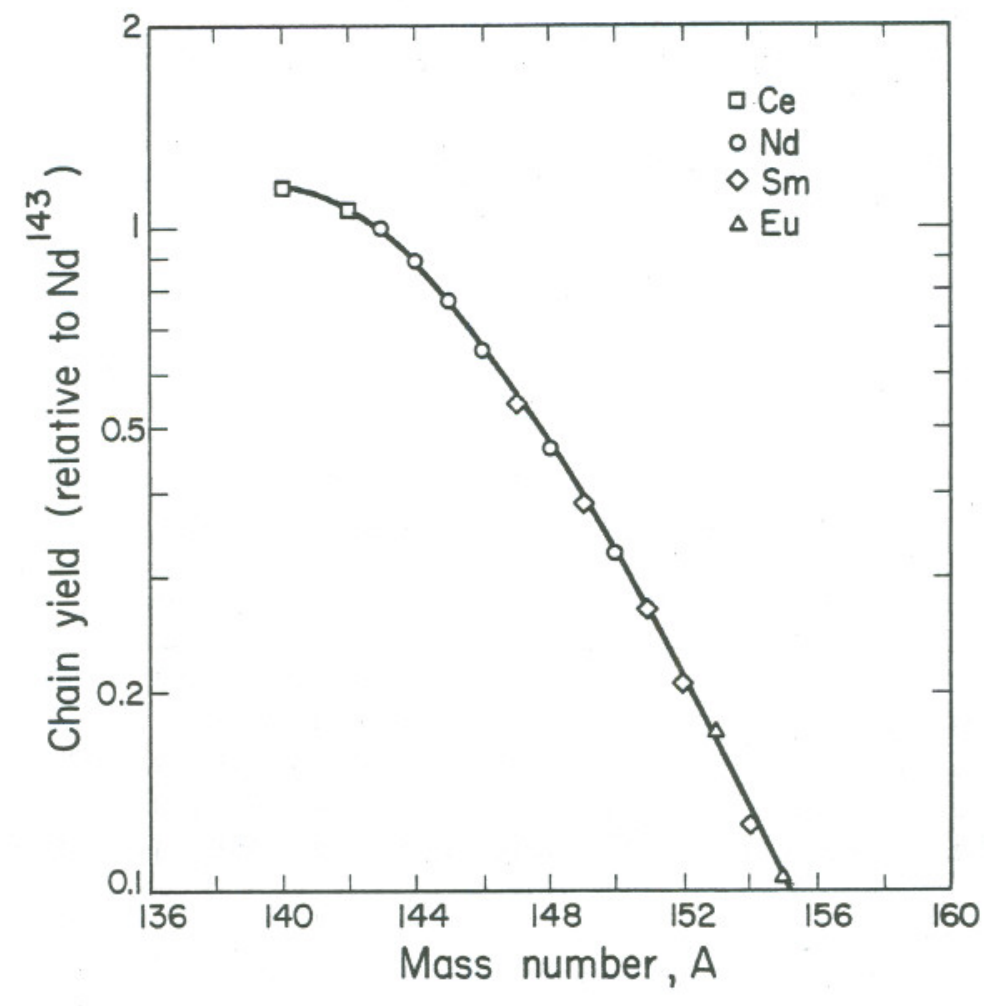

Fig. 8. Yield-mass curve for fission of $\mathrm{U}^{235}$ induced by $45.7-\mathrm{Mev}$ helium ions. 


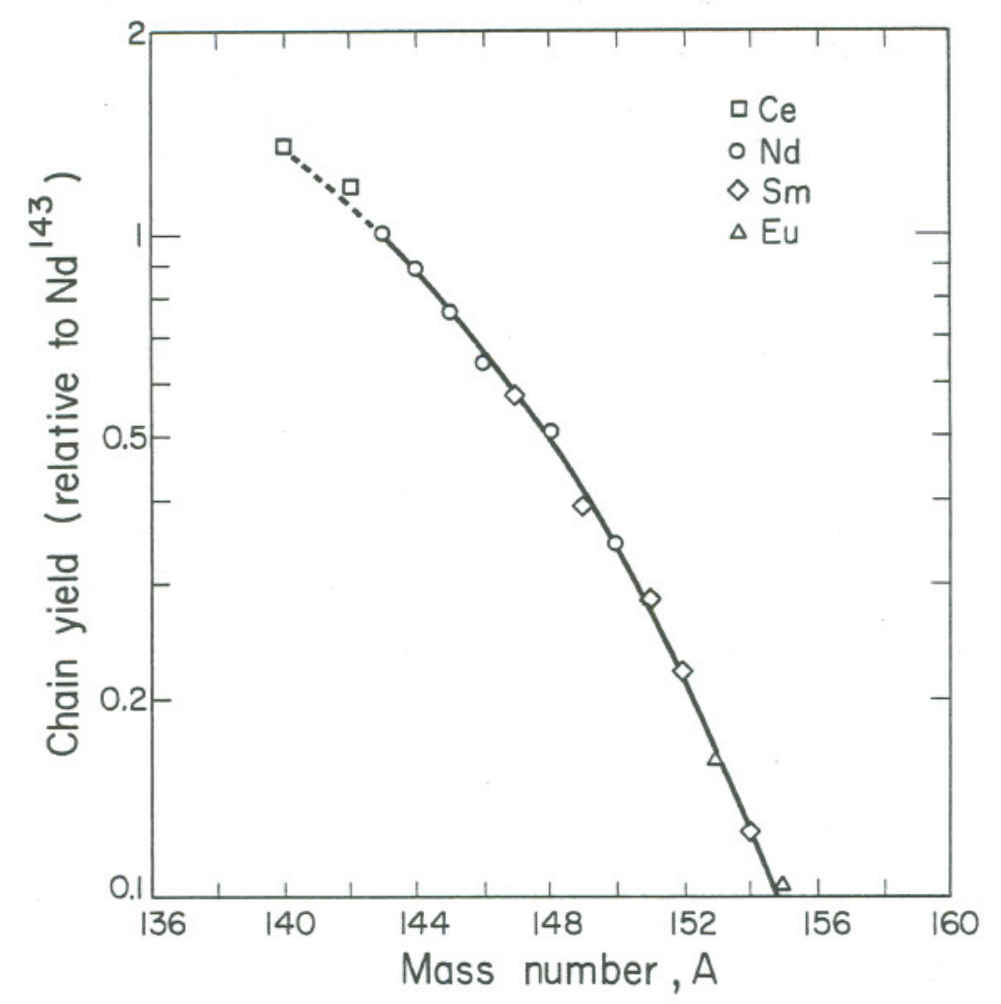

$\mathrm{MU}-18563$

Fig. 9. Yield-mass curve for fission of $\mathrm{U}^{238}$ induced by $24-\mathrm{Mev}$ helium ions. 
with either, but with perhaps a slight bias in favor of the latter. This is in qualitative agreement with the work of Gibson. 4 However, considering the precision of the present data, neither treatment could be considered satisfactory.

A very good correlation may be made, however (see Fig. 10), by using the equal-charge-displacement treatment, but using the set of linear $Z_{A}$ values given by Friedlander and Kennedy ${ }^{5}$ along with a $3 / 1$ asymmetric split of the postfission mutrons in favor of the heavy fragment. Such a treatment would indicate that the nuclear shells play no significant role in fission at these excitations. It is quite clear that the shell-affected $\mathrm{Z}_{\mathrm{A}}$ values from other sources 6,7 cannot correlate the data with any reasonable assumptions about the emitted neutrons.

A broad and asymmetric independent-yield distribution with a given $\mathrm{Z}$ was observed for the fission of $\mathrm{U}^{238}$ by $730 \mathrm{-Mev}$ protons (see Fig. 11). The width is quite in accord with the number of fissioning nuclides expected at this energy. A similar but reduced effect was observed in the fission of $\mathrm{U}^{238}$ by $100-\mathrm{Mev}$ carbon ions. report.8

A more complete discussion of these studies is available in a separate

${ }^{4}$ Walter M. Gibson, Fission and Spallation Competition from the Intermediate Nuclei Americium-241 and Neptunium-235 (Thesis), UCRL-3493, Nov, 1956.

${ }^{5}$ G. Friedlander and J. W. Kennedy, Nuclear and Radiochemistry (John Wiley and Sons Inc., New York, 1955) p. 50.

${ }^{6}$ C. D. Coryell, Ann. Rev. Nuclear Sci. 2, 305 (1953).

${ }^{7}$ W. E. Grummitt and G. W. Milton, J. Inorg. Nuclear Chem. 5, 93 (1957);

W. E. Grummitt and G. W. Milton, A Re-Assessment of Two Postulates of Charge Distribution in Fission in the Light of Mev Nuclear Data, CRC-694, Chalk River, Ontario, May 1957.

${ }^{8}$ Yung-Yee Chu, Charged-Particle-Induced Fission: A Mass-Spectrometric Yield Study (Thesis), UCRL-8926, Nov. 1959. 


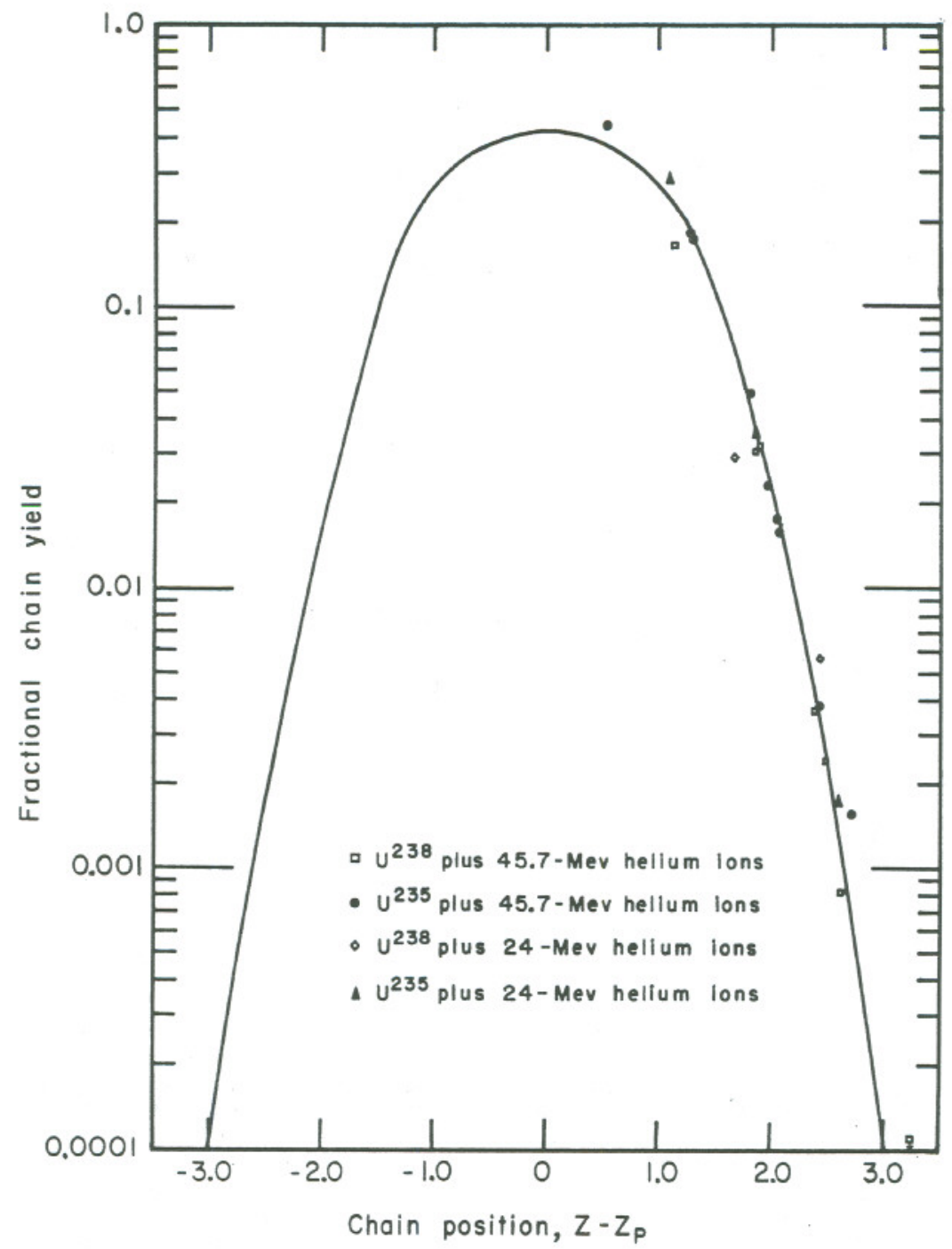

MU-18411 Fig. 10. Charge-distribution curve based on $\mathrm{Z}_{\mathrm{A}}{ }^{\prime} \mathrm{s}$ of Friedlander
and Kennedy. 


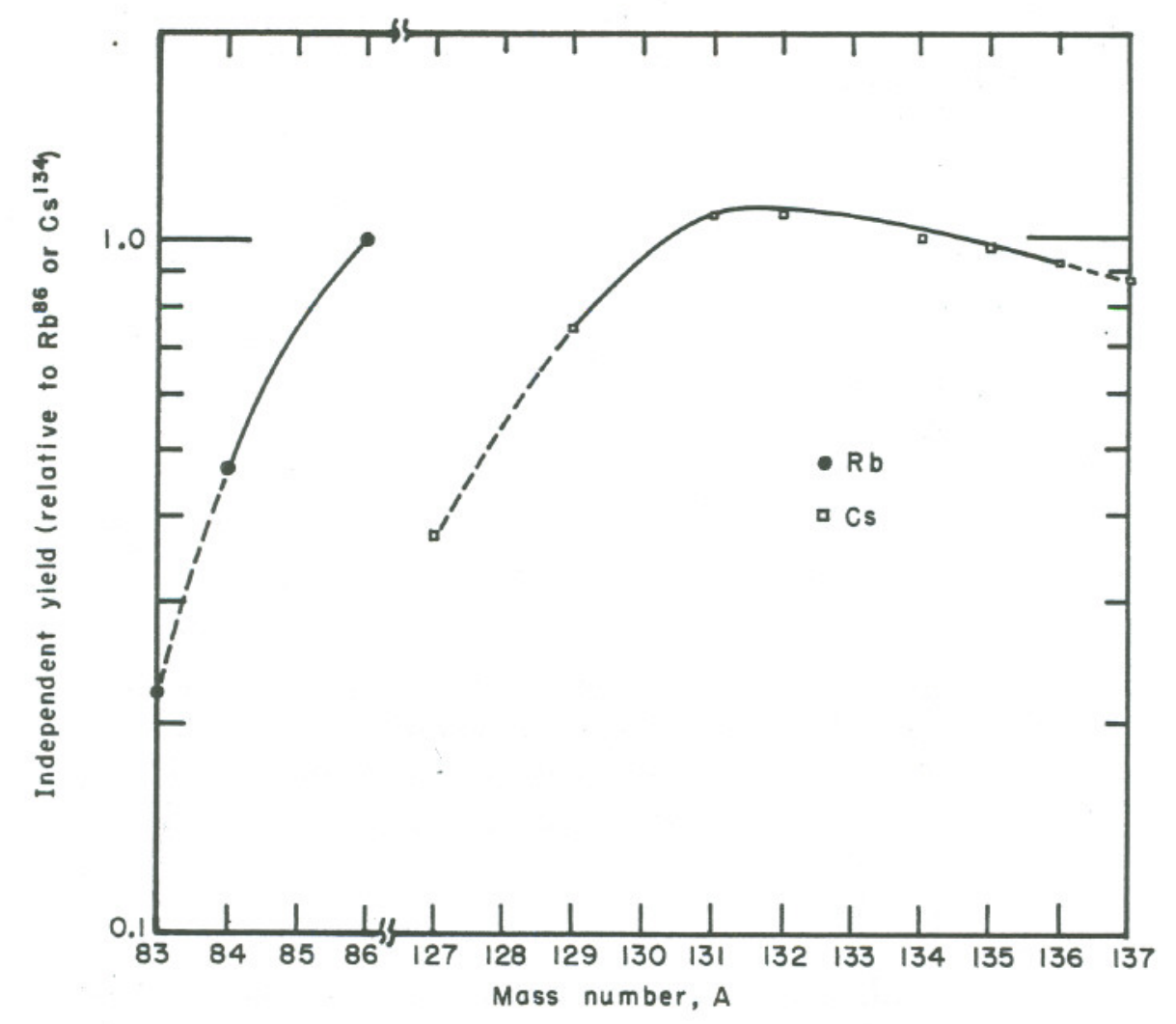

MU-18404

Fig. 11. Independent yield distributions of cesium fraction and rubidium fraction from fission of $\mathrm{U}^{238}$ induced by $730-\mathrm{Mev}$ protons. 
Radioactivity and Nuclear Properties

\section{MULTIPLE FISSION BY C ${ }^{12}$ INTERACTIONS WITH U $\mathrm{U}^{238}$}

\section{Eldon Haines}

Investigation of the fission yield curve for fission produced by the reaction

$$
\mathrm{C}^{12}(115 \mathrm{Mev})+\mathrm{U}^{238} \rightarrow \mathrm{Cf}^{250 \%} \rightarrow \text { fission }
$$

has given evidence of the existence either of ternary fission or a very asymmetric mode of binary fission. In the low-mass region, the lightest isotope found was $\mathrm{Mn}^{56}$ with a cross section on the order of a microbarn. Other isotopes observed were $\mathrm{Ni} 65, \mathrm{Ni} 66, \mathrm{Cu} 67$, and $\mathrm{As}{ }^{77}$. The high-mass region is being investigated to determine whether the light masses observed are due to highly asymmetric binary fission. The heaviest isotope definitely identified was Gd ${ }^{159}$, although the presence of even heavier isotopes was indicated.

Accurate determination of these yields depends upon more information concerning the counting efficiencies of the beta counters being used. Further experiments in the high-mass region will also employ gamma-counting techniques in order to determine yields of $\mathrm{K}$-capture isotopes which may be produced along with beta emitters in a given element fraction.

Some new emulsion techniques and the use of solid-state detectors are being considered as possible approaches to this general problem. 


\title{
TERNARY FISSION IN Cf 252
}

\author{
M. Luis Muga, Harry R. Bowman, and Stanley G. Thompson
}

A study of the long-range alpha particles associated with the spontaneous fission decay of californium-252 has been undertaken, using nuclear emulsion techniques. The alpha energy spectrum was found to peak at about $19 \mathrm{Mev}$ with a half-width of $10 \mathrm{Mev}$, and the preferential angle of emission was found to be slightly less than 90 deg with respect to the light fission fragment. These results support the view that alpha-particle emission occurs at the time of scission and that the direction is determined by the extent of electrostatic repulsion by the fragments. A plot of the fragment range ratio indicates that the average ranges are about 1 micron shorter than for binary fission.

The division also appears to be slightly more symmetric than for binary fission. The frequency of occurrence of the long-range alpha particles was observed to be 1 in 415 binary fissions.

A parallel search was made for ternary fission events in which division into comparable masses occurs. Such events were observed in emulsions with a frequency of at least 1 in 20,000 binary fissions, and could not be attributed to scattering of binary fission fragments by silver and bromine nuclei in the emulsion.

Ternary events consisting of two heavy fragments and one light fragment of short range were observed, but the frequency with which these events occur was not measured.

Equipment was assembled and experimental work started in an attempt to make more precise measurements of the above phenomena by using solidstate counters (silicon crystals), which had been found to give very good energy resolution for fission fragments from Cf 252 . In this case a weightless Cf 252 source prepared by self-transfer onto nickel foil $180 \mathrm{mg} / \mathrm{cm}^{2}$ thickness) was placed in the center of a vacuum chamber and surrounded by three solid-state detectors. The angles of the detectors relative to the source and the other detectors is variable. The output of the detectors is amplified and fed into a triple-coincidence circuit. Ultimately the heights of pulses from the detector are recorded simultaneously in binary form on paper tape. The data-recording system was constructed for, and is also being used for, determination of the neutron energy and angular distributions in fission. 


\section{VELOCITY AND ANGULAR DISTRIBUTION OF PROMPT NEUTRONS FROM SPONTANEOUS FISSION OF Cf 252}

\section{Harry R. Bowman, Wladislaw J. Swiatecki, and Stanley G. Thompson}

Our previous experiments ${ }^{1}$ have shown that the main features of the prompt-neutron distribution from spontaneous fission of $\mathrm{Cf}^{252} \mathrm{can}$ be explained by evaporation from moving fragments. There was in addition a slight indication of an excess of neutrons observed at an angle $90 \mathrm{deg}$ relative to the motion of fragments. From these first experiments, however, no definite conclusion could be reached because the velocities of only single fragments were measured and it was necessary to assume average velocities for the opposite fragments. Therefore an experimental program was undertaken which involves the measurements of the velocities of both fragments simultaneously.

The equipment for the measurement of the time of flight of prompt neutrons and both fission fragments has been set up and tested. The angles of the neutron detectors relative to fission fragments can be varied through a range from 6 to $90 \mathrm{deg}$. The measurements are being made at present by using a Cf 252 source which produces $2 \times 10^{6}$ spontaneous fission events per minute. Two neutron detectors (4-in. plastic crystals 2 in. thick) and two fission-fragment detectors (4-in. plastic scintillators 5 mils thick) are operated simultaneously. Time-of-flight measurements are made when events occur in which one neutron and two fragments occur in coincidence. Rare events in which two neutrons occur simultaneously are also measured.

The detectors are mounted at the circumference of an 80-in.-diameter steel drum which is evacuated to a pressure of $10^{-6} \mathrm{~mm}$ of $\mathrm{Hg}$. The $\mathrm{Cf}^{252}$ source, which was prepared by self-transfer on a thin nickel foil (thickness $\left.80 \mu \mathrm{g} / \mathrm{cm}^{2}\right)$, is located at the center of the drum. Delta rays (electrons) knocked out of the nickel foil by fission fragments pass through an accelerating lens and are detected by a plastic scintillator to give a zero time pulse. The four detectors located around the periphery of the drum are mounted on 5-in. photomultipliers, the outputs of which are fed to time-to-pulse-height converters and also through a slow system to the coincidence circuit. Outputs from the time-to-pulse-height converters are fed to a 400-channel pulseheight analyzer (split into two 200-channel sections so that prompt gamma rays and neutron-velocity distributions from the two neutron detectors are observed directly). Pulses from the time-to-pulse-height converters are amplified, stretched, and fed through a system which ultimately punches the four pulse heights in paper tape. Equipment for converting the data on perforated paper tape to magnetic tape in a form that can be used directly in the IBM 704 computor has been constructed and is being "debugged". Approximately $2 \times 10^{5}$ neutron coincidence events have been recorded simultaneously on paper tape at angles 6 and $90 \mathrm{deg}$. A rough layout drawing of the system is shown in Fig. 12.

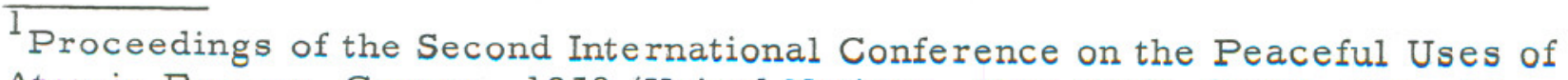
Atomic Energy, Geneva, 1958 (United Nations, New York, 1959), Vol. 15, P. 652 . 


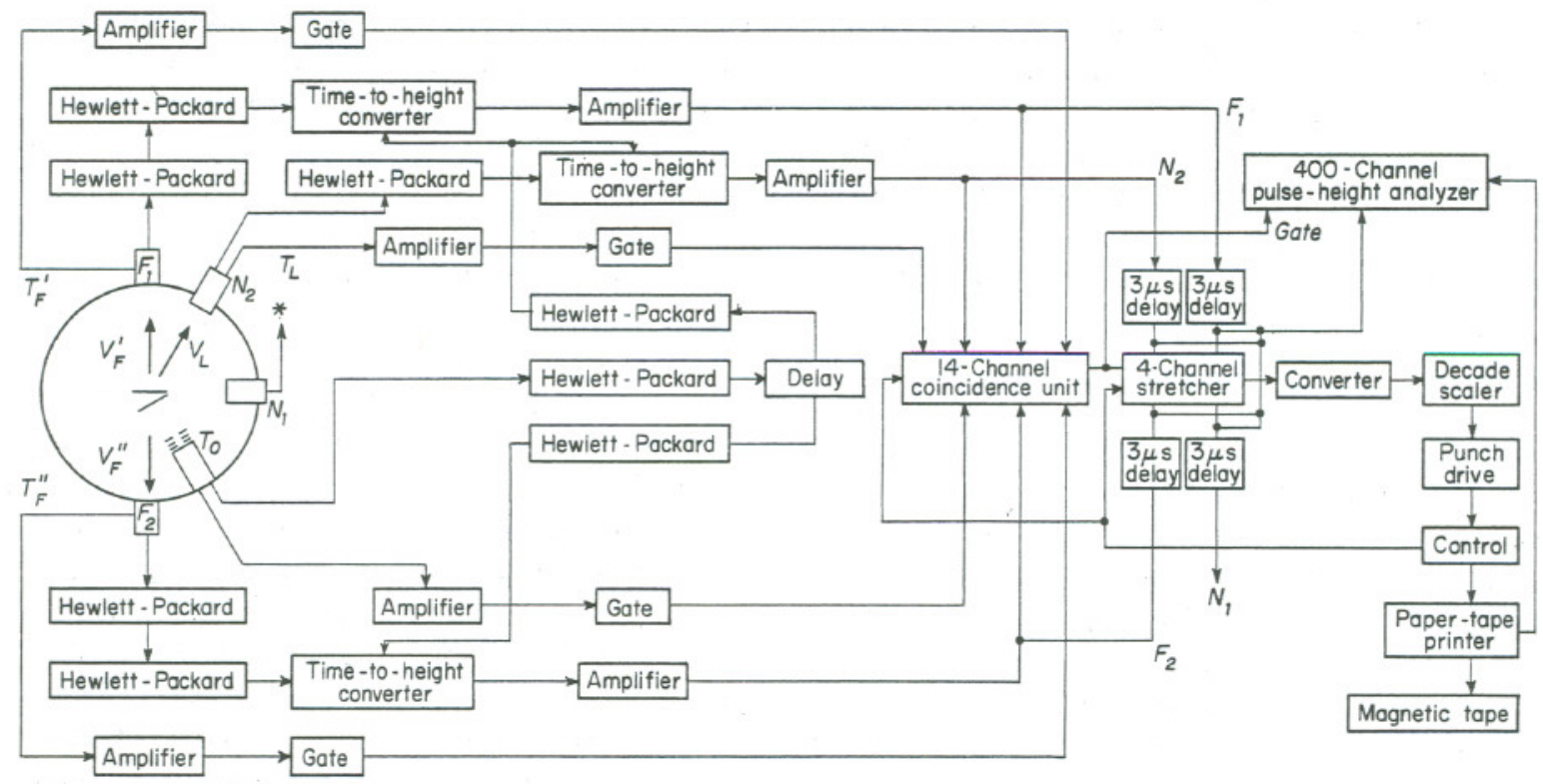

${ }^{*} N_{1}$ same as $\mathrm{N}_{2}$

$M U-19544$

Fig. 12. Detection and recording system for prompt neutrons from Cf ${ }^{252}$ fission. 


\author{
SELF-TRANSFER OF $\mathrm{Cf}^{252}$ \\ Raymond C. Gatti, Llad Phillips, Harry R. Bowman, \\ and Stanley G. Thompson
}

Several years ago it was observed that sources of $\mathrm{Cf}^{252}$ electroplated on platinum surfaces have an unusual and interesting property. Under certain conditions this isotope transfers itself in a vacuum at a rather high rate to an adjacent metal surface when a negative potential is applied to the collector plate. This property makes possible a large number of useful applications in the preparation of targets and sources. The mechanism is not well understood, but was thought possibly to be related to the high spontaneous fission rate of the $\mathrm{Cf}^{252}$ and to the volatility of the Cf $f^{252}$ deposit. Therefore a study of the self-transfer processes has been undertaken. The source being used is $1.74 \mu \mathrm{g}$ of $\mathrm{Cg}^{252}$ electroplated in an area of $0.315 \mathrm{~cm}^{2}$ on a 5-mil-thick platinum plate.

The self-transfer rate of $\mathrm{Cf}^{252}$ at atmospheric pressure and with no potential difference between the source and a collecting plate $1 / 4 \mathrm{in}$. away is approximately $10^{-5} \%$ per hour. The self-transfer rate increases with decreasing pressure until a plateau is reached at which the rate is $\sim 0.3 \%$ per hour (2500 atoms of $\mathrm{Cf}^{252}$ per fission) at pressures ranging from $7 \mathrm{~mm}$ to 1 micron.

The transfer rate at atmospheric pressure increases with increasing potential difference, reaching a rate of $0.02 \%$ per hour at 500 volts. These data apply to a separation distance of $1 / 4$ in. between source and collector. The transfer rate at atmospheric pressure increases with applied voltage irrespective of the sign of the potential on the collecting plate.

The transfer rates in a vacuum of approximately 35 microns and a source-to-collector distance of 4-1/8 in. were compared for three different collecting potentials--0, +500 , and -500 volts. The transfer rate at $+500 \mathrm{v}$ was the same as for $0 \mathrm{v}$. At $-500 \mathrm{v}$ collecting potential the transfer rate increased by a factor of 10 to about the transfer rate observed at $1 / 4 \mathrm{in}$. collecting distance.

The transfer rates at various collecting distances have been compared, and preliminary data indicate anisotropic transfer. Radioautographs of collected sources have shown that partial focusing has been achieved by using shaped electrostatic fields.

Experiments are now in progress to study the transfer rate as a function of source density. A study of the nature of the charge and mass of the particles transferred is planned. The experiments studying the geometry of transfer and the possibility of focusing the californium on a small area are being continued. Some preliminary experiments on the self-transfer of other heavy elements have had promising results. 


\title{
PRODUCTION AND PURIFICATION OF HEAVY ISOTOPES
}

\author{
Llad Phillips, Raymond C. Gatti, and Stanley G. Thompson
}

The production of transcurium isotopes from irradiations of plutonium and its transmutation products in the MTR continued. (Program started in 1952.) The chemical processing and purification of the isotopes was completed last fall (Sept. 1959). Approximately $10 \mu \mathrm{g}$ of californium, a comparable amount of berkelium, and equilibrium amounts of einsteinium and fermium were obtained. Approximately half the purified californium was given to the group which is attempting to produce new elements to be used as target material for heavy-ion bombardments. Milligram amounts of purified $\mathrm{Cm}^{244}$ mixed with heavier curium isotopes were also given to the newelement group to be usedas target materials for heavy-ion bombardments. The einsteinium ( $50 \mathrm{m \mu g}$ ) was purified and used in an unsuccessful attempt to measure its magnetic susceptibilities. Finally the einsteinium and fermium isotopes were repurified and used in the study of their alpha decay schemes.

A large number of $\mathrm{Cf}^{252}$ sources on thin nickel foils have been prepared for use in fission research. Approximately ten such sources have been given to the Los Alamos Scientific Laboratory for research purposes. The Livermore laboratory has used our largest $\mathrm{Cf}^{252}$ source for the collection of fission fragments and for measurements of the mass-yield curve in $\mathrm{Cf}^{252}$ fission. Another group at Livermore is using our source to study fission-fragment ranges as a function of mass number.

\section{ON THE Am ${ }^{242}$ ISOMERIC PAIR \\ Isadore Perlman, Frank Asaro, John O. Rasmussen, and Stanley G. Thompson}

The isomers of $\mathrm{Am}^{242}$ (half-lives 16 hours and 152 years) have presented some major inconsistencies when attempts have been made to reconcile their apparent decay modes with existing selection rules for beta and gamma transitions. From measured energies of beta spectra the longlived isomer has previously been presumed to be the ground state. We have found by an isomer-separation technique that the $16-\mathrm{hr}$ isomer is present in equilibrium with the long-lived isomer and hence is the ground state.

Electron spectra of a sample of Am $241,242,243$ taken in a permanentmagnet spectrograph have shown more than 70 conversion lines. All conversion lines are assigned to known transitions in $\mathrm{Np}^{237}, \mathrm{Cm}^{242}$, and $\mathrm{Pu}^{242}$ except 11 lines assigned to a 48.6-kev transition in americium, very probably the $\mathrm{Am}^{242}$ isomeric transition. The $\mathrm{M}$-subshell ratios were consistent only with the theoretical results of $\mathrm{E} 4$ transitions. 1

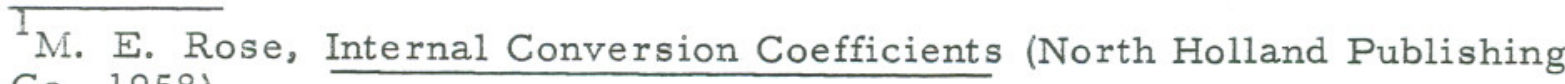
Co. 1958). 
Recent atomic-beam studies ${ }^{2}$ have shown the $16-\mathrm{hr} \mathrm{Am}^{242}$ to have spin 1 and a ratio $\mu / Q_{\text {spec }}$ which is negative, in contrast to neighboring $\mathrm{Am}^{241}$ and $\mathrm{Am}^{243}$. These studies show that $\mu= \pm 0.33 \mathrm{~nm}$ and $\mathrm{Q}_{\text {spec }} \mp 2.8$ barns.

We are able to explain theoretically most of the data on these isomers by couplings of the 5/2-proton orbital of the Am 241 ground state with the $5 / 2+$ neutron of the $\mathrm{Pu}^{241}$ ground state to give an upper 5- $(\mathrm{K}=5)$ and $\mathrm{a}$ lower $1-(\mathrm{K}=0)$ state, with the isomeric transition a $\mathrm{K}$-forbidden $\mathrm{E} 4$.

A negative spectroscopic quadrupole moment for the 1 - isomer is a consequence of a positive intrinsic quadrupole deformation and the negative projection factor for $K=0$ states, and the experimental values of the moments are in excellent agreement with theory for a $K=0$ state.

2Winocur, Marrus, and Nierenberg, Bull. Am. Phys. Soc. 4, 451 (1959) Paper I3. Also see report of Lipworth and Marrus elsewhere in this semiannual report. 


\title{
MEASUREMENT OF THE HALF LIVES \\ OF THE 74.6-kev EXCITED STATE OF Np239 \\ AND THE 68-kev EXCITED STATE OF Ra226
}

\author{
John P. Unik
}

The half-life of the $74.6-\mathrm{kev}$ excited state of $\mathrm{Np}^{239}$ was determined by studying the time relationship between the emission of the a particles in the decay of $\mathrm{Am}^{243}$ and the subsequent emission of the 74.6-kev gamma rays from $\mathrm{Np}^{239}$. This time relationship was determined by using a fastcoincidence circuit employing a time-to-pulse-height converter in conjunction with a 100-channel pulse-height analyzer. From the delayedcoincidence curve for $\mathrm{Am}^{243}$ and the prompt-coincidence curve obtained with $\mathrm{Bi}^{207,}$ the half-life of the $74.6-\mathrm{kev}$ excited state was calculated by using the centroid-shift analysis described by Bay. I The energetic internalconversion electrons and the associated $\mathrm{K}$ x-rays of $\mathrm{Pb}^{207}$ proved very useful in obtaining the prompt-coincidence curve used in this analysis. The $\mathrm{K} x$-rays associated with the internal-conversion process are in prompt coincidence with the conversion electrons. The conversion electrons of $\mathrm{Pb}^{207}$ gave approximately the same pulse heights as the a particles of $\mathrm{Am} 243$ in the thin Livermore plastic scintillator (this plastic scintillator is composed of styrene with $2.5 \%$ terphenyl, $0.03 \%$ tetraphenyl butadiene, and $0.01 \%$ zinc stearate) used as one detector. Also the $\mathrm{K}$ x-rays of lead are almost identical in energy to the $74.6-\mathrm{kev}$ gamma ray of $\mathrm{Np}^{239}$. The delayed-coincidence curves for $\mathrm{Bi}^{207}$ and $\mathrm{Am}^{243}$ are shown in the section "Analysis of Delayed Coincidence Curves" (Strominger and Unik) of this report.

From a detailed centroid-shift analysis the half-life of the 74.6-kev excited state of $\mathrm{Np}^{239}$ was determined to be $1.2 \pm 0.2 \times 10^{-9} \mathrm{sec}$. The $74.6-\mathrm{kev}$ El gamma ray depopulating this state is hindered by a factor of roughly 6000 from the single-proton transition probability estimates of Moszkowski. 2

During this work there was occasion to check the half-life of the 68 -kev excited state of $\mathrm{Ra}^{226}$ populated by alpha decay of $\mathrm{Th}^{230}$. The halflife obtained by using $\mathrm{Bi}_{207}$ as a prompt comparison was $0.49 \pm 0.09 \times 10^{-9} \mathrm{sec}$, slightly lower than the value of $0.63 \pm 0.07 \times 10^{-9} \mathrm{sec}$ reported by Vartapetian and Foucher. 3

Iz. Bay, Phys. Rev. 77,419 (1950).

${ }^{2}$ S. A. Moszkowski, in Beta- and Gamma-Ray Spectroscopy, K. Siegbahn, Ed. (Interscience Publishers, Inc., New York, 1955), Chap. XIII.

${ }^{3}$ H. Vartapetian and R. Foucher, Compt. rend. 246, 939 (1958). 


\section{ANAL YSIS OF DELA YED-COINCIDENCE CURVES Donald Strominger ${ }^{*}$ and John P. Unik}

An IBM-650 program has been written and tested to analyze delay curves. This program will aid the interpretation of data used to measure half-lives in the musec region. It is largely based upon the theory of Bay ${ }^{1}$ and Newton. 2

The input data for the program are composed of a "prompt" delay curve ( $\mathrm{Bi}^{207}$ data in Fig. 13) and a second delay curve with a measurable half-life (Am 243 data in Fig. 13). The program computes a lifetime from the centroid shift between the two curves and then uses this lifetime to calculate a theoretical curve for the second delay curve.

Figure 13 shows the results of the calculation for the comparison of $\mathrm{Am}^{243}$ with $\mathrm{Bi}^{207}$. The solid curve was computed from the half-life of $1.21 \mathrm{~m} \mu \mathrm{sec}$ determined by centroid shift. The other two curves were also calculated, one by assuming a half-life $20 \%$ greater and the other a halflife $20 \%$ smaller.

The agreement is satisfactory within the limits of experimental error.

\footnotetext{
"Present address: Atomic International, Canoga Park, California.

lz. Bay, Phys. Rev. 77, 418 (1950).

${ }^{2}$ T. D. Newton, Phys. Rev. 78, 490 (1950).
} 


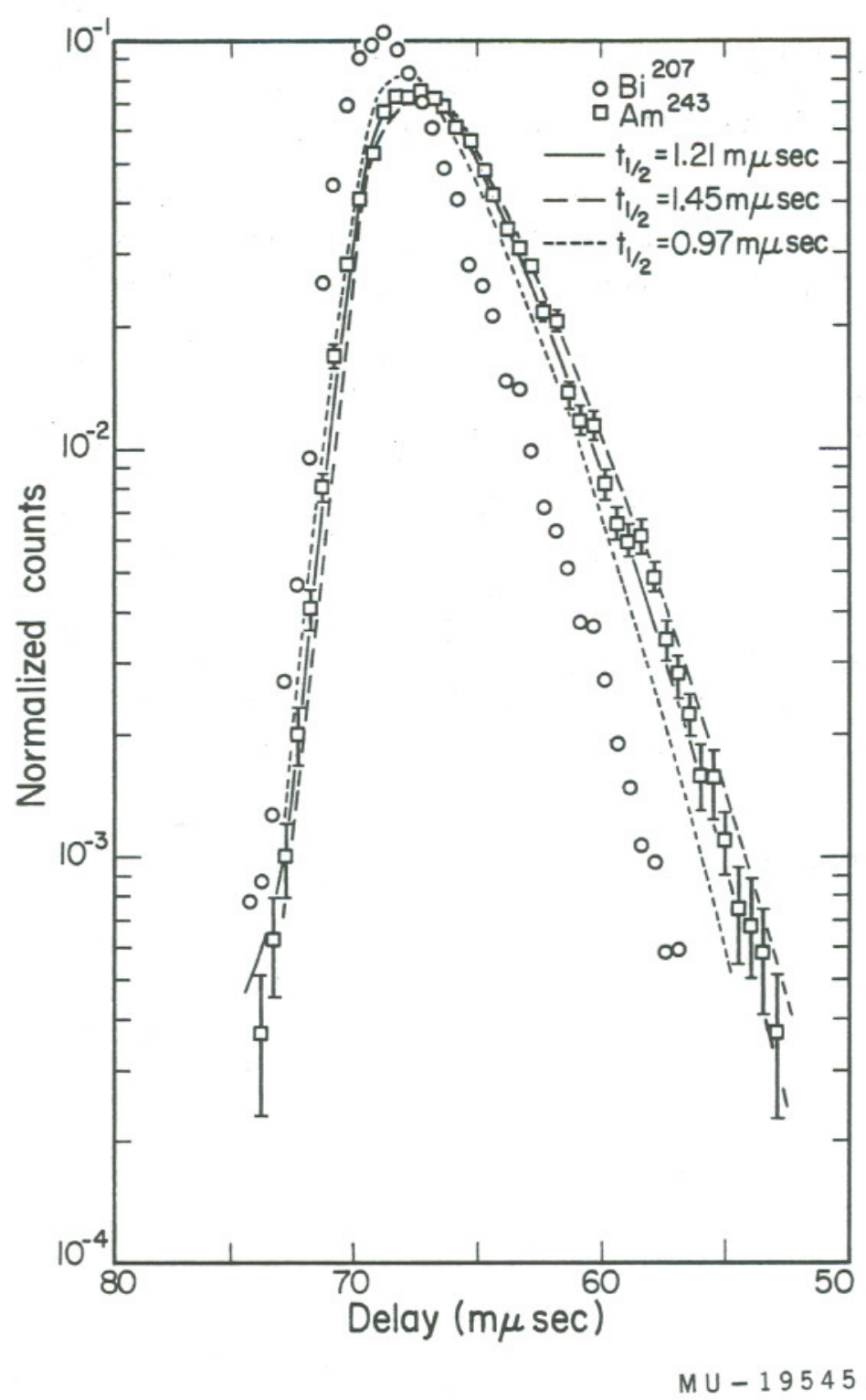

Fig. 13. Calculated and experimental delay curves. 


\section{GAMMA-GAMMA ANGULAR-DISTRIBUTION STUDIES IN THE BETA DECAY OF U237}

John A. Stone, Donald Strominger, ${ }^{*}$ and John P. Unik

An attempt was made to study the influence of the chemical environment on the angular distributions of two gamma-ray cascades in $\mathrm{Np}^{237}$. The diagram below shows the pertinent portions of the decay scheme of $\mathrm{U}^{237}$, taken from the work of Rasmussen, Canavan, and Hollander. 1

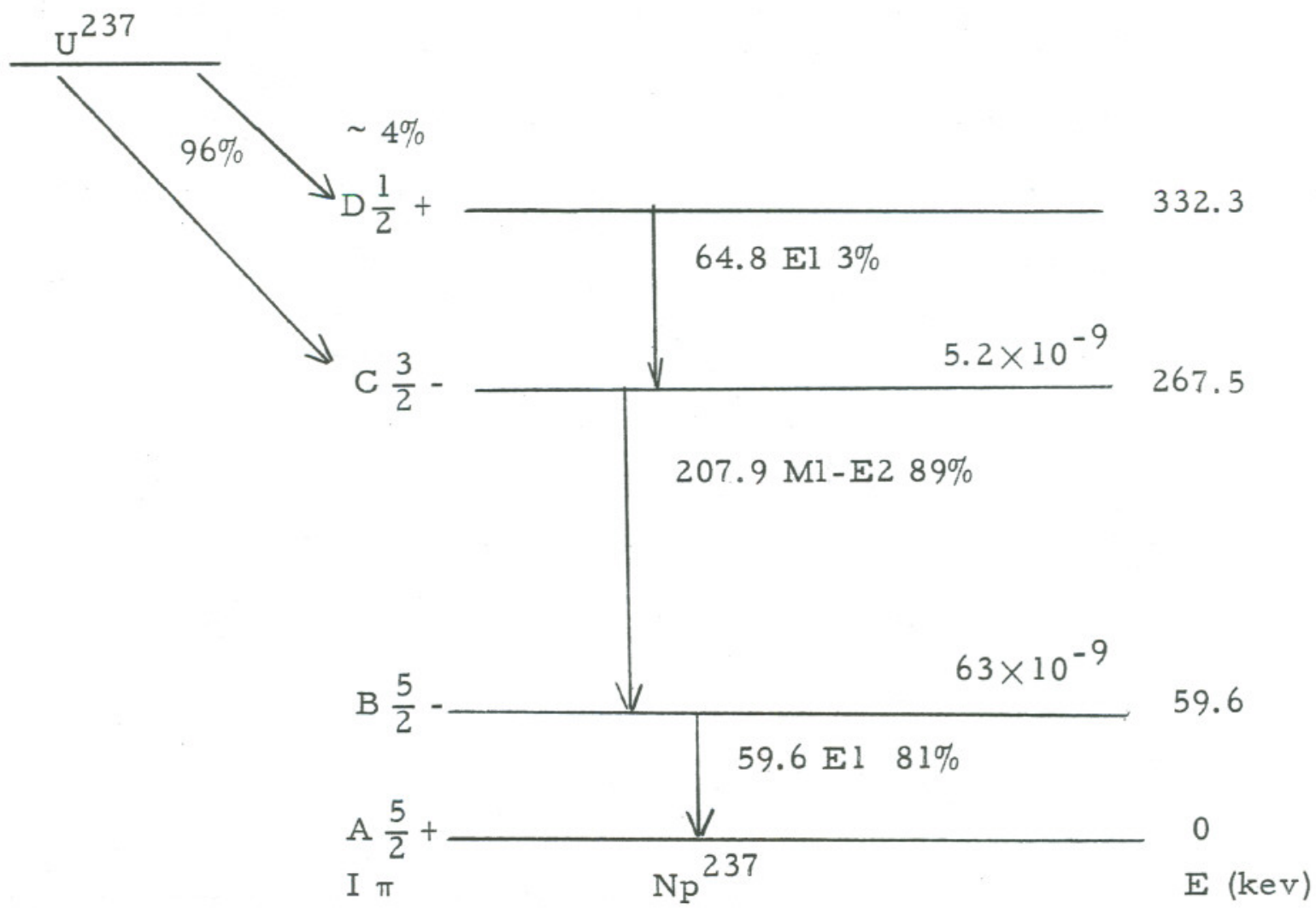

We have attempted to study the angular distributions of gamma-ray cascades DC, CB and CB, BA as a function of the time interval between the emission of the gamma rays. Although the 64.8-kev gamma ray DC, and the $59.6 \mathrm{kev}$ gamma ray, BA cannot be resolved simply by energy discrimination, the two gamma-ray cascades can be resolved on a time scale. This is made possible by delayed decay of the intermediate states $B$ and $C$. The coincidence circuit used in this work has been described earlier. 2

\footnotetext{
Present address: Atomics Internationa, Canago Park, California. ${ }^{1}$ Rasmussen, Canavan, and Hollander, Phys. Rev. 107, 141 (1957) 2 John A. Stone, Donald Strominger, and John P. Unik, in Chemistry Division Semiannual Report, UCRL-8867, July 1959, p. 50.
} 
The data were analyzed in a number of ways. The dependence of the anisotropy of the angular distribution

$$
\left[\frac{W\left(180^{\circ}\right)}{W(900)}-1\right]
$$

on the delay between the emission of the two gamma rays showed that the anisotropy for cascade CB, BA was negative, very small, and less than -0.09 at zero delay. The anisotropy vs delay for cascade DC, CB showed that the anisotropy is definitely negative. However, because of the rather low coincidence counting rates of this cascade compared with the cascade $\mathrm{CB}, \mathrm{BA}$, a good quantitative analysis of the anisotropy vs delay for cascade DC, CB could not be performed. To show the existence of a small anisotropy which might be weakly time-dependent, the anisotropies were calculated by averaging the data from 3 to $100 \mathrm{m \mu sec}$ for cascade CB, BA and from 3 to $10 \mathrm{~m} \mu \mathrm{sec}$ for cascade DC, CB as per columns 2 and 4 of Table III. The centroid of a prompt-coincidence curve defined time zero. The width at half maximum for this prompt-coincidence curve was $6 \mathrm{~m} \mu \mathrm{sec}$. To show the existence of a stronger time dependence, the anisotropy for cascade $C B, B A$ was also averaged from 3 to $10 \mathrm{~m} \mu s e c$ (Column 3).

Table III

\begin{tabular}{|c|c|c|c|}
\hline \multicolumn{3}{|c|}{ Integrated anisotropies } & . \\
\hline \multirow{2}{*}{ Source } & \multicolumn{2}{|c|}{ Cascade (CB, BA) } & Cascade (DC, CB) \\
\hline & 3 to $100 \mathrm{~m} \mu \mathrm{sec}$ & 3 to $10 \mathrm{~m} \mu \mathrm{sec}$ & 3 to $10 \mathrm{~m} \mu \mathrm{sec}$ \\
\hline $\mathrm{UO}_{2}^{++} 1 \mathrm{M} \mathrm{HCl}$ & $-0.010 \pm 0.005$ & $-0.01 \pm 0.03$ & $-0.06 \pm 0.02$ \\
\hline $\mathrm{U}^{+4} 6 \mathrm{MHCl}$ & $-0.001 \pm 0.005$ & $-0.005 \pm 0.015$ & $-0.01 \pm 0.04$ \\
\hline $\mathrm{U}^{+4} 1 \mathrm{M} \mathrm{HClO}_{4}$ & $-0.005 \pm 0.008$ & $-0.022 \pm 0.02$ & $-0.028 \pm 0.036$ \\
\hline $\mathrm{UO}_{2}^{++}$Solid & $-0.022 \pm 0.007$ & $-0.039 \pm 0.02$ & $-0.10 \pm 0.04$ \\
\hline
\end{tabular}

The measured anisotropies are much smaller than the -0.11 to $-0,32$ expected for the previously reported $\mathrm{E} 2$ gamma-ray mixing ratio $\left(\delta^{2}{ }_{208}\right)$ for the $208-\mathrm{kev}$ gamma ray, $0.005 \pm 0.005$. 1 A re-examination of the relative L-subshell internal-conversion electron intensities of the $208-\mathrm{kev}$ transition showed that the mixing ratio may be higher, $0.015 \pm 0.01$. With this mixing ratio, the data are consistent with (a) a positive phase for $\delta_{208}$ (b) the spin sequence $5 / 2,5 / 2,3 / 2,1 / 2$ for levels $A, B, C$, and D respectively, and (c) a $\lambda_{2}$ greater than $4.3 \times 10^{7} \mathrm{sec}^{-1}$, assuming the time dependence of $\mathrm{G}_{2}(\mathrm{t})$ in the angular distribution

$$
\left[W(\theta)=1+A_{2} G_{2}(t) P_{2}(\cos \theta)\right] \text { is of the form } e^{-\lambda_{2} t} \text {. }
$$




\title{
$\mathrm{Np}^{234}$ CONVERSION-ELECTRON SPECTRUM \\ Fr. Jacques Valentin and Jack M. Hollander
}

\begin{abstract}
A study has been undertaken of the relative intensities of the conversion lines in the electron spectrum of $\mathrm{Np}^{234}$, a 4 -day electron-capturing isotope. The decay of this isotope had been studied by Gallagher and Thomas in this laboratory, ${ }^{1}$ but they had evaluated only the energies of the conversion lines. Their electron plates are being re-examined for the intensity measurement. A new method of evaluating the intensities is being used, analogous to the quite common method of measuring energies with reference to internalstandard lines exposed on the same plate. In these experiments $\mathrm{Np}^{239}$, $\mathrm{Np}^{238}$, and $\mathrm{Np}^{236}$ were produced as well as $\mathrm{Np}^{234}$. The intensities of the electron lines in the internal-conversion spectrum of $\mathrm{Np}^{239}$ have recently been determined quite accurately by Ewan et al. 2 with use of the Chalk River high-resolution iron-free spectrometer, hence we determine our intensities by a visual method relative to close-lying lines of $\mathrm{Np}^{239}$ which occur on the same plates. In this way we avoid having to make uncertain correction concerning the varying transmission of the spectrographs, changing line shapes, and efficiencies of the emulsion--all of which are functions of the electron energy.
\end{abstract}

${ }^{1}$ C. J. Gallagher and T. Darrah Thomas, Vibrational States in $\mathrm{U}^{234}$ Excited by $\mathrm{Np}^{234}$ Decay and Evidence for an E0 Transition between States with I $\neq 0$, UCRL-8864, Aug. 1959.

${ }^{2}$ Ewan, Geiger, Graham, and MacKenzie Phys. Rev. 116, 950 (1959). 


\section{ALPHA-PARTICLE AND GAMMA-RAY STUDIES OF THE U229 AND U 228 FAMILIES}

Carl P. Ruiz, Frank Asaro, and Isadore Perlman

The uranium isotopes $\mathrm{U}^{229}$ and $\mathrm{U}^{228}$ give rise to a series of shortlived daughters $1,2,3$ as shown in Fig. 14 .

The activities were prepared by the irradiation of thorium $\left(\mathrm{Th}^{232}\right)$ metal with the minimum-energy a particles produced in the 184 -in. synchrocyclotron. The alpha and gamma radiations were studied by using a doublefocusing alpha-particle spectrograph, an alpha grid chamber, and scintillation counters. The grid chamber was modified in order to make alphagamma coincidence studies possible. All the gamma spectra were observed in coincidence with alpha particles by using either a zinc sulfide screen or the grid chamber as the alpha detector.

$$
\underline{\text { Results-- }} \mathrm{U}^{229} \text { Family }
$$

$\underline{\mathrm{U}^{229}}$

The following alpha groups have been observed.

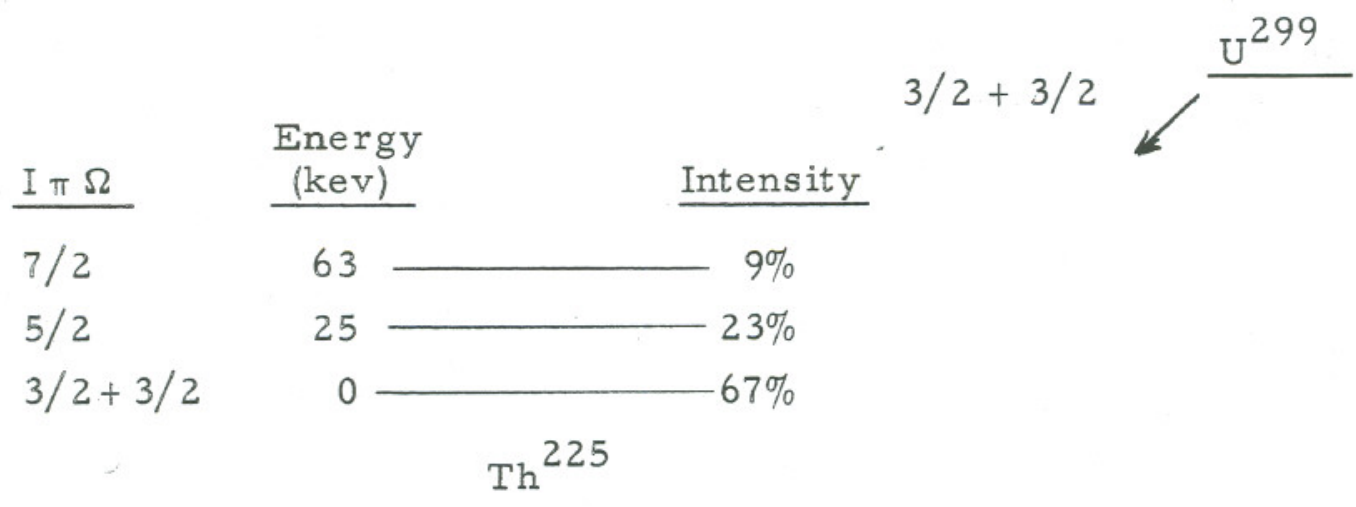

The energy of the ground-state alpha group is $6.355 \mathrm{Mev}$, compared to the previous value of $6.42 \mathrm{Mev} .1$ No gamma rays were found to be associated with this decay, although $L$-rays were observed in the abundance of $13 \%$ (approx. 31\% L-electron vacancies). This would suggest that the level at 6.355 Mev is the ground state or within the L-electron binding energy of the ground state. This was verified by an L-x-ray-alpha coincidence study, which showed this alpha group was not in coincidence with $L$ x-rays.

${ }^{1}$ Meinke, Ghiorso, and Seaborg, Phys. Rev. 81, 782 (1951).

2. A. Orth, A. Ghiorso, and G. T. Seaborg (Lawrence Radiation Laboratory) unpublished data, April 1950.

${ }^{3}$ P. A. Tove, Arkiv Fysik 13, 549 (1958). 


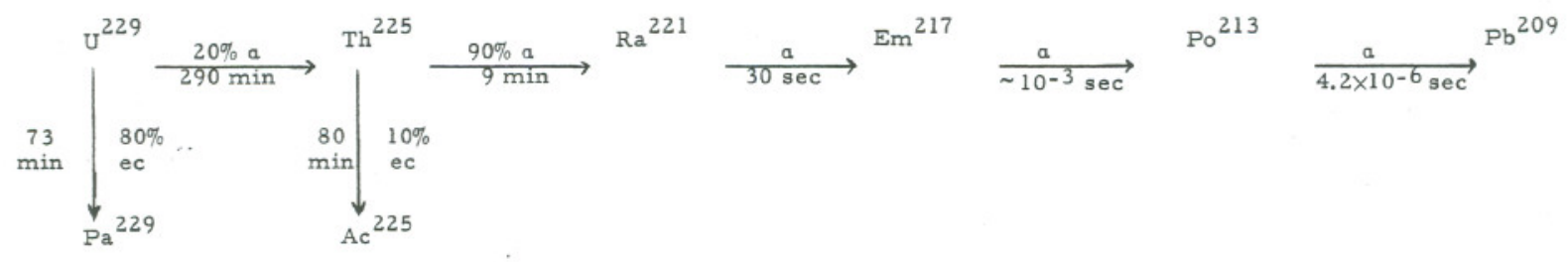

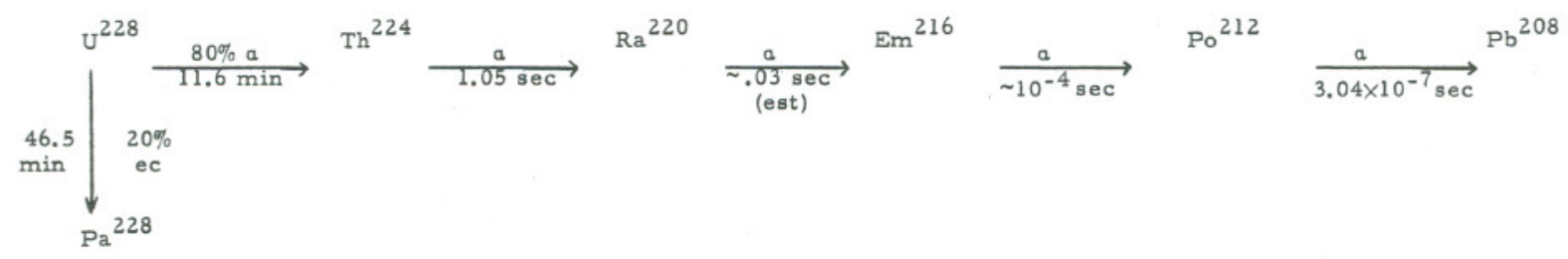

MU-19293

Fig. 14. Decay schemes for $\mathrm{U}^{229}$ and $\mathrm{U}^{228}$. 
The excited-state energies suggest a rotational band with $K=3 / 2$. If the $\mathrm{U}^{229}$ ground state has the same configuration as that of $\mathrm{Th}^{225}$, the relative alpha intensity to the various levels should agree with the expectations of the Bohr, Froman, and Mottelson theory. The calculated intensities are $69 \%, 22 \%$, and $9 \%$, in good agreement with the experimental values.

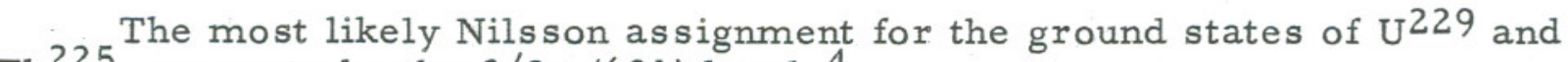
$\mathrm{Th}^{225}$ appear to be the $3 / 2+(631)$ level. 4

$\mathrm{Th}^{225}$

The following alpha groups and gamma rays were observed in this decay:

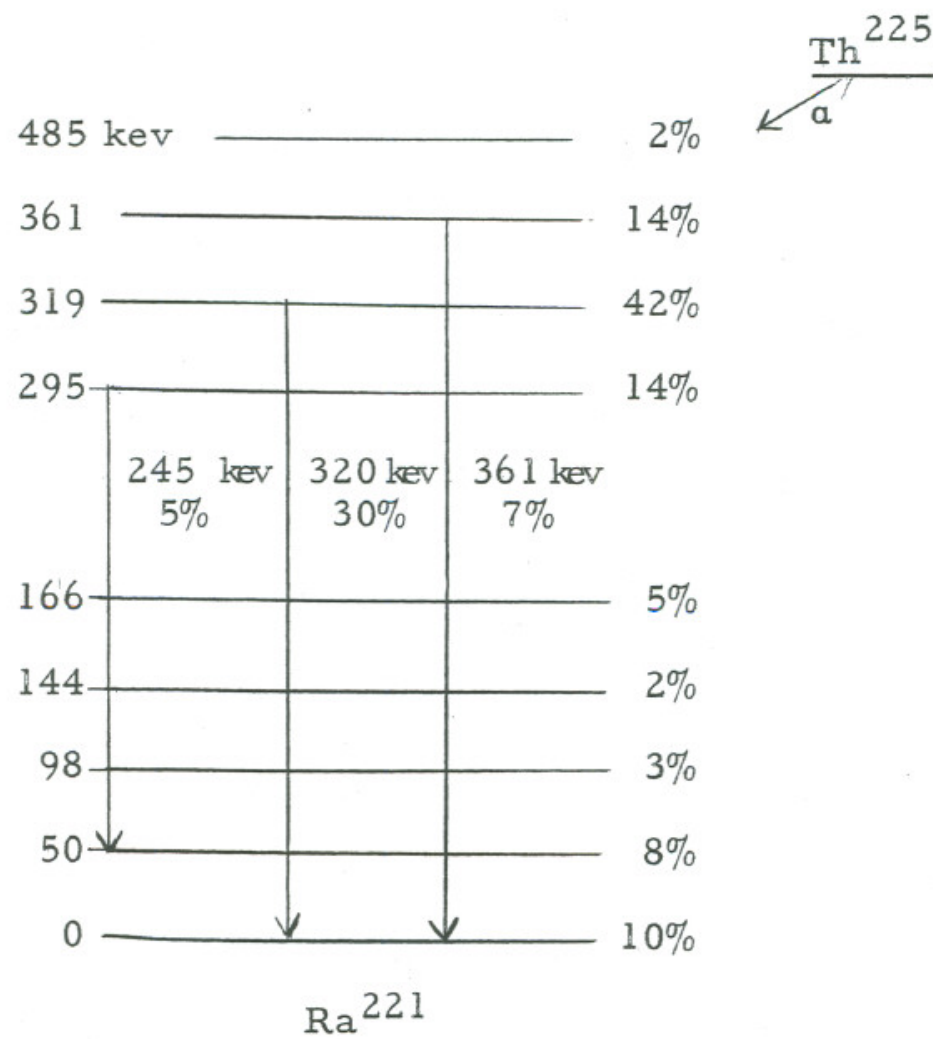

The energy of the ground-state group was found to be $6.79 \mathrm{Mev}$ compared to the previous value of $6.57 \mathrm{Mev}{ }^{1}$ This level is within the Lelectron binding energy of the ground state, since it was not seen in coincidence with gamma rays or L x-rays.

${ }^{4}$ S. G. Nilsson, Kgl. Danske Videnskab. Selskab, Mat. fys. Medd. 29, No. 16 (1955). 


\section{$\mathrm{Ra}^{221}$}

The following alpha groups and gamma rays were seen in the decay of $\mathrm{Ra}^{221}$

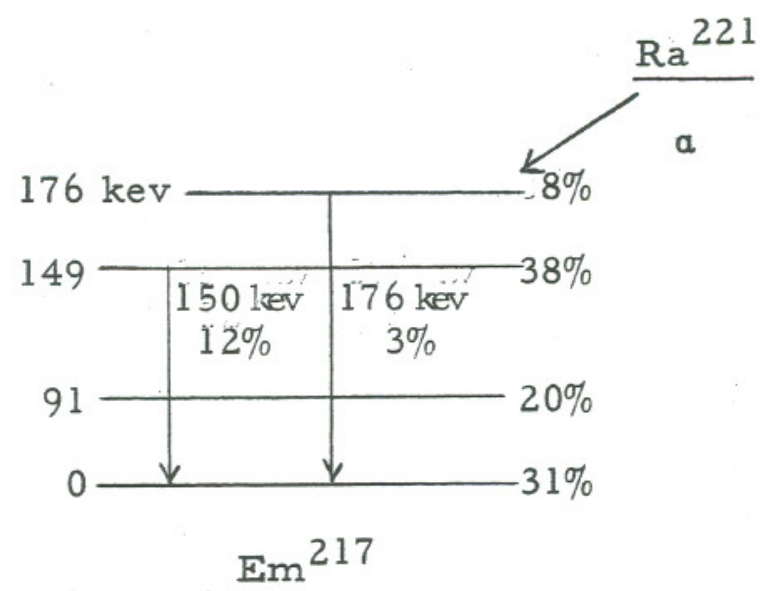

The energy of the ground-state alpha group is $6.75 \mathrm{Mev}$ compared to the previous value of $6.71 \mathrm{Mev}$. ${ }^{1}$ No coincidences were observed between the 6.75-Mev alpha group and gamma rays or $\mathrm{L} x$-rays, thus indicating that the lowest observed state is within the L-electron binding energy of the ground state.

$\underline{\mathrm{Em}^{217}}$

Only one alpha group was seen in the decay of Em 217; its energy was $7.735 \mathrm{Mev}$, compared to the previous value of $7.74 \mathrm{Mev}{ }^{1}$ The limit of detection for an excited state was $0.2 \%$.

$\mathrm{Po}^{213}$

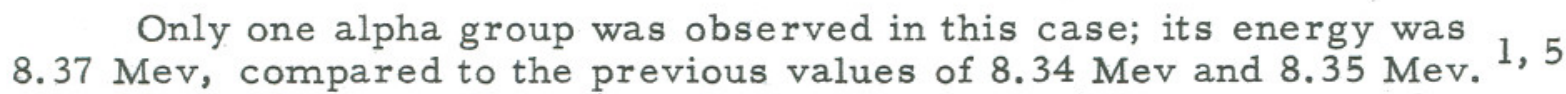
The limit of detection for an excited state was $0.2 \%$.

\footnotetext{
${ }^{5}$ Frank S. Stephens, Jr., Decay Schemes and Nuclear Spectroscopic States in the Heavy-Element Region (Thesis), UCRL-2970, June 1955.
} 


$$
\underline{\text { Results--U }}{ }^{228} \text { Family }
$$

$\underline{\mathrm{U}^{228}}$

Two alpha groups have been seen in the decay of $\mathrm{U}^{228}$ :

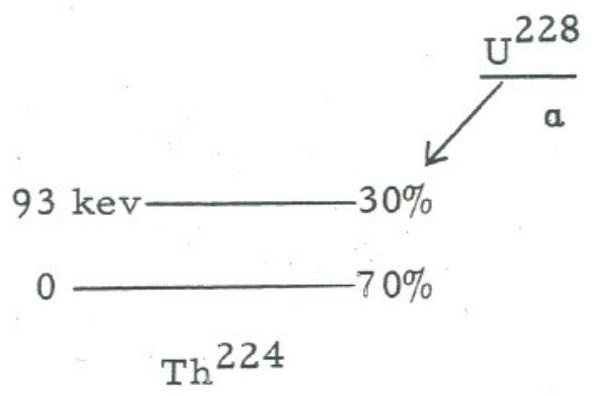

The energy of the ground-state alpha group was found to be $6.68 \mathrm{Mev}$ compared to the values obtained previously of 6.72 and $6.67 \mathrm{Mev} .1,2$ Higher excited states could not be seen directly because of the interference from the alpha groups of $\mathrm{Th}^{225}$ and $\mathrm{Ra} 2 \mathrm{I}$. For this same reason gamma rays associated with this decay could not be seen.

$\underline{\mathrm{Th}^{224}}$

In this case the ground-state and first-excited-state alpha groups were seen directly in the alpha spectrum:

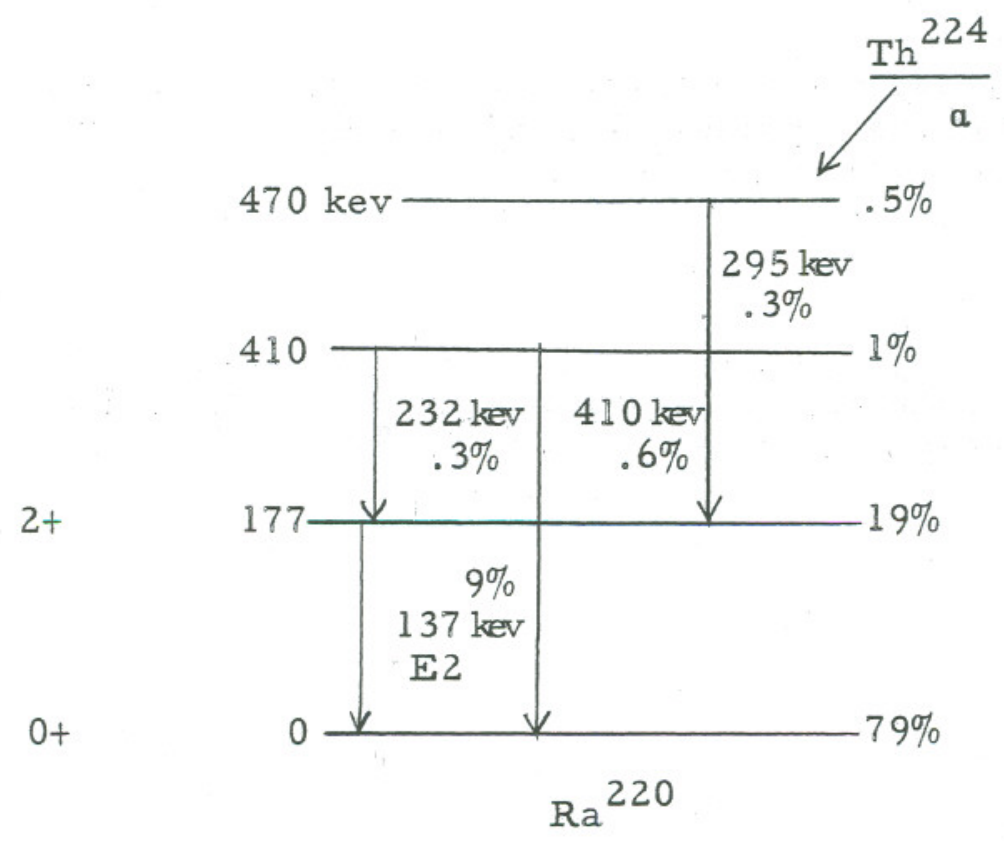

The energy of the ground-state group was 7.17 Mev compared to previous values of $7.13 \mathrm{Mev}$ and $7.20 \mathrm{Mev}, 1,2$ By means of gamma-alpha coincidences, the other two excited states were uncovered. From alpha-gamma coincidence studies the gamma rays shown in the decay scheme were found. The multipolarity of the $177-\mathrm{kev}$ gamma was determined from the intensity of the $\mathrm{K} \mathrm{x}$-rays from its conversion. 
$\mathrm{Ra}^{220}$

The ground-state alpha group was observed directly in the alpha spectrum and was found to have an energy of $7.45 \mathrm{Mev}$ compared with previous values of $7.49 \mathrm{Mev}$ and $7.43 \mathrm{Mev}, 5,2$

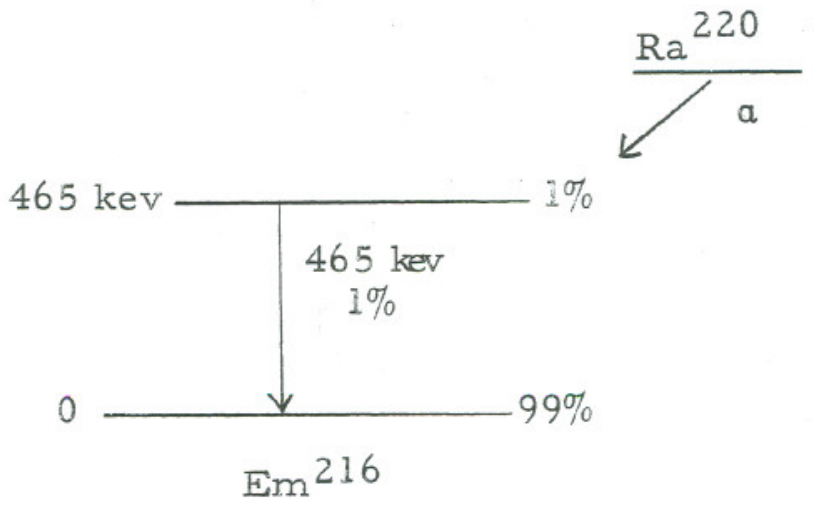

The excited state at $465 \mathrm{kev}$ was found by alpha-gamma and gamma-alpha coincidence measurements. It was not seen directly in the alpha spectrum because the alpha group occurs at the same energy as the $\operatorname{Th}^{224} \mathrm{a}_{177^{\circ}}$.

$\operatorname{Em}^{216}$

The only group thus far observed is the ground-state alpha group, having an energy of $8.04 \mathrm{Mev}$ compared with $8.01 \mathrm{Mev}$ and $8.07 \mathrm{Mev}$, previously reported. 1,2 


\section{NEW NEUTRON-DEFICIENT ISOTOPES OF ANTIMONY AND TELLURIUM}

\section{Samuel S. Markowitz and Frank Wilson}

Several new neutron-deficient isotopes of antimony and tellurium have been produced by nuclear reactions of $\mathrm{He}^{3}$ and $\mathrm{He}^{4}$ ions with indium and tin targets of natural and enriched isotopic composition. The atomic number has been definitely established by appropriate radiochemical purifications. The mass assignments, however, are tentative; characterization of the new nuclides is difficult because of (a) the similarity of neighboring half-lives, (b) isomerism in this region near the closed shell of 50 protons in tin, and (c) possible reactions with other isotopes in the target materials. Table IV summarizes the results obtained thus far, giving the half-lives of the new species and the mode of formation.

A genetic or "milking" experiment proved that the $16-m i n$ tellurium activity decays to form a 3.5-min antimony daughter. The 16-min tellurium, in this experiment, was produced in good yield by bombardment of tin, enriched to contain $72 \% \mathrm{Sn}^{12}$, with $37-\mathrm{Mev} \mathrm{He}$ ions at the Crocker 60-inch cyclotron. Antimony was chemically purified from a solution of the tellurium parent at known constant time intervals (every 8 minutes) by precipitation of the tellurium metal with $\mathrm{SnCl}_{2}$ followed by precipitation of $\mathrm{Sb}_{2} \mathrm{~S}_{3}$. The growth of the antimony daughter into a freshly purified tellurium fraction is shown in Fig. 15. The activity was measured with an end-window gas-flow proportional counter with a $97 \mathrm{l}-\mathrm{mg} / \mathrm{cm}^{2} \mathrm{Al}$ absorber placed close to the window to minimize detection of radiations from the 16 -min tellurium parent. Analysis of the curves yields an approximate value of $3 \mathrm{~min}$ for the half-life of the antimony daughter. In Fig. 16, the activities of the antimony daughter fractions are plotted as a function of the time of separation from the tellurium parent. A parent half-life of $16 \mathrm{~min}$ is indicated.

Bombardment of 49 In of natural isotopic composition with $31-\mathrm{Mev} \mathrm{He}^{3}$ ions at the heavy-ion linear accelerator produced a 3.5-min antimony and a 32 -min antimony activity. Decay of these activities is shown in Fig. 17.

It has been established that the 3.5-min antimony and the $32-\mathrm{min}$ antimony isotopes are positron emitters of maximum energy $3.96 \pm 0.2 \mathrm{Mev}$ and $1.55 \pm 0.08 \mathrm{Mev}$ respectively. These results were obtained by FermiKurie plots of the positron spectrum measured with a plastic scintillator and a 100-channel pulse-height analyzer; $\mathrm{P}^{32}\left(\beta^{-}, 1.71 \mathrm{Mev}\right)$ and $\mathrm{Rh}^{106}\left(\beta^{-}, 3.53 \mathrm{Mev}\right)$ were among the standards used. The activities, in a duplicate set of energy measurements, were produced by reaction of indium with $31-\mathrm{Mev} \mathrm{He}^{3}$ ions. The maximum positron energies were also determined by methods of aluminum absorption and Feather analysis; the 32 -min antimony had a measured maximum positron energy of $1.5 \mathrm{Mev}$, and the 3.5-min antimony, which in this experiment was in transient equilibrium with its 16 -min tellurium parent produced by $37-\mathrm{Mev} \mathrm{He}{ }^{4}$ bombardment of $72 \% \mathrm{Sn} 112$, gave a maximum positron energy of $3.8 \mathrm{Mev}$. The maximum positron energy of the 16-min tellurium activity itself has not been determined thus far. 
Table IV

\begin{tabular}{|c|c|c|c|c|c|c|c|c|}
\hline \multicolumn{9}{|c|}{ New isotopes of antimony and tellurium ${ }^{a}$} \\
\hline Target & $\begin{array}{l}\text { Energy } \\
(\mathrm{Mev})\end{array}$ & $\begin{array}{l}\text { Proj- } \\
\text { ectile }\end{array}$ & Isotope & $\begin{array}{l}\text { Tentative } \\
\text { mass } \\
\text { assignment }\end{array}$ & Reaction & $\begin{array}{l}\mathrm{Q}^{\mathrm{b}} \\
\text { calc. }\end{array}$ & $\begin{array}{c}\mathrm{E} \beta^{+}(\max ) \\
(\mathrm{Mev})\end{array}$ & Comments \\
\hline \multirow[t]{2}{*}{$49^{\text {In }}$ (natural) } & 31 & $\mathrm{He}^{3}$ & $3.5-\min _{51} \mathrm{Sb}$ & 114 & & & & \multirow{2}{*}{$\begin{array}{l}\mathrm{E}_{\beta}+(\max ) \text { by plastic scintillation } \\
\text { counting, and Fermi-Kurie plot } \\
\text { of } \beta^{+} \text {spectrum. }\end{array}$} \\
\hline & 31 & $\mathrm{He}^{3}$ & $32-\operatorname{min~Sb}$ & 115 & $\operatorname{In}^{115}\left(\mathrm{He}^{3}, 3 \mathrm{n}\right) \mathrm{Sb}^{115}$ & -13 & $1.55 \bowtie 0.08$ & \\
\hline $\operatorname{In}^{115}(99.8 \%)$ & 27 & $\mathrm{He}^{3}$ & $32-\min \mathrm{Sb}$ & 115 & $\operatorname{In}^{115}\left(\mathrm{He}^{3}, 3 \mathrm{n}\right) \mathrm{Sb}^{115}$ & -13 & & Not the daughter of $16-\mathrm{min} \mathrm{Te}$ \\
\hline \multirow[t]{2}{*}{ In(natural) } & 18.5 & $\mathrm{He}^{3}$ & $3.5-\operatorname{min~} \mathrm{Sb}$ & 114 & $\mathrm{In}^{113}\left(\mathrm{He}^{3}, 2 \mathrm{n}\right) \mathrm{Sb}^{114}$ & \multirow{2}{*}{\multicolumn{2}{|c|}{-4}} & \\
\hline & $14: 2$ & $\mathrm{He}^{3}$ & $\begin{array}{l}\text { No } 3.5 \text { min or } \\
32-\text { min Sb }\end{array}$ & & & & & \\
\hline \multirow[t]{2}{*}{${ }_{50} \mathrm{Sn}^{112}(72 \%)$} & $\sim 19$ to 37 & $\mathrm{He}^{4}$ & ${ }^{16-\min }{ }_{52} \mathrm{Te}$ & 114 & $\mathrm{Sn}^{112}\left(\mathrm{He}^{4}, 2 \mathrm{n}\right) \mathrm{Te}^{114}$ & -20 & 3.8 & \multirow{2}{*}{$\begin{array}{l}\mathrm{E}_{\beta}+(\max ) \text { of } 3.5 \text { min daughter in } \\
\text { equilibrium; by Feather analysis } \\
\text { of Al absorption curve. The } 16-\mathrm{m} \text { - } \\
\text { Te does not decay to form a } \\
32 \text {-min Sb daughter. }\end{array}$} \\
\hline & $\sim 14$ & $\mathrm{He}^{3}$ & $16-\min \mathrm{Te}$ & 114 & $\mathrm{Sn}^{112}\left(\mathrm{He}^{3}, \mathrm{n}\right) \mathrm{Te}^{114}$ & +0.4 & & \\
\hline
\end{tabular}

${ }^{a}$ A 16-min Te activity has been observed: Ann Rhodes, Decay Studies of Some Neutron-Deficient Studies of Antimony and Tellurium (Thesis), UCRL-3879, August 1957. Also detected were 1.4-hr and 7.5-hr Te activities which were not detected in this work.

${ }^{b} \mathrm{Q}$ values were calculated from mass data of A. H. Wapstra, Physica 21, 367 (1955). If masses were not tabulated, they were calculated from decay-energy approximations. 


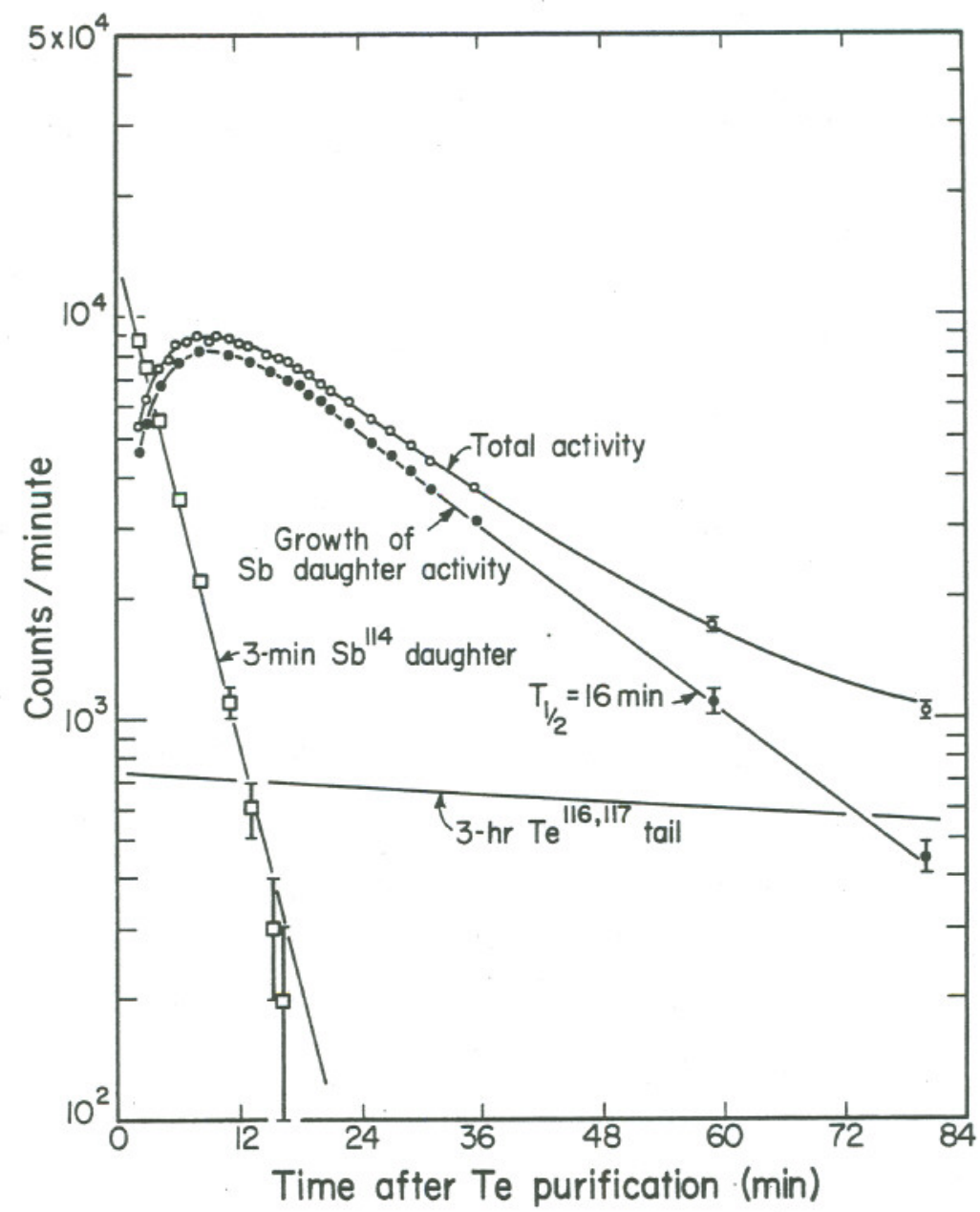

$M U-19546$

Fig. 15. Activity of a freshly purified tellurium fraction counted with an end-window beta proportional counter through $971 \mathrm{mg} / \mathrm{cm}^{2} \mathrm{Al}$ absorber, which discriminates against the betas emitted by the 16-min tellurium parent. Growth of the 3-min antimony daughter is observed. The tellurium was produced by bombardment of $72 \%$ enriched Sn 112 with $37-\mathrm{Mev} \mathrm{He}{ }^{4}$ ions. (Mass assignments tentative.). 


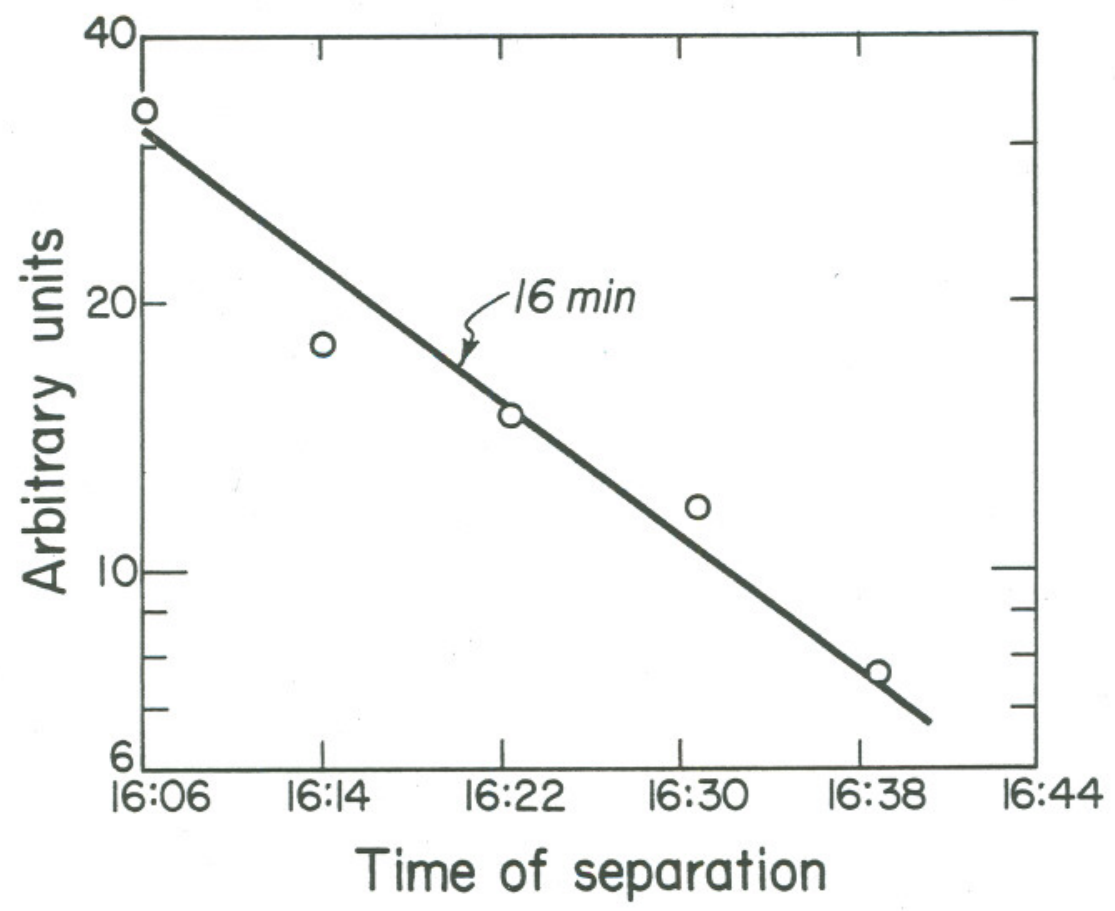

$M U-19547$

Fig. 16. Activity of antimony daughter fractions chemically "milked" from tellurium parent. The average half-life of the five antimony fractions was $3.35 \pm 0.15 \mathrm{~min}$. A line corresponding to a 16-min half-life was drawn through the above points. 


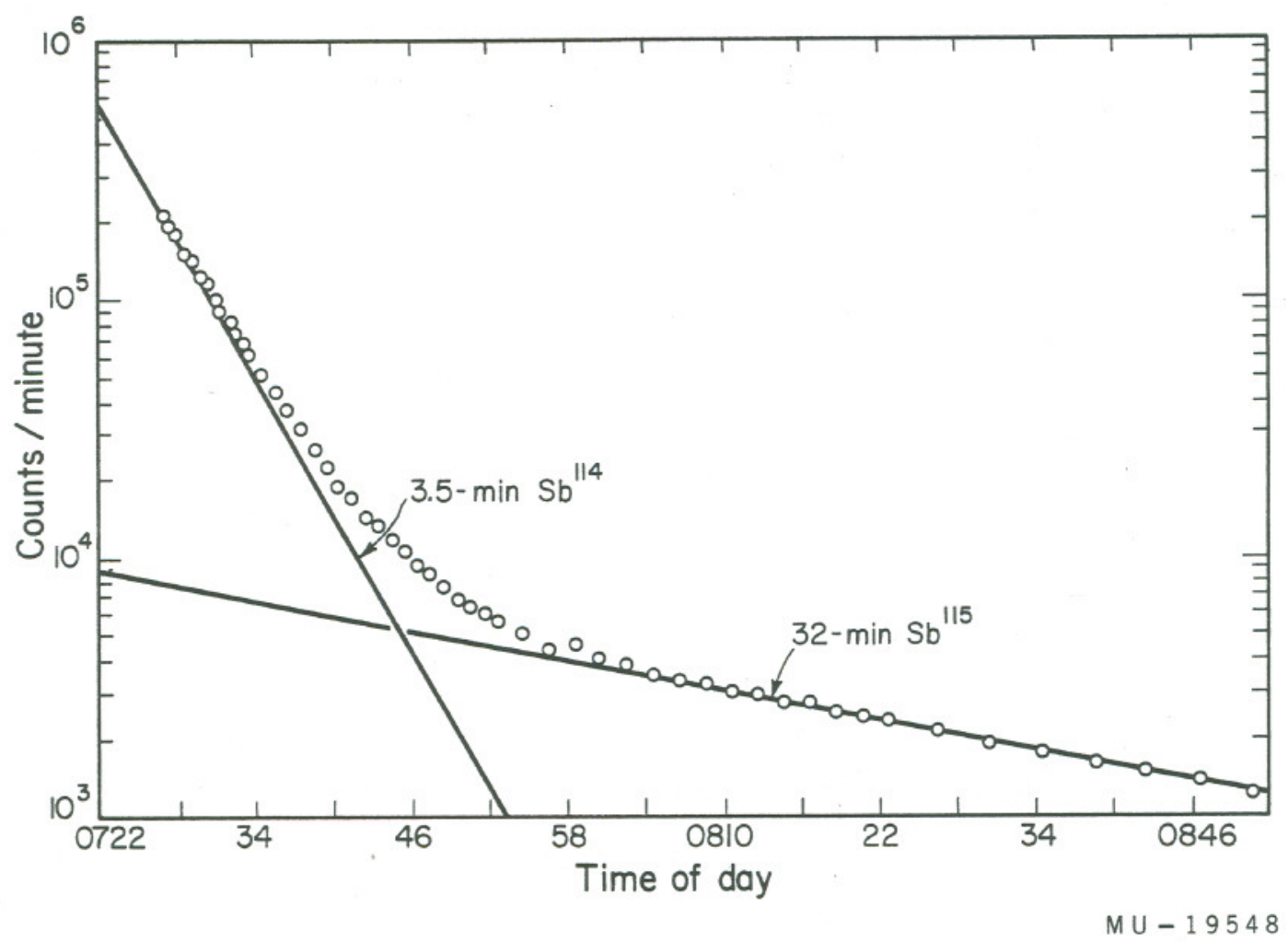

Fig. 17. Decay of activities induced in indium foil by bombardment with $31-\mathrm{Mev} \mathrm{He}$ ions. Radiations are counted with an endwindow proportional counter through a $64-\mathrm{mg} / \mathrm{cm}^{2} \mathrm{Al}$ absorber which absorbs nearly all the betas emitted by 32 -min Sb115. 
Gamma radiation from the various activities is currently being measured with $\mathrm{NaI}(\mathrm{T} 1)$ scintillation techniques and pulse-height analysis. Excitation functions for various appropriate reactions are also being determined in order to prove or disprove the tentative mass-number assignments shown in Table IV.

\title{
MAGNETIC MOMENT OF CERIUM-137m
}

\author{
James N. Haag, C. E. Johnson, and D. A. Shirley
}

Cerium-137m free of lower-mass cerium isotopes was prepared by the reaction La139 $\mathrm{p}, 3 \mathrm{n}) \mathrm{Ce}^{137 \mathrm{~m}}$ in the Oak Ridge 86 -inch cyclotron. 1 This isomer, its daughter $\mathrm{Ce}^{137}$, and $\mathrm{Ce}^{139}$ produced by the side reaction $\mathrm{La}{ }^{139}(\mathrm{p}, \mathrm{n}) \mathrm{Ce}^{13}$ ) were aligned at $0.02^{\circ} \mathrm{K}$ in a single crystal of neodymium ethyl sulfate. Gamma rays from all three cerium nuclides were anisotropic。 The Ce 139 data were in agreement with earlier, unpublished Oxford results (C.E.J.). Anisotropy of the 445-kev gamma ray from the decay of Ce 137 excludes the previous spin assignment of $1 / 2+$ for the $455-\mathrm{kev}$ level of La 137. In fact it is possible to conclude from the sign of this anisotropy that a spin assignment of $3 / 2+$ implies a strong E2/M1 admixture in the $445-\mathrm{kev}$ gamma $r a y$, since the sign would be different if the transition were pure M1 or E2. The large anisotropy of the gamma ray from the isomeric transition yields

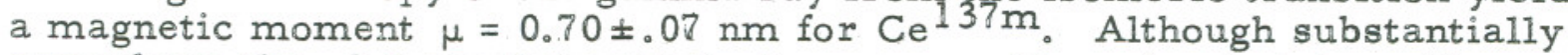
away from the $-1.9-\mathrm{nm}$ Schmidt limit, presumably owing to interactions between the odd $h_{1} / 2$ neutron and paired nucleons, this value is in line with the moments of other even-odd nuclei with lower spins. There is no other measured moment of a nucleus with spin $11 / 2$ available for direct comparison.

A detailed account of the above work is being prepared for publication. A polarimeter is being built with which the plane polarization of the $445-\mathrm{kev}$ gamma will be measured. It is hoped in this way to obtain the $\mathrm{E} 2 / \mathrm{Ml}$ mixing ratio of this transition and thus the spin of the $455-\mathrm{kev}$ level from which it is emitted and the magnetic moment of $\mathrm{Ce}^{137}$.

\footnotetext{
The cooperation of Dr。 John L. Need of Oak Ridge National Laboratory is gratefully acknowledged.
} 


\title{
NUCLEAR ALIGNMENT OF RARE EARTH ISOTOPES
}

\author{
Carolyn A. Lovejoy and D. A. Shirley
}

Terbium-155 and terbium-156 were aligned in a single crystal of neodymium ethyl sulfate at low termperatures, and the angular distributions of their gamma radiations were measured. The results can be fitted to an expression of the form

$$
W(\theta)=1+X_{2} P_{2}(\cos \theta),
$$

where $W(\theta)$ is the gamma-ray intensity as a function of the angle from the crystalline c axis. Approximate values of $\mathrm{X}_{2}$ at $0.02^{\circ} \mathrm{K}$ are tabulated below

\begin{tabular}{|c|c|}
\hline Gamma-ray energy (kev) & $\mathrm{x}_{2}$ \\
\hline 90 & +.07 \\
\hline $106\left(\mathrm{~Tb}^{155}\right)$ & \pm .00 \\
\hline $165\left(\mathrm{~Tb}^{155}\right)$ & +.05 \\
\hline 195 & -.07 \\
\hline 265 & $\pm \sim .00$ \\
\hline 360 & -.09 \\
\hline 535 & -.23 \\
\hline 770 & +.04 \\
\hline 920 & -.04 \\
\hline 1050 & +.05 \\
\hline 1200 & +.10 \\
\hline 1400 & -.13 \\
\hline 1615 & +.06 \\
\hline 1815 & +.15 \\
\hline 1935 & +.12 \\
\hline
\end{tabular}

A detailed interpretation and further experiments are in progress. 


\title{
ELECTRIC HYPERFINE-STRUCTURE ALIGNMENT OF IODINE
}

\author{
C. E. Johnson, James F. Schooley, and D. A. Shirley
}

Nuclear orientation by interaction of the electric quadrupole moment with the field gradient of a strong covalent bond was suggested by Pound in 1949,1 but had not been done at temperatures below $10 \mathrm{~K}$. In fact it was not clear that such a process might not entail a long relaxation time and thus not be feasible. Partly to test this hypothesis an experiment was performed in which a (: trioclinic) single crystal of copper p-iodobenzenesulfonate, in which some of the stable iodine atoms were replaced by $I^{131}$, was cooled to a magnetic temperature of $0.032^{\circ} \mathrm{K}$ by adiabatic demagnetization, and anisotropic distributions of the $364-\mathrm{kev}$ and $637 \mathrm{-kev}$ gamma rays were observed.

The quadrupole coupling constant for $I^{131}$ in this bond may be calculated from the measured value for $\mathrm{I}^{127}$ in similar bonds, by using the measured quadrupole moments of these two isotopes. We assume that the $637-\mathrm{kev}$ gamma ray of $\mathrm{Xe} \mathrm{P}^{131}$ is pure $\mathrm{E} 2$ and proceeds from a $5 / 2+$ state to the measured $3 / 2+$ ground state, in accord with decay-scheme studies. The calculated anisotropy of the $637 \mathrm{kev}$ gamma ray is then +0.059 at $0.033^{\circ} \mathrm{K}$, in excellent agreement with the experimental value of $+0.056 \pm .010$. Conversely the experimental anisotropy yields a value of $-950 \pm 160$ megacycles for the coupling constant. This measurement gives the sign of the coupling constant.

The 364-kev gamma ray exhibited an anisotropy of $-0.033 \pm .003$ at the same temperature. From the relative magnitudes and signs of anisotropy the mixing ratio of $\mathrm{E} 2 / \mathrm{Ml}$ for the $364 \mathrm{-kev}$ transition can be calculated; it was found to be $\delta=6.7 \pm 0.5$. Thus the transition is $2.2 \pm .3 \% \mathrm{M} 1$.

Because the rate of heat leak into the apparatus was quite low, it was possible to look for relaxation effects. In 1 hour the susceptibility and the gamma ray anisotropy changed linearly, while the temperature rose from $0.032^{\circ} \mathrm{K}$ to $0.038^{\circ} \mathrm{K}$. No relaxation effects were observed.

This experiment has been completed and is being prepared for publication.

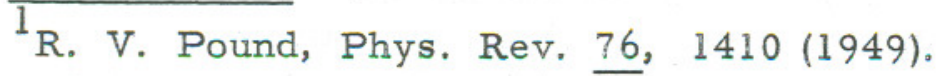




\section{ATOMIC BEAMS}

Edgar Lipworth and Richard Marrus

During the past year, work has been continued to determine the nuclear spins and moments of the radioactive halogen isotopes. The results are shown in Table V.

Table , V

Nuclear properties of some halogens

\begin{tabular}{cccc}
\hline Isotope & Nuclear spin & $\begin{array}{c}\text { Magnetic } \\
\text { moment (nm) }\end{array}$ & $\begin{array}{c}\text { Quadrupole } \\
\text { moment (barns) }\end{array}$ \\
\hline Br $^{76}$ & 1 & $\pm 0.5480(2)$ & $\mp 0.27(2)$ \\
$\mathrm{Br}^{80}$ & 1 & - & - \\
$\mathrm{Br}^{80 m}$ & 5 & - & - \\
$\mathrm{I}^{131}$ & $7 / 2$ & + & + \\
$\mathrm{I}^{132}$ & 4 & + & + \\
$\mathrm{I}^{133}$ & $7 / 2$ & + & + \\
\hline
\end{tabular}

In those cases marked t the measurements have been performed but a final value is not available at this time.

A program has been initiated to determine the spins and moments of those radioactive rare earths accessible to study by the method of atomic beams. Some results are shown in Table VI.

Table VI

\begin{tabular}{lc}
\hline \multicolumn{2}{c}{ Nuclear spins of some rare earths } \\
\hline Isotope & Nuclear spin \\
\hline $\mathrm{Pr}^{142}$ & 2 \\
$\mathrm{Pm}^{147}$ & $7 / 2$ \\
$\mathrm{Sm}^{153}$ & $3 / 2$ \\
$\mathrm{Tm}^{170}$ & 1 \\
$\mathrm{Lu}^{176}$ & 1 \\
\hline
\end{tabular}

In addition, the hyperfine structure of $\mathrm{Tm}^{170}$ and $\mathrm{Pr}^{142}$ have been determined, and tentative values for the nuclear moments of $\mathrm{Pr}^{142}$ obtained.

The atomic-beam program in the heavy elements has been continued and measurements completed on Am 241. These measurements have indicated a surprisingly large deviation of the measured $g_{J}$ value in the electronic ground state from the pure L-S-coupled value. A theory based 
on the breakdown of L-S coupling has been successful in accounting for the measured $g_{\mathrm{J}}$ value and, taken together with the optically measured nuclear moments, the measured absolute values of the A and B constants of hyperfine structure. A discrepancy between the measured sign of $B / A$ and that determined from the theory is expected to arise from contributions to the A value from other effects.

Measurements have been made on $16-\mathrm{hr} \mathrm{Am}^{242}$ and we have ascertained the nuclear spin to be $I=1$. In addition, the nuclear moments have been inferred from measurements on the ground-state hyperfine structure, and from the hyperfine-structure and moment measurements in $\mathrm{Am}^{241}$. These moments are $\mu= \pm 0.33 \mathrm{~nm}$ and $Q=\mp 2.8$ barns.

Observations were continued on $\mathrm{Pa}^{233}$ and substantial progress made toward completion of the hyperfine-structure measurements. It now seems that a direct measure of the nuclear magnetic dipole moment may be possible.

It is planned in the coming year to complete the work on $\mathrm{Pa}^{233}$ and to initiate research on $\mathrm{Pa}^{232}$ and 52-yr Am 242. 


\section{CALCULATION OF GYROMAGNETIC RATIO FOR ROTATION OF EVEN-EVEN NUCLEI}

\section{Lung-Wen-Chiao and John O. Rasmussen}

Gyromagnetic ratios $\mathrm{g}_{\mathrm{R}}$ of $66^{\mathrm{Dy}} \mathrm{y}^{160}$ and $74^{\mathrm{W}} 184$ are calculated by using the asymptotic wave functions for deformed nuclei and using the formulas for moment of inertia, $\widetilde{\jmath}$, and $g_{R}$ derived from the "cranking model" theory, 1

$$
\tilde{J}=2 \hbar^{2} \sum_{i} \frac{\left(0\left|J_{x}\right| i\right)^{2}}{E_{i}-E_{0}}
$$

where $J_{x}$ is the angular momentum operator about the intrinsic $\mathrm{x}$ axis and

$$
g_{R}=\frac{\hbar^{2}}{2 \tilde{U}} \sum \frac{1}{E_{i}-E_{0}}\left(\left\langle 0\left|\mu_{x}\right| i\right\rangle\left\langle i\left|J_{x}\right| 0\right\rangle+\text { compl. conj. }\right)
$$

The magnetic moment operator is given by

$$
\mu_{\mathrm{x}}=\sum_{\mathrm{p}}\left(\mathrm{g}_{\ell} \ell_{\mathrm{x}}+\mathrm{g}_{\mathrm{S}} \mathrm{S}_{\mathrm{x}}\right) \quad \text { in terms of the orbital and spin }
$$

contribution of the indivudual particles; $g_{s}=\left(\begin{array}{r}5.585 \\ -3.826\end{array}\right)$ and $g_{\ell}=\left(\begin{array}{l}1 \\ 0\end{array}\right)$

for protons and neutrons.

In our calculations, the additional pairing energy, $\Delta$, required to excite a paired nucleon to an unpaired state is neglected. This energy arises from the special residual interaction of paired nucleons (cf. Belyaev ${ }^{2}$ ).

Energy values for the various orbitals are obtained from the eigenvalues for the deformed field in Nilsson's paper with deformation parameter $\delta=0.3$.

The results are $g_{R}=0.412$ for $66^{D y^{160}}$ and $g_{R}=0.417$ for $74^{W^{186}}$, showing very little variation, while the experimentally observed values are $0.18 \pm 0.008,3$ and $0.38 \pm 0.05,4$ respectively. Our calculated $g_{R}$ values are rather close to the simple theoretical value $\mathrm{Z} / \mathrm{A}$ originally proposed by Bohr and Mottelson. 5 ${ }^{\circ}$ The low experimental value for dysprosium must signify a greater role of neutrons relative to protons in carrying the rotational angular momentum. We doubt that inclusion of the pairing-energy refinement will bring about a significant.lowering of the theoretical $g_{R}$ values unless one invokes a considerably larger pairing energy for protons than for neutrons.

1s. G. Nilsson, Kgl. Danske Videnskab. Selskab, Mat. -fys. Medd. 29, No. 16 (1955). ${ }^{2}$ S. T. Belyaev, Kgl. Danske Videnskab. Selsk, Mat. -fys. Medd. 31,No. 11 (1959). ${ }^{3}$ P. Debrunner et al. , Helv. Phys. Acta 31, 326(1958).

${ }^{4}$ Bodenstedt, Matthias, Köraer, Terdan, Srisiusu, and Havestaat (Physikalisches Staatsinstitut Hamburg, II. Institute J. Experimentalphysik) private communication. 5A. Bohr and B. R. Mottelson, Kgl. Danske Videnskab. Selskab, Mat. -fys. Medd. 27 No. 16 (1953). 


\title{
INTRINSIC QUADRUPOLE MOMENTS OF DEFORMED NUCLEI
}

\author{
Norman K. Glendenning and Jerzy Sawicki
}

Migdal, 1 basing his work on the field theoretic derivation by Gor ${ }^{8}$ kov $^{2}$ of the Bardeen-Cooper-Schrieffer ${ }^{3}$ theory of superconductivity, has shown how to calculate the single-particle-mixed-density function corresponding to any perturbation on the Hamiltonian of a system of fermions interacting through a pairing force.

We have applied these results to obtain the mixed-density function corresponding to a quadrupole deformation of the spherical well in which the particles move. This enables us to calculate, for deformed nuclei, any observable which can be expressed as the sum of single-particle operators over all particles of the system.

In particular we are interested in the intrinsic quadrupole moments of deformed nuclei, which may be written

$$
Q_{0}=\sum_{\mu \mu^{\prime}}\left\langle\mu|\rho| \mu^{\prime}\right\rangle\left\langle\mu^{\prime}\left|Q_{o p}\right| \mu^{\prime}\right\rangle \text {, }
$$

where $\mu$ denotes the quantum numbers of the basic states and $\left\langle\mu|\rho| \mu^{\prime}\right\rangle$ is the mixed-density function, which depends on the chemical potential $\lambda$ and energy gap $\Delta$, and is linear in the deformation $\delta$.

Corresponding to the quadrupole deformation ${ }_{2} 4$

$$
V^{\prime}=-\frac{\delta}{3} \quad M \omega_{0}^{2} \sqrt{\frac{16 \pi}{5}} \mathrm{r}^{2} \mathrm{Y}_{20^{\prime}}
$$

Eq. (1) takes the form

$$
Q_{0}=-\frac{4}{3} \delta M \omega_{0}^{2} \sum_{\mu \mu^{\prime}} \cdot b_{\mu \mu^{\prime}}\left[\left\langle N \ell\left|r^{2}\right| N^{\prime} l^{\prime}\right\rangle C\left(j^{\prime} 2 j ; \frac{1}{2} 0 \frac{1}{2}\right)\right]^{2}
$$

IA. B. Migdal, Zh. Ekspt1. i Teoret. Fiz. 37, 249 (1959).

2L. P. Gor'kov, Soviet Physics JETP 34(7), 505 (1958).

${ }^{3}$ Bardeen, Cooper, and Schrieffer, Phys.Rev。 108, 1175 (1957).

${ }^{4}$ S. G. Nilsson, Kgl. Danske Videnskab. Selskab. Mat.-fys. Medd. 29, No. 16 (1955). 
where

$$
b_{\mu \mu^{\prime}}=\frac{\epsilon_{\mu} \epsilon_{\mu^{\prime}}-E_{\mu} E_{\mu^{\prime}}-\Delta^{2}}{2 E_{\mu^{\prime}} E_{\mu^{\prime}}\left(E_{\mu^{\prime}}+E_{\mu^{\prime}}\right)}+\eta_{\mu \mu^{\prime}},
$$

where $\eta$ is a small term arising from the change in the gap $\Delta$ induced by the perturbation $V^{\prime}$, and

$$
\begin{aligned}
& \epsilon_{\mu}=E_{\mu}^{0}-\lambda, \\
& E_{\mu}=\sqrt{\epsilon_{\mu}^{2}+\Delta^{2}} .
\end{aligned}
$$

Here $E^{0}$ are the single-particle levels of the spherical well, and $\mu \equiv\{n \ell j\}$. The matrix elements of $\mathrm{r}_{0}^{2}$ were evaluated with harmonic oscillator wave functions ${ }_{5}{ }_{\text {Nilsson. }}$ The levels $E_{\mu}^{0}$ were taken from Nilsson ${ }^{4}$ and Mottelsan and

For strongly deformed nuclei the quadrupole moment will be calculated by using Nilsson wave functions and eigenvalues. In this case, the density matrix takes the simpler form, 6

$$
\left\langle\mu|\rho| \mu^{\prime}\right\rangle=\mathrm{v}_{\mu}^{2} \delta_{\mu \mu^{\prime}}
$$

but quadrupole matrix elements now involve a sum over the Nilsson eigenfunction amplitudes.

Of the above two methods we have results so far only for small deformations, which we now describe. For small deformations, the quantity $Q_{0} / \delta$, which we shall call the quadrupole susceptibility, is independent of $\delta$. The results of the calculation exhibit two features: (a) In the absence of the pairing force $(\Delta \rightarrow 0)$ the quadrupole susceptibility shows a pronounced shell-closure effect in contrast to the slow monotonic variation proportional to $\mathrm{ZR}^{2}$ assumed in the use of the hydrodynamical result $Q_{0} / \delta=0.8 \mathrm{ZR}^{2}\left(1+\frac{2}{3} \delta\right)$. (b) However, the pairing force has the effect of reducing the strong shell-closure dependence of $Q_{0} / \delta$, restoring the approximate validity of the hydrodynamical result.

A detailed comparison with measured quadrupole moments will be carried out with calculations based on the method described above for strongly deformed nuclei.

${ }^{5}$ B. R. Mottelson and S. G. Nilsson, Kgl. Danske Videnskab. Selskab. Mat. -fys.Skr. Medd. 1, No. 8 (1959).

${ }^{6}$ S. T. Belyaev, Kgl. Danske Videnskab. Selskab. Mat. -fys. Medd. 31, No. 11 (1959). 
Chemical and Physical Properties

\section{PARAMAGNETIC RESONANCE IN TETRAVALENT PA $231^{*}$}

John D. Axe, Ru-tao Kyi, H. J. Stapleton, and Burris B. Cunningham

The paramagnetic-resonance spectrum of tetravelent $\mathrm{Pa}^{231}$ has been observed in a single crystal of $\mathrm{Cs}_{2} \mathrm{ZrCl}_{6}$. A melt of $\mathrm{Cs}_{2} \mathrm{ZrCl}_{6}$ was "doped" with approximately $500 \mu \mathrm{g}$ of anhydrous $\mathrm{Pa}^{231} \mathrm{Cl}_{4}$ and allowed to crystallize in an atmosphere of hydrogen by slow passage through a furnace. At $4.2^{\circ} \mathrm{K}$ and a frequency of $9457 \mathrm{Mc}$, the observed resonance pattern consisted of four widely separated hyperfine components. The spectrum was isotiopic to within the accuracy of the field measurements (approx 1/2\%). These features are interpreted as the usual $\Delta \mathrm{M}_{\mathrm{S}}= \pm 1, \Delta \mathrm{M}_{\mathrm{I}}=0$ transitions between the eigenstates of the spin Hamiltonian

$$
\not A=g \beta H \cdot S+A I \cdot S,
$$

with $S=1 / 2, I=3 / 2,|g|=1.15( \pm .02)$, and $|A|=0.0518( \pm .001) \mathrm{cm}^{-1}$. The large hyperfine interaction necessitates the use of exact solutions for the energy levels. 2 No resonance was detected at $77^{\circ} \mathrm{K}$.

The nuclear-spin value of $3 / 2$ is verified. ${ }^{3}$ The paramagnetism can be most plausibly ascribed to a single 5 f electron. A magnetically isotropic Kramers" doublet is expected to be the lowest lying as the result of the octahedral perturbation present at the zirconium site. $4,5 \mathrm{As}$ an alternative, a $6 \mathrm{~d}^{1}$ configuration is expected to give rise to a fourfold degenerate magnetically anisotropic level if octahedral symmetry is preserved, 6 or an anistropic doublet if distortion is present. 7 Further work on the optical absorption spectra of this system is in progress and should allow amplification of the above conclusions. An attempt to measure the nuclear magnetic moment of $\mathrm{Pa}_{231}$ by a "double-resonance" technique is likewise in progress. We wish to thank Professor C. D. Jeffries for his invaluable advice.

\footnotetext{
Supported in part by the U. S. Atomic Energy Commission and the Office of Naval Research.

${ }^{1}$ Prepared by the method of Sellers, Fried, Elson, and Zachariasen, J. Am. Chem. Soc. 76, 5935 (1954).

${ }^{2}$ B. Bleaney, Phil. Mag. 42, 441 (1951).

${ }^{3} \mathrm{H}$. Schtller and H. Gollnow, Naturwiss. 22, 511 (1934).

${ }^{4}$ See, for example, J. S. Griffith and L. E. Orgel, J. Chem. Phys. 26, 988 (1956).

${ }^{5}$ C. A. Hutchison and B. Weinstock, to be published in J. Chem. Phys. These authors discuss paramagnetic resonance in another $\mathrm{f}^{1}$ octahedral system, $\mathrm{NpF}_{6}$.

6. Bleaney, Proc. Phys. Soc. (London) 73, 939 (1959).

${ }^{7}$ Griffiths, Owen, and Ward, Proc. Roy. Soc. (London) A219, 526 (1953).
} 


\section{ENERGY LEVELS OF Tm IV}

\section{John B. Gruber and John G. Conway}

Work on the energy levels of $\mathrm{Tm}$ IV $\left(\mathrm{Tm}^{+3}\right.$ ion) has been completed and reported in three papers. 1 The experimental lines have been fitted for a $F_{2}=450 \mathrm{~cm}^{-1}$ and $\zeta_{4}=2700 \mathrm{~cm}^{-1}$. The agreement is to within $200 \mathrm{~cm}^{-1}$. Crystal field calfulations have been made and a good fit has been obtained.

\section{SPECTRA OF $\mathrm{PmCl}_{3}$}

John B. Gruber and John G. Conway

A crystal of $\mathrm{PmCl}_{3}$ in $\mathrm{LaCl}_{3}$ has been prepared. Before the growing of the crystal was finished some observations were made. The material will be grown into a single crystal and the work refined. The Pm preparation is intensely self-luminescent. This spectrum has been taken on an $\mathrm{f} / 4$ spectrograph. The absorption spectrum of the crystalline mass has been taken and the multiplets are well grouped. One unusual effect is that upon cooling of the mass the color is a light yellow. In about 5 minutes there is a noticeable darkening and after $1 / 2$ hour the material is almost black. The blackening may be bleached by heat or irradiation with light. This suggests trapped electrons which are the end product of the decay of the soft $\beta^{\prime} s$ of $\mathrm{Pm}$ as they are degraded in the crystal. The bleaching by light permits good spectra at room temperature but since the bleaching is greatly reduced at $770 \mathrm{~K}$, absorption work at this temperature will be more difficult.

\section{THE NEAR INFRARED ABSORPTION SPECTRUM OF CeCl 3 John G. Conway}

Crystals of $\mathrm{CeCl}_{3}$ diluted in $\mathrm{LaCl}_{3}$ have been grown and the spectrum taken under low resolution. The absorption due to the transition of a single f electron from a ${ }^{2} \mathrm{~F}_{5 / 2}$ to a ${ }^{2} \mathrm{~F}_{7 / 2}$ occurs in the region of 4 to 5 microns. Under the conditions so far used two broad peaks are observed, one at 4.5 microns $\left(2200 \mathrm{~cm}^{-1}\right)$ and one at 4.2 microns $\left(2400 \mathrm{~cm}^{-1}\right)$. These peaks show polarization. Under higher resolution it should be possible to analyze this transition.

I John B. Gruber and John G. Conway, Electronic Energy Levels for Tm(IV); Electronic Energy Levels and Crystal Quantum States of Tm(IV); Crystal Field Splitting of Energy Levels of Thulium Ethylsulfate (submitted to J. Chem. Phys.) 


\title{
MASS SPECTROSCOPY
}

\author{
Frederick L. Reynolds
}

Surface ionization investigations have usually been done with polycrystalline filaments. 2 Such filaments generally exhibit a bulk work function characteristic of the polycrystalline surface. Under various heat treatments the exposed surface of the filament could well consist of large crystals in which each exposed face would present a significantly different work function. During the course of some of our work on ionization-potential determinations by the hot-filament method we have found some unexplained shifts in the Saha-Langmuir plots which could have surface work function shifts as one possible explanation. In order to check this point it became necessary to form single-crystal filament material and to know the orientation of such crystals as used in our mass spectrometer experiments. The production of single-crystal filaments is the subject of this report. This work was done on tungsten, but other refractory metals can be employed.

Attempts to grow single-crystal tungsten from 10-or 20-mil-diameter wire by the electron-bombardment-floating-zone method failed. This method has been successful on 1/8-in. -diameter tungsten rod. 3 In this method the wire was held stationary and a moving tungsten filament loop bombarded the wire with electrons of $2 \mathrm{kv}$ energy. The electron beam could be confined to a length equal to approximately twice the wire diameter, but the end-cooling rates of these small wires allowed a molten zone several wire diameters long, and a stable zone could not be maintained. A description of the apparatus appeared in an earlier semiannual report (UCRL8369).

In an attempt to stabilize the molten zone from gravitational effects a method suggested by $\mathrm{Pfann}^{4}$ was tried. This method involved passing a small current through the bombarded sample wire, now supported in a horizontal plane between the pole faces of two small permanent magnets. However, no stable molten zone produced by electron bombardment could be maintained with 10- or 20-mil-diameter tungsten wire by using this modified method.

The most useful form of single-crystal tungsten would be as ribbon filament material. Becker, 5 by private communication, suggested a method of strain annealing. In this method crystal growth takes place below the melting point of the metal. The tungsten ribbon is clamped at one end and a length of this ribbon immersed in a column of mercury. Current is passed through the ribbon, heating it to $2300^{\circ} \mathrm{C}$. The mercury column is slowly lowered. There is a large thermal gradient between the heated tungsten ribbon and the mercury column. Large grain growth is promoted by this

\footnotetext{
I J. R. Werning, Thermal Ionization at Hot Metal Surfaces, (Thesis), UCRL-8455, Sept. 1958.

I. N. Bakalina and N. I. Ionov, Soviet Physics JETP 36, 709 (1959).

${ }^{3}$ A. Calverley, J. Sci. Instr. 34, 142 (1957).

${ }^{4}$ W. G. Pfann, Zone Melting (John Wiley and Sons, New York, 1958).

5 J. A. Becker, Bell Telephone Laboratories, N. Y.
} 
method, but in a number of attempts no single-crystal material occcupying the entire cross section of the filament is produced. Under various conditions several long crystals, 2 or $3 \mathrm{~cm}$ long, were produced adjacent to each other. Both visual observation and Laue diffraction patterns showed the se to be single crystals.

Since the Nichols method ${ }^{5,6}$ ('suggested to: me by Becker) showed some promise of single-crystal growth below the melting point of tungsten, the same technique was tried, using the electron bombardment method previously described under zone melting, but keeping the temperature of the ribbonfilament-heated zone at $2300^{\circ} \mathrm{C}$. Temperature was controlled by emission regulation. Various rates of linear travel were tried but mostly bracketed around speeds of 1 to 2 in. per hour, with one attempt at a very slow rate of approximately $1 / 70$ in. per hour.

The former rate conditions produced long single-crystal material, but multiple nucleation always took place, producing three or four adjacent crystals 1 to $2 \mathrm{~cm}$ long. These could be observed under low magnification by etching the filaments in a solution of $10 \% \mathrm{~K}_{2} \mathrm{Fe}(\mathrm{CN})_{6}$ and $10 \% \mathrm{NaOH}$ for 5 to 10 seconds. The filaments were electrolytically polished in $10 \% \mathrm{NaOH}$, using a 5- to $10-v$ dc supply previous to the etching process.

The slow-rate run produced a polished surface condition that was apparently the result of long electron bombardment of the surface. This electron bombardment also produced a mild etch, and Laue diffraction patterns showed this run to be single-crystal tungsten. Additional slowrate runs are in progress.

Mass spectrometer analysis of these filaments for impurity concentration has not been completed. Their use in surface ionization studies will also be reported in a subsequent report.

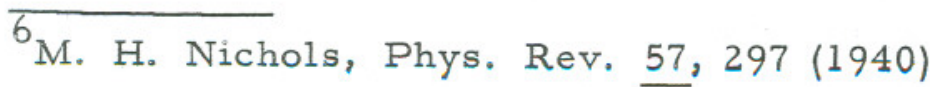




\title{
RADIATION CHEMISTRY GROUP
}

\author{
Amos S. Newton, Gilbert J. Mains, Aldo F. Sciamanna, \\ Sylvia Waters, Michael P. Sweeney, and Cao Luyen Phan
}

Several programs are in progress in the Radiation Chemistry Group. A study of the effect of electronegative groups on possible molecular rearrangements was started last year and is continuing. Recently a study of aldehydes and ketones was started. This study will emphasize the higherboiling products and the processes leading to their formation.

An attempt was made to detect radicals and triplet-state molecules formed in radiolysis by direct measurement of their absorption spectra. Porter has recently studied the absorption spectra of several radicals and triplet-state molecules by flash photolysis techniques, 1,2 and a similar setup was used to search for radicals in radiolysis. Differences were in the radiation source used. Porter used a high-intensity flash lamp to produce his radicals, but we used the microwave linear electron accelerator at LRL, and the pure compound rather than a solution. The accelerator has a beam pulse of 100-ma current of 4.5-Mev electrons of 5-microsecond duration. By single-pulse techniques, this beam was impinged on the liquid under study contained in a quartz cell. A few microseconds after the electron pulse, a xenon filled flash bulb of 5 to $20 \mu \mathrm{sec}$ duration was flashed and the collimated light from this flash was passed through the cell and was focused on the slit of a medium Hilger quartz spectrograph. The spectrum was recorded photographically. Spectra taken before and immediately after the electron pulse were compared. Porter found that solutions of toluene gave high yields of benzyl radicals by his photolysis technique. We were unable to observe such radicals in the radiolysis of pure toluene; in fact, no absorptions were observed. The beam pulse injected approximately $2 \times 10^{19} \mathrm{ev}$ into an active volume of about $10 \mathrm{cc}$ of liquid during the pulse. If $\mathrm{G}_{\mathrm{rad}}=1$, the concentration of radicals formed should have been about $3 \times 10^{-5}$ molar, which should be readily observable if the molar extinction coefficient of the radicals is higher than 104. As no absorption was observed, two conclusions are possible: first, the yield of radicals is very low, or secondly, the lifetime of the radicals formed by radiolysis in the pure solvent is shorter than about $10^{-5}$ second.

A similar experiment with anthracene dissolved in glycerine showed no observable triplet state of anthracene to be formed by radiolysis. An absorption was observed but this was shown to be caused by the flash itself, i. e. the flash was producing triplet-state anthracene which later absorbed light passing through the solution. As there is no possibility of increasing the electron-beam current to much more than $100 \mathrm{ma}$, the experiment was discontinued.

In service work for other groups, approximately 100 samples were analyzed on the mass spectrometer.

\footnotetext{
${ }^{1}$ G. Porter and W. N. Windsor, Observation of Short-Lived Free Radicals in Solution, Nature 180, 187 (1957).

${ }^{2}$ G. Porter and W. N. Windsor, The Triplet State in Fluid Media, Proc. Roy. Soc. (London) A-245, 238 (1958).
} 


\section{HOT-ATOM CHEMISTRY OF SULFUR-35}

\section{Monte L. Hyder and Samuel S. Markowitz}

A study is being made of the chemical fate of $\mathrm{S}^{35}$ atoms formed by the slow-neutron irradiation of gaseous sulfur compounds. Because sulfur has a large number of gaseous compounds these atoms may be studied in a wide range of chemical systems without the complications of condensedphase effects. Of particular interest are the extent of dissociation of the original molecule and the possibility of reactions of the free sulfur atoms while they still have kinetic energies much greater than thermal energies.

In practice these studies involve varying the conditions of irradiation (such as pressure, and amount of inert and (or) chemically active additives) and observing the amounts of the various $\mathrm{S}^{35}$-containing products formed.

Equipment, including a vacuum line and an internal gas proportional counter, has been built for handling and counting these radioactive products. Some investigations have been made on $\mathrm{SO}_{2}$, which was irradiated in the thermal column of the Livermore LPTR reactor where the flux is 3 to $6 \times 10^{11}$ neutrons $/ \mathrm{cm}^{2}-\mathrm{sec}$.

It has been found in this work that $\mathrm{S}^{35} \mathrm{O}_{2}$ may be counted internally in a proportional counter by mixing it with large quantities of methane, or $90 \%$ argon $+10 \%$ methane. A counter similar to that described by Wolfgang and $\mathrm{MacKay}^{1}$ is used. The counter, $8 \mathrm{in.}$ long by $1 \mathrm{in}$. in diameter, is constructed of brass with Teflon gaskets and a 2 -mil tungsten center wire. $\mathrm{SO}_{2}$ up to about $2.0 \mathrm{~cm} \mathrm{Hg}$ may be mixed with methane to a total pressure of 1 atmosphere before the plateau is totally destroyed. Plateau curves are shown on the accompanying Figs. 18 and 19. Best results are obtained with methane gas. The background is about $100 \mathrm{cpm}$ when 2 in. of lead is used as shielding. The $\mathrm{S}^{35} \mathrm{O}_{2}$ does not leave contamination in the counter.

the $\mathrm{S}^{35}$ The preliminary $\mathrm{SO}_{2}$ experiments show that between 15 and $20 \%$ of $\mathrm{S}_{2} \mathrm{O}$ in very small concentrations. There is, however, considerable fluctuation from sample to sample irradiated at the same $\mathrm{SO}_{2}$ pressure, which may be due to insufficient radiochemical purity. Experiments are being carried out to check the fractional-distillation method of purification, and to learn the fate of the remaining $\mathrm{S}^{35}$.

\footnotetext{
${ }^{1}$ Richard Wolfgang and C. F. MacKay, Nucleonics 16, No. 10, 69 (1958).
} 


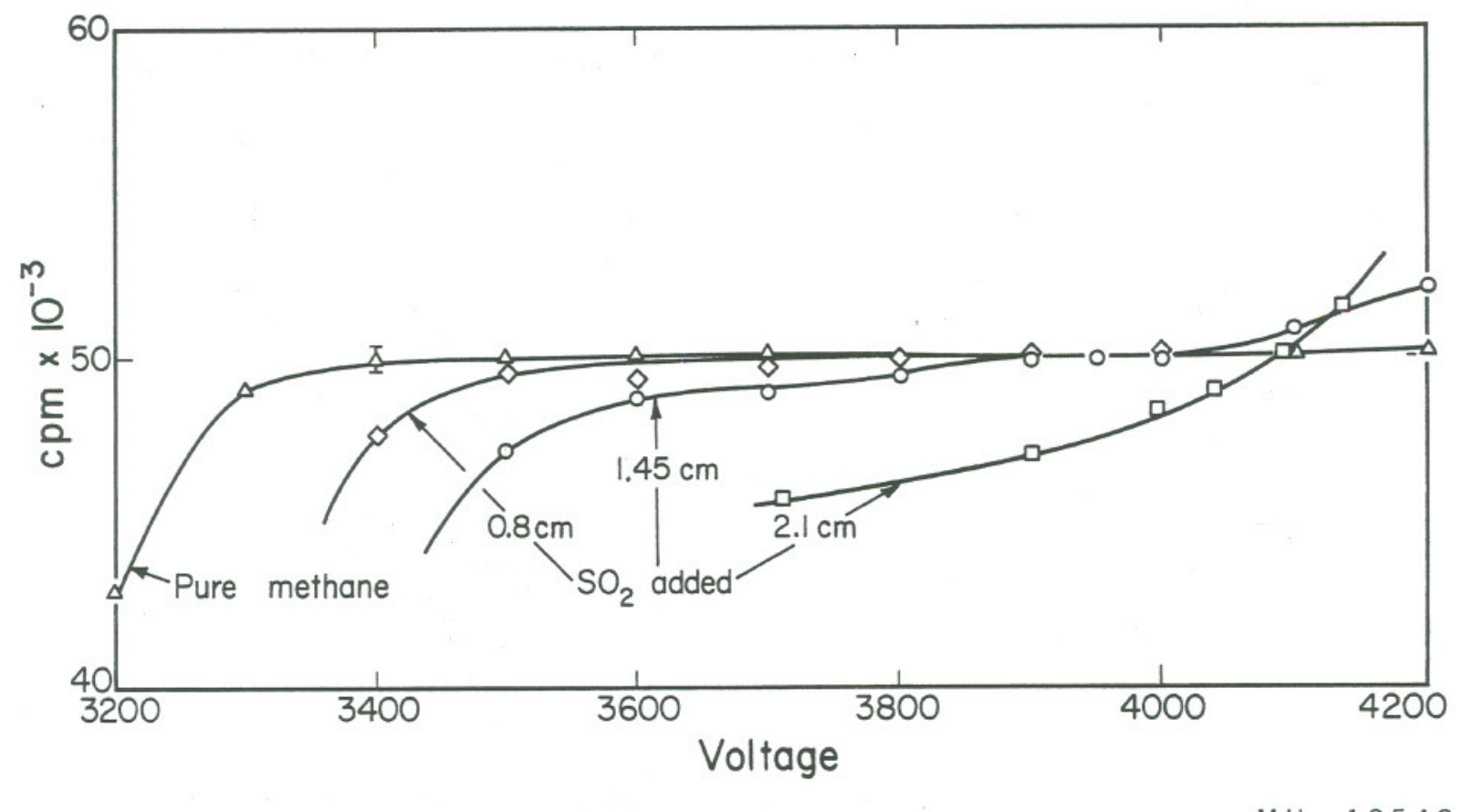

Fig. 18. Counter plateaus for methane gas plus various pressures of $\mathrm{SO}_{2}$. The source is Co60 external to the counter. 


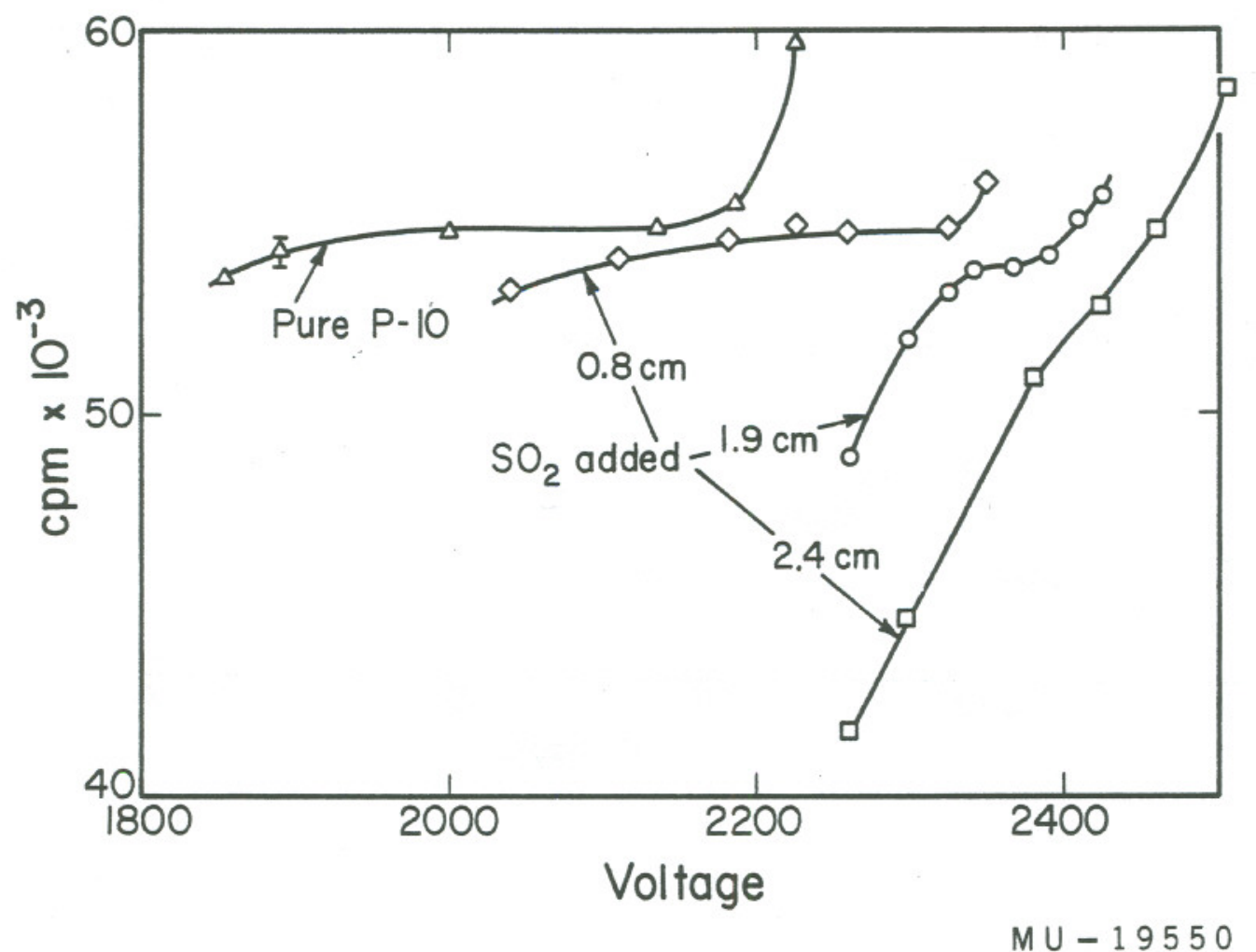

Fig. 19. Counter plateaus for P-10 gas (90\% Argon $+10 \%$ Methane) plus various pressures of $\mathrm{SO}_{2}$. The source is Co 60 external to the counter. 


\section{PREPARATION AND PROPERTIES OF CURIUM METAL James C. Wallmann and Burris B. Cunningham}

Further microgram-scale reductions of $\mathrm{CmF}_{3}$ with lithium have been carried out by using the techniques described previously. 1,2 The metal produced by the "twisted wire" method" (where 1 to $10 \mu \mathrm{g}$ of $\mathrm{CmF}_{3}$ is held by wedging it between the loops of a twisted 3-mil Ta wire) has consistently yielded metal which does not spread on the wire and is readily recovered in bulk. Two such reductions gave curium metal of double hexagonal closepacked structure. One sample was no more than about 80 atom $\%$ pure, so the observed lattice constants will not be quoted except to note that the calculated density was 13.5. A magnetic-susceptibility measurement was made on another $\mathrm{Cm}$ metal sample, but these results also are preliminary and will not be quoted.

\section{PREPARATION OF AMO AND PUO \\ Yumi Akimoto}

Americium and plutonium monoxides, $\mathrm{AmO}$ and $\mathrm{PuO}$, were prepared by the direct reaction between molten metals and oxygen that was generated from $\mathrm{Ag}_{2} \mathrm{O}$ by thermal decomposition. As predicted previously, ${ }^{2}$ the $\mathrm{x}-$ ray investigations for AmO showed the lattice constant $5.05 \mathrm{~A}$, which is about 0.1 A larger than that reported by Zachariasen et al., while the constant for $\mathrm{PuO}$ was consistent with his data.

\section{Amo preparation}

About $50 \mu \mathrm{g}$ of pure americium metal was placed in a carefully degassed quartz capillary. The upper part of the capillary was enlarged for the placement of a small quartz container which contained the stoichiometric amount of $\mathrm{Ag}_{2} \mathrm{O}$.

After rough evacuation, the system was cooled with a dry ice-butanol bath. The system was further evacuated to $10^{-6} \mathrm{~mm} \mathrm{Hg}$. It was then sealed off at the neck above the distended portion. The sealed system was removed from the bath, heated gradually to $850^{\circ} \mathrm{C}$, and kept at this temperature for 1 week.

After cooling, the capillary containing americium was sealed off from the distended portion and used for $\mathrm{x}$-ray investigations.

\footnotetext{
Wallman and Cunningham, Submilligram-Scale Production of ActinideElement Meta1, UCRL-8369, July 1958, p. 74.

${ }^{2}$ Akimoto, Cunningham, McWhan, and Wallman, The Preparation of Americium Metal, Curium Metal, Americium Nitride, and Americium Monoxide, UCRL-8867, July 1959, p. 59.
} 
PuO was made by the same technique, but the temperature was kept below $800^{\circ} \mathrm{C}$.

Both products were brittle and compact, with dark gray metallic appearance. The powder patterns, investigated by using CuK a radiation and a 4.5-cm-radius camera, were indexed as fcc $a=5.047 \pm 0.002 \mathrm{~A}$ for $\mathrm{AmO}$, and $\mathrm{fcc} \mathrm{a}=4.960 \pm 0.003 \mathrm{~A}$ for $\mathrm{PuO}$.

\section{AMERICIUM METAL: PREPARATION AND CRYSTAL STRUCTURE Denis McWhan}

Two methods for preparing americium metal are being studied. An effusion and collection method (UCRL-8867 - p. 59) has been continued. Preparations have been made for a "large-scale" reduction of americium fluoride $(50 \mathrm{mg})$ with barium metal.

By use of the former method, coatings of americium metal have been obtained on 10-mil quartz and tantalum fibers. The reductions were carried out at 1200 to $1300^{\circ} \mathrm{C}$. The temperature at which the americium oxide is prepared by decomposition of the oxalate is critical. The reduction of the americium oxide with lanthanum metal takes place rapidly only if the oxalate is decomposed at a temperature not higher than approximately $600^{\circ} \mathrm{C}$. Spectrographic analysis of the coatings shows less than $1 \%$ lanthanum. X-ray analysis has yielded a fcc structure similar to that obtained by Asprey (see table below). If the pressure is kept low during the collection period the amount of americium monoxide seen by $x$-ray analysis is small. The crystal structure of one sample has been studied up to $360^{\circ} \mathrm{C}$ by using a Von der Heyde $57.3-\mathrm{mm}$ camera. No change in structure was observed in this region. By using the Nelson-Riley extrapolation, and tantalum as an internal standard, a preliminary coefficient of thermal expansion of $a=(10 \pm 5) \cdot 10^{-6 / 0} \mathrm{C}$ was obtained over the range from room temperature to $360^{\circ} \mathrm{C}$.

In the preparation of multimilligram quantities of americium metal, several problems arise. It is found empirically that the temperature of the reduction must be kept below $1100^{\circ} \mathrm{C}$ or the product metal will be dispersed as little beads in the barium fluoride. If the temperature is much higher than this, the product will spread completely. On the other hand, the temperature and time of reduction must be sufficient to assure complete reduction of the fluoride and distillation of the excess barium. The rate of distillation of barium is optimized by varying the temperature and the size of the orifice in the crucible cap. After several reductions using lanthanum fluoride, a successful reduction of approximately $15 \mathrm{mg}$ of americium fluoride with about a tenfold excess of barium metal was made in an all-tantalum double crucible system with a $0.6-\mathrm{mm}^{2}$ hole in the cap. The reduction was carried out at $1000^{\circ} \mathrm{C}$ for 30 minutes. Spectroscopic analysis showed three atomic percent barium and an over-all purity of 93 atomic percent Am. X-ray analysis showed a dhcp structure on the basis of 18 of the 19 measurable lines. 
The present status of the crystal-structure determinations of americium metal is summarized below:

\begin{tabular}{lccccc}
\hline Structure & Item & $\begin{array}{l}\text { Ref- } \\
\text { ence }\end{array}$ & $\begin{array}{c}\text { Lattice constants } \\
\text { (A) }\end{array}$ & $\begin{array}{c}\text { Density } \\
(\mathrm{g} / \mathrm{cc})\end{array}$ & $\begin{array}{c}\text { Metallic radius } \\
\mathrm{CN}=12\end{array}$ \\
\hline dhcp & A & 1 & $\begin{array}{l}\mathrm{a}_{0}=3.642 \pm .005 \\
\mathrm{c}_{0}=11.76 \pm .01\end{array}$ & $11.87 \pm .05$ & 1.82 \\
\hline (fcc) & B & 2 & $\left(\mathrm{a}_{0}=5.10\left(600^{\circ} \mathrm{C}\right)\right)$ & & \\
\hline dhcp & $\mathrm{C}$ & 3 & $\mathrm{a}_{0}=3.47 \pm .01$ & $13.7 \pm .1$ & 1.73 \\
\hline fcc & $\mathrm{D}$ & 4 & $\mathrm{a}_{0}=4.895 \pm .010$ & $13.65 \pm .11$ & 1.73 \\
& $\mathrm{E}$ & 5 & $\mathrm{a}_{0}=4.897 \pm .003$ & & \\
& $\mathrm{~F}$ & 6 & $\mathrm{a}_{0}=4.893 \pm .005$ & 13.66 & 1.730 \\
\hline
\end{tabular}

1. Graf, Cunningham, and others, J. Am. Chem. Soc. 78, 2340 (1956).

2. High-temperature studies by Peter Graf。 1

3. This study.

4. This study; sample collected on quartz fiber; Cohen's least-square method used to determine $a_{0}$.

5. This study: sample collected on tantalum fiber; Nelson-Riley extrapolation used with tantalum as internal standard.

6. L. B. Asprey and F. H. Ellinger (Los Alamos Laboratory); reported by Asprey in private communication.

It is probable that the fcc structure, $D, E$, and $F$, is a quenched high-temperature form of $\mathrm{C}$, as the americium is vaporized and collected on a fiber which is probably at about 100 to $200^{\circ} \mathrm{C}$. This is in agreement with reductions of americium fluoride with lithium made by J. C. Wallmann in which varying amounts of $f c c, h c p$, and dhcp structures were fiound. Also, metal prepared by the vaporization method by Asprey has shown mixtures of hcp and fcc. Ellinger found that on annealing of these samples the intensity of the hcp 10.1 line increased and fcc 200 and 331 lines decreased, 6 indicating that the fcc structure is a higher-temperature form.

The difference in the metallic radius of the two dhcp phases is quite surprising. The major differences in preparation were:

(a) Graf used resistance heating and a thoria crucible cap, and annealed his sample by cooling from $1000^{\circ} \mathrm{C}$ to room temperature over an 8-hour period.

(b) This study used induction heating and an all-tantalum system, and no annealing (although the system is such that it takes overnight to reach room temperature, the initial drop is sharp).

These differences are being investigated. Also an $\mathrm{x}$-ray camera to study small samples at high and low temperatures is being constructed to see if americium is similar to cerium, which exhibits a "collapsed" phase below liquid nitrogen temperatures. 


\title{
STRUCTURES OF ORGANIC COMPOUNDS
}

\author{
George L. Hardgrove, F. J. Strieter, and David H. Templeton
}

The structures of several organic crystals, refined by Fourier and least-squares methods, have been reported in two $\mathrm{Ph}$. D. theses. George Hardgrove, The Crystal Structures of Several cis-1,2-Dihalobenzocyclobutenes, UCRL-8803, June 1959, reports structures for the monoclinic dichloro compound at two temperatures and for the orthorhombic dibromo and diiodo compounds. Frederick J. Strieter, The Crystal Structures of Several Organic Compounds, UCRL-8906, Sept. 1959, reports structures for an addition compound of $\mathrm{p}$-xylene and carbon tetrabromide, for propionic acid, and for n-butyric acid.

In the dihalides, the interesting features of the results are the bond distances in the highly strained four-member rings, and the bond angles of the halogen atoms, which reveal progressively the strain of these atoms in close proximity. In the addition compound, one observes secondary bonding from bromine to the benzene ring, with each ring having a bromine atom on each side, just on the 6 -fold axis of the ring. In the two fatty acids, interest centers on the hydrogen bonding into dimers, and on the short bonds (1.50 and $1.48 \mathrm{~A})$ from the carbonyl to the adjacent carbon atom.

\section{POLARIZED OCTAHEDRA IN BARIUM TETRATITANATE}

\author{
David H. Templeton and Carol H. Dauben
}

Single-crystal $x$-ray diffraction studies show that $\mathrm{BaTi}_{4} \mathrm{O}_{9}$ is orthorhombic, space group Pmmn, with $a=14.53 \pm 0.02, b=3.79 \pm 0.01$, and $c=6.29 \pm 0.01 \mathrm{~A}$, with two formula units per unit cell and calculated density $4.54 \mathrm{~g} \mathrm{~cm}^{-3}$. The atomic positions have been determined by leastsquares methods. An interesting feature of this structure is that titanium atoms occur at points $0.30 \mathrm{~A}$ and $0.21 \mathrm{~A}$, respectively, from the centers of gravity of the oxygen atoms of two kinds of octahedra. This polarization of the octahedra is similar to or greater in magnitude than that observed in the ferroelectric phases of $\mathrm{BaTiO}_{3}$ and $\mathrm{PbTiO}_{3}$. This tetratitanate is not polar, because half the octahedra of each kind are polarized in one way and the other in the opposite way. Nor is it antiferroelectric as that term is customarily defined. An extensive account of this work (by these authors and under this title) has been issued as UCRL-8923, October 1959. 


\section{LEAST SQUARES AND CHOICE OF ORIGIN IN POLAR SPACE GROUPS \\ David H. Templeton}

A theoretical study has been made of the way in which one atomic coordinate is statistically correlated with the corresponding coordinate of another atom in a crystal belonging to a polar space group. This correlation depends on the precise manner in which the origin is defined. Some of the consequences of these correlations in the refinement of structure by least squares have been calculated. This work is reported (by this author under the above title) in. UCRL-8751, August 1959. 
Instrumentation

\title{
A NEW PERMANENT-MAGNET $\beta$-SPECTROGRAPH
}

\author{
Bent Elbek and Jack M. Hollander
}

Permanent-magnet $\beta$ spectrographs utilizing deflection through 180 deg in a homogeneous magnetic field have for several years been extremely useful for the investigation of decay schemes in this laboratory. The main disadvantage of this type of instrument is its relatively low transmission, which necessitates strong sources.

By adapting focusing principles originally developed for use in magnetic spectrographs for heavy particles, it should, however, be possible to construct a spectrograph preserving most of the valuable properties of the $180-\mathrm{deg}$ instrument but having a higher transmission. Such an instrument would bring within scope experiments otherwise difficult for reasons of intensity.

For the actual construction of a spectrograph the sector geometry shown on Fig. 20 was selected. The angle of incidence for the median rays is $35 \mathrm{deg}$. Because of the special position of the point of entrance on the extension of the straight-line exit boundary, all the median rays leave the field under the same angle irrespective of energy. The sector angle was chosen to be $108.8 \mathrm{deg}$. This angle ensures, to very close approximation, focusing of second order along all points of the slightly curved focal line. The photographic plate used as detector for the electrons is in a plateholder bent to follow the focal line accurately. The fringing field of the magnet on the entrance side gives some focusing in the direction of the lines of force (vertical focusing), whereas on the exit side there is a defocusing in this direction. For the range of energies focused there is a net gain in transmission from vertical focusing. Most of the increase in transmission for a given resolution (relative to a 180-deg instrument) will, however, be due to the larger permissible angle of acceptance in the horizontal plane. The expected increase in transmission relative to a $180-$ deg instrument is a factor of about 5 .

An instrument of this type has been constructed, and a preliminary experimental investigation confirms the theoretical predictions quite well. Thus the improvement in transmission relative to an existing $180-$ deg spectrograph of similar dimensions appears to be by a factor of 2 for low energies, increasing to a factor of 5 for medium and high energies. The resolution is of the order of $0.2 \%$. The instrument is presently being used in collaboration with Richard $M$. Diamond in an investigation of the decay of platinum isotopes produced by bombardment of tantalum with carbon ions in the Hilac. 


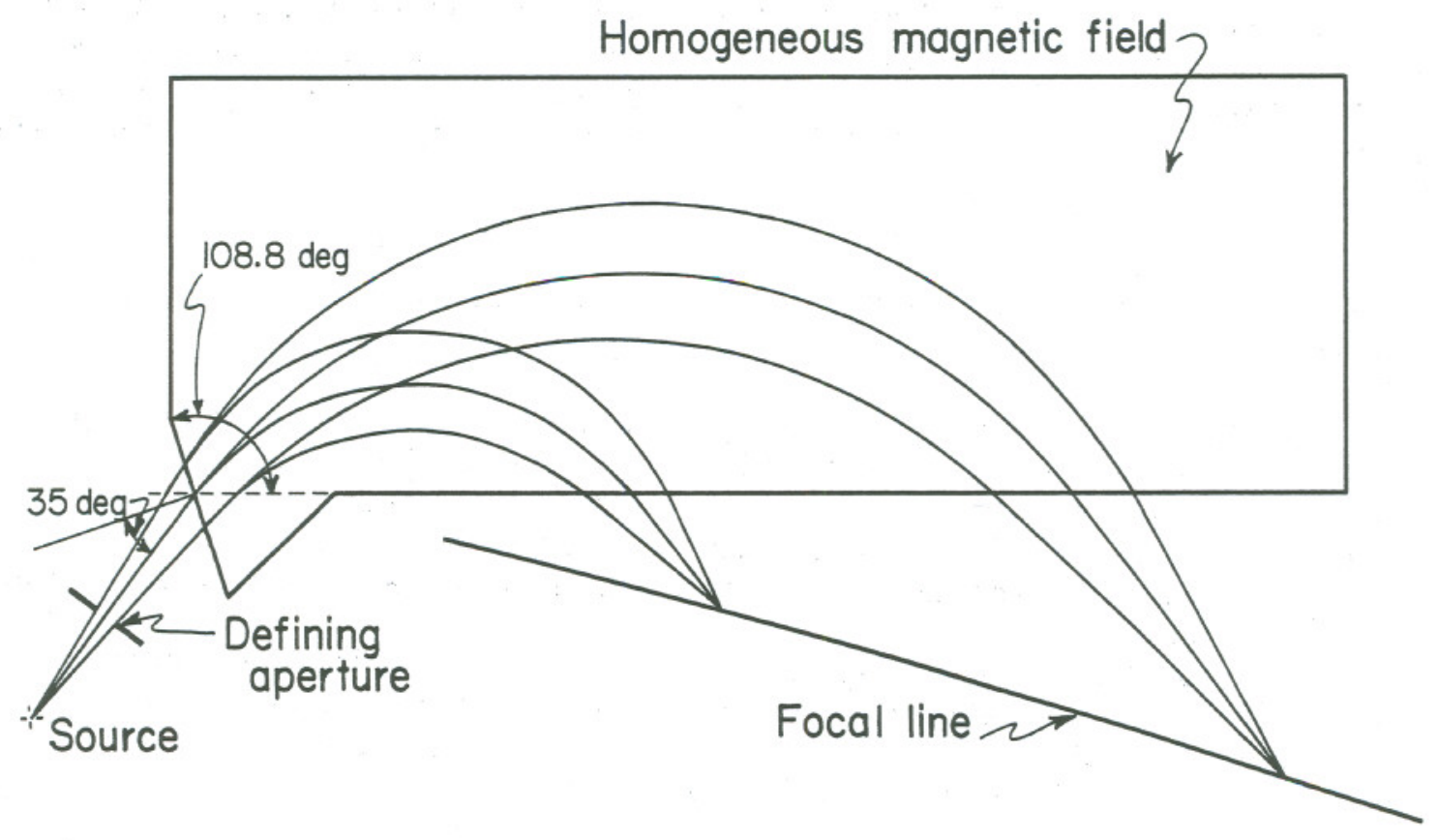

$M U-19551$

Fig. 20. Sector geometry for permanent-magnet $\beta$ spectrograph. 


\section{MODIFICATION OF 25-cm DOUBLE-FOCUSING $\beta$ SPECTROMETER}

Daniel J. Horen and Jack M. Hollander

A program of modification of the $25-\mathrm{cm}$ double-focusing beta spectrometer has been undertaken. The following changes have been made or are planned:

1. The former Geiger-counter assembly has been removed and has been replaced by a proportional counter, of a type used by Langer and his group at Indiana University. It is hoped that this counter will prove more reliable in operation and will accept higher counting rates than the Geiger counter.

2. A new, more precise, counter slit system has been installed, which permits external adjustment of both the counter slit width and the counter radius.

3. The source holder is being replaced by one of a new design which permits the placement and removal, from outside the machine, of an external converter assembly to be used for photoelectron and conversionelectron measurements with the same source. With this arrangement it is possible to measure absolute conversion coefficients in this spectrometer.

4. It is planned to study the exact magnetic-field distribution in the spectrometer. If necessary, the field shape will be shimmed to approximate more closely the theoretical shape. This will allow use of a higher solid angle without sacrifice in resolving power. 


\section{ABSOLUTE BETA COUNTING}

Samuel S. Markowitz, H. Marshall Blann, Frank Wilson, Ralph G. Korteling, Eldon L. Haines, Ursula Abed, and Edward Jeung

A program is under way to calibrate the existing-end-window proportional counters for absolute beta counting. Curves are being determined for efficiency (here defined as $\beta$ counts registered per minute $\div \beta$ dis integrations in sample per minute) as a function of average energy, of sample thickness, and of shelf position. A small amount of data is also being collected on the effect of $Z$ of sample on efficiency. These studies are being done according to the method suggested by Bayhurst and Prestwood. 1

For the Berkeley program a sample diameter of $1.90 \mathrm{~cm}$ has been adopted; these samples are prepared by filtration through a chimney onto Whatman No, 42 filter paper. This sample is dried and mounted on double-sided Scotch tape on a 50-mil aluminum plate, covered with a 0.1or $0.25 \mathrm{mil}$ plastic film to avoid contaminating counters. Samples of zero to $\approx 25 \mathrm{mg} / \mathrm{cm}^{2}$ thickness are made and counted for each $\beta$ emitter studied. Specific-activity determination of $\beta$ "standard" solutions is accomplished by $4 \pi$ counting of gold-plated VYNS films of 10 to $20 \mu \mathrm{g} / \mathrm{cm}^{2}$ total thickness. All micropipets used have been mercury calibrated and are good to 0.1 to $0.5 \%$. Samples (macro) are analyzed for percent yield to determine total activity, while some are gamma counted for this purpose.

Some samples run so far range from $\mathrm{Pm}^{147}\left(\beta_{0} 230 \mathrm{kev}\right)$ through $\mathrm{Na}^{22}$, plotted for a particular sample thickness on an $\epsilon \mathrm{vs} \bar{E}$ graph, fall on a smooth curve within about $2 \%$. The range of values for Shelf 1 for $8 \mathrm{mg} / \mathrm{cm}^{2}$ is from 0.57 for $\mathrm{K}^{42}$ to approx 0.20 for Pm 147; this considerable range shows the importance of having calibration curves.

I Bayhurst and Prestwood, A Method for Estimating Beta-Counting Efficiencies, Nucleonics 17, No. 3, 82-85 (1959). 


\section{SOLID-STATE PARTICLE DETECTORS}

\section{William L. Hansen}

The program in semiconductor particle detectors has been limited, to date, to the study of silicon $\mathrm{p}-\mathrm{n}$ junctions. The design parameters for these devices are now well known and most of the construction problems have been solved.

Several detectors have been constructed from $3000 \Omega$-cm p-type and $100 \Omega$-cm n-type silicon. Typical energy resolutions, using natural $a^{\prime} s$, are in the range of $0.6 \%$. It has not been possible as yet to determine the noise contribution from the counter, as the resolution is always limited by preamplifier input noise.

Thus, for any given counter and radiation, the pulse height can be calculated directly from the nature of the initial silicon crystal. The depletion-layer width is given by

$$
\mathrm{W}=\mathrm{w}_{1} \mathrm{v}^{1 / 2} \text {, }
$$

where $W_{1}=1.44 \times 10^{-6}(\rho \mu)^{1 / 2}$.

$\mathrm{V}$ is the applied reverse voltage,

$\rho$ is the silicon resistivity $(\sim 3000 \Omega \mathrm{cm})$,

$\mu$ is the carrier mobility $\left(\sim 1000 \mathrm{~cm}^{2} /\right.$ volt-sec $)$.

The counter capacity is, then,

$$
C=\frac{k A}{4 \pi W} \text {, }
$$

where

A is the counter sensitive area,

and

$\mathrm{k}$ is the dielectric constant (12 for silicon).

The output voltage pulse height is, then,

$$
\mathrm{V}=\frac{\mathrm{e} E}{3.6 \mathrm{C}} \text {, }
$$

where

and

$e=$ electronic charge (in coulombs),

$\mathrm{E}=$ incident radiation energy lost in depletion layer.

As an example, a counter $1 / 8 \mathrm{in}$. in diameter with $500 \mu$ depletion width gives an output pulse height of $24 \mathrm{mv}$ for a $6-\mathrm{Mev}$ energy loss. In practice, the counter area is limited to less than $2 \mathrm{~cm}$ in diameter by the size of silicon crystals available, and the depletion-region width is limited to about 20 to 30 mils because of the high reverse voltage needed. 
The counter-window thickness has been found to be essentially zero if the junction is less than about $1 / 4 \mu$ from the surface. With junction depths of about $1 / 4 \mu$, no absorber effect could be seen in the products from the spontaneous fission of $\mathrm{Cf}^{252}$.

These counters appear to have many desirable characteristics when used to count highly ionizing particles in the presence of more penetrating radiation, because of the energy selectivity it is possible to achieve simply by varying the applied voltage. The counters, even in the presence of a large background of $\mathrm{C}^{14}, \mathrm{a}, \beta$, and $\gamma$, give a clean fission-product spectrum from a gold or uranium target irradiated with $\mathrm{C}^{14}$ nuclei on the Hilac. Attempts have been made to use the counters to measure $d E / d x$ for particles from the 60-inch cyclotron, but the expected energy resolutions have not been obtained. For example, with 8.4 mils of silicon the energy resolution for $48-\mathrm{Mev}$ a particles $(\Delta \mathrm{E} \approx 6 \mathrm{Mev})$ is $9 \%$, while the statistical scattering due to the Landau effect gives $2.4 \%$. However, this effect seems to be due to a lack of parallelism of the crystal faces.

The rise time of the voltage pulse has been measured and found to be less than $7 \mathrm{~m} \mu \mathrm{sec}$. Calculations based on resistivity and charge-carrier mobility indicate rise times in the range $10^{-9}$ to $10^{-12} \mathrm{sec}$ depending upon the applied voltage.

This program with silicon junctions will continue, with immediate emphasis on surface protection of the junction and on extending the depletionlayer width.

\section{A PRECISION HIGH-GEOMETRY ALPHA CHAMBER}

\section{Herman P. Robinson}

A relatively high-geometry alpha chamber has been designed, constructed, and tested which permits precision measurements on alpha sources deposited on a backing plate. The acceptance angle is chosen so that backscattered particles are excluded, and this limits the geometry to not more than approximately $\pi$ steradians.

A conventional counter configuration of such transmission would suffer in precision because of the large uncertainty in geometry caused by very small variations in axial position of the source. To overcome this defect a central axial stop is placed in such a manner that compensation for axial variation is obtained over a suitable range. Additional compensation is incorportated to reduce the effects on geometry of a lateral translation of the source, or use of an extended source. Figure 21 shows the design of the precision alpha chamber. 


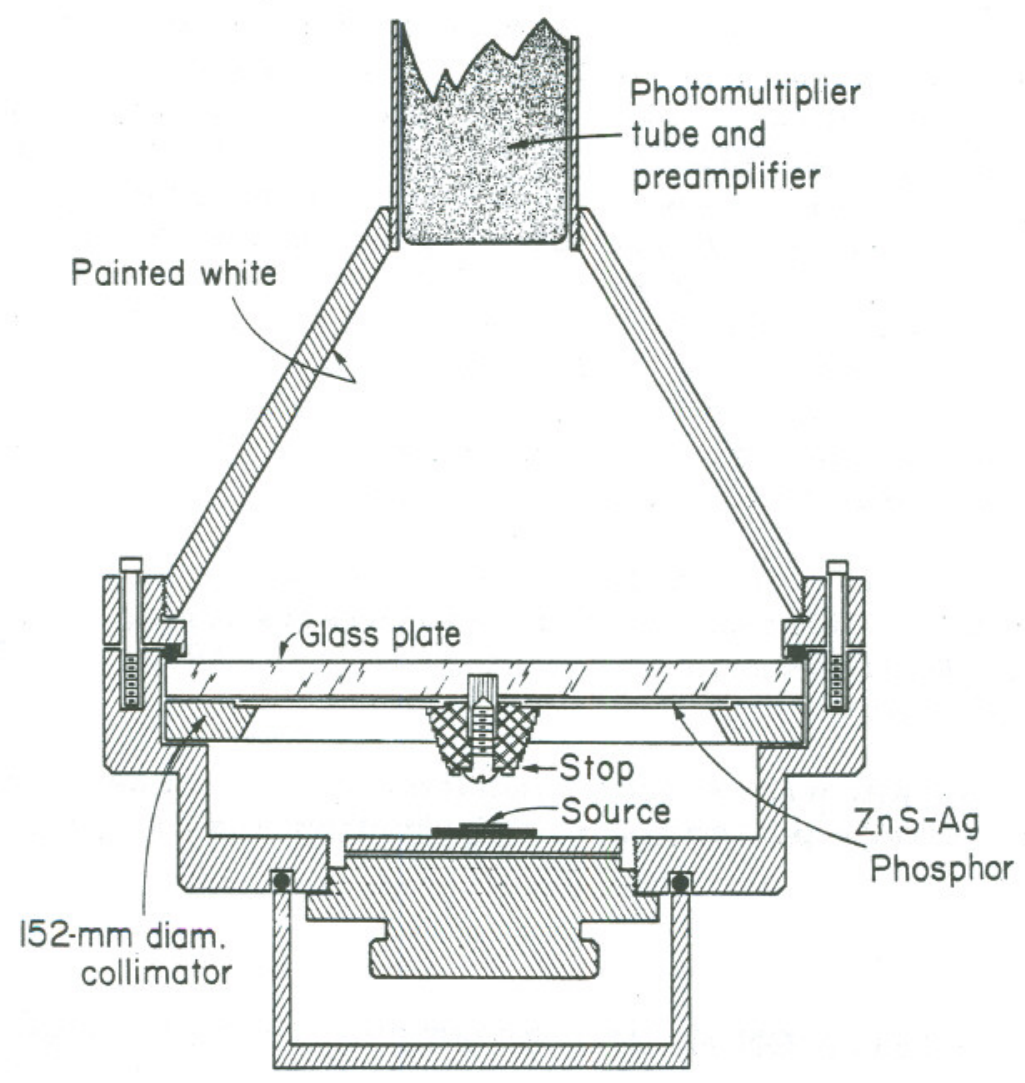

MU-18341

Fig. 21. Precision high-geometry alpha chamber. 


\section{GENERAL CHEMISTRY}

Leo Brewer, Robert E. Connick, and Kenneth S. Pitzer in charge

Metals and High-Temperature Thermodynamics

\section{ABSOLUTE-LIFETIME APPARATUS \\ Robert Berg and Leo Brewer}

The lifetime apparatus with two time-scale regions has been completed. Additional tests are proceeding using iodine as a testing molecule. The first high-temperature molecule to be studied is LaO.

Report Issued

Fred E. Stafford, Measurement of Radiative Lifetimes: Part I, An Apparatus for Measurement of Millimicrosecond Radiative Lifetimes of Gas-Phase Molecules; and Part II, The Radiative Lifetime of the B $\mathrm{O}_{u}^{+}$ State of $\mathrm{I}_{2}$ by Two Absolute Absorption Methods. (Thesis) Part III (with Jerry M. Sakai), Appendix: Description of Electronic System; UCRL-8854, Sept. 1959.

\section{MAGNESIUM OXIDE AND HYDROXIDE GASEOUS SPECIES}

Sandor Trajmar and Leo Brewer

The effect of hydrogen upon the ultraviolet bands of $\mathrm{MgO}$ is being studied in an effort to determine whether the band system is due to hydroxide molecules or whether the spectral region consists of a mixture of oxide and hydroxide spectral features.

\section{ABSOLUTE ABSORPTION COEFFICIENT OF $\mathrm{C}_{2}$ AND CN Sandor Trajmar, Lucy Hagan, and Leo Brewer}

Measurements of the intensity of emission by $\mathrm{CN}$ and $\mathrm{C}_{2}$ molecules in the King furnace are being made in order to fix the absolute absorption coefficient for the molecules.

\section{THERMODYNAMIC COMPILATIONS}

\section{Leo Brewer and Kenneth S. Pitzer}

Extensive compilations of thermodynamic data for the elements, halides, oxides, and a number of other substances have been prepared for inclusion in the revised edition of Lewis and Randall's Thermodynamics. 
Theoretical Studies

\section{THEORY OF BONDING OF GASEOUS HALIDES AND OXIDES OF TRANSITION METALS \\ Robert Berg and Oktāy Sinanoglu}

Ligand field theory has been applied to the prediction of excited electronic states and heats of formation of gaseous diatomic and triatomic halides and oxides of the transition metal elements. A paper has been. prepared: Robert A. Berg and Oktay Sinanoglu, Ligand Field Theory of Linear Gaseous Molecules. Involving the First Transitions Series Elements, submitted to J. Chem. Phys.

\section{LOW EXCITED STATES IN $\mathrm{C}_{2}$ MOLECULE \\ Enrico Clementi and Kenneth S. Pitzer}

This work is complete and has been reported by Clementi and Pitzer, J. Chem. Phys. (in press).

\section{CALCULATION OF THE "f NUMBERS" FOR ALLOWED TRANSITIONS IN $\mathrm{C}_{2}$ MOLECULES \\ Enrico Clementi}

The experimentally known transitions and some of the yet unknown transitions are considered in this calculation. This work is completed and will be reported in a separate paper.

\section{ABUNDANCE OF C 2 MOLECULE IN THE SOLAR REVERSAL LAYER} Enrico Clementi

Work is in progress.

$$
\begin{gathered}
\text { PROBABILITY OF THE }{ }^{3} \prod_{\mathrm{u}} \rightarrow{ }^{1} \Sigma^{+} \text {g FORBIDDEN TRANSITION } \\
\text { IN C }{ }_{2} \text { MOLECULE }
\end{gathered}
$$

Enrico Clementi and Kenneth S. Pitzer

This computation requires essentially the following steps: (a.) computation of the spin-orbital coupling matrix elements, (b) computation of $f$ number of several allowed transitions. Work is in progress. 


\section{ELECTRONIC STATES OF $\mathrm{C}_{3}$ MOLECULE \\ Enrico Clementi and Kenneth S. Pitzer}

Work is in progress on more refined calculations than those published in a recent paper on large molecules in carbon vapor. 1 The approach is similar to that used for $\mathrm{C}_{2}$.

\section{GENERAL THEORY OF "CORE POLARIZATION" AND INTER - AND INTRA-ATOMIC "VAN DER WAALS" FORCES \\ Oktay Sinanoglu}

The usual theories of "London-forces" as well as the polarization of a core by a valence electron--e.g., in alkali atoms--depend on multipole expansions considering the systems widely separated.

From a generalized perturbation treatment it is shown that, even for very close electron groups such as the shells of an atom and where firstorder energies are large, the correlation energy can be represented as a "fluctuation" potential determined by one group acting on the other. 2 Thus these energies can sometimes be obtained semi-empirically. This approach also gives some additional justification to the " $\pi$-electron approximation" in organic molecules.

\section{"CORE POLARIZATION" IN ALKALI MOLECULE-IONS \\ Oktay Sinanoglu and Earl M. Mortensen}

The contribution of the polarization of the cores by the outer electron to the binding energy of alkali molecule ions such as Lit, $\mathrm{Na}+$, are being calculated by using the core-polarization potentials obtained from the free atoms.

\footnotetext{
$\overline{1_{\text {Kenneth S. }}}$. Pitzer and Enrico Clementi, Large Molecules in Carbon Vapor, J. Am. Chem. Soc。 81,4477 (1959).

${ }^{2}$ Oktay Sinanoglu, Intermolecular Forces and Statistical Mechanics, (Thesis) UCRL-8835, August 1959.
} 
Spectroscopy

\title{
INFRARED SPECTRA OF MARGINALLY METALLIC SYSTEMS
}

\author{
Tad Beckman, Enrico Clementi, and Kenneth S. Pitzer
}

The reflection of infrared light from surfaces of liquid ammoniasodium solutions is to be studied. Work is now being completed on the construction of a suitable reflection cell. It is hoped that results will yield some information on the transitions between metallic, semiconducting, and electrolytic states.

\section{MICROWAVE SPECTROSCOPY AT ELEVATED TEMPERATURES}

\section{John Howe}

The design of a microwave spectrometer for use at elevated temperatures (about $1000^{\circ} \mathrm{C}$ ) is nearly complete and construction will begin shortly. Because of the limited flux available from even poorly collimated molecular-beam sources, and because of the low signal levels resulting from molecular absorption in the microwave region, it is necessary to use a static-sample method in which the cell and the sample vapor can be heated to elevated temperatures; furthermore, the absorption cell must make provision for a. Stark modulation electrode assembly. Although the ultimate test lies in whether or not the instrument operates successfully, we believe that the design makes adequate provision for coping with these difficulties.

That it is worth the effort to attempt to surmount these difficulties can be seen from the following considerations. In the first place, there is a large class of simple molecules whose vapor pressures at or near room temperature are too small to permit observation of their pure rotation absorption spectra. However, at elevated temperatures, their spectra can be observed, with the result that values of internuclear distances (and angles), of changes of these quantities with vibrational state, of nuclear electric quadrupole coupling constants, and of electric dipole moments can be determined. Of particular interest in this respect are the Group Ib halides; determination of the above quantities and comparison with the known values for the Ia halides will give considerable insight into the effect of the d electron subshell and into the degree of validity of the ionic-bonding $\bar{m}$ odel.

In the second place, microwave spectroscopy, with its inherently great resolving power, will permit both qualitative and semiquantitative analysis of gas mixtures at elevated temperatures. For semiquantitative analysis of high-temperature species, microwave spectroscopy offers one unique advantage not afforded by ultraviolet or infrared techniques: that is that the peak absorption coefficient for a given transition can be quite accurately calculated if the value of the permanent electric dipole moment is known. The value of the dipole moment is determined by measuring differences in transition frequencies and does not require intensity meas urements on samples of known concentration. 


\title{
NUCLEAR-MAGNETIC-RESONANCE SPECTRA OF SOME MOLECULAR COMPLEXES
}

\author{
Juana Acrivos
}

The coupling between the magnetic moments of the protons in methyl groups and those of the ring protons in methylated aromatics has been studied by NMR. The observation of a coupling depends on the symmetry of the molecule. The observation of this coupling, which proceeds via a nuclear spin - electron spin - electron spin - nuclear spin interaction in admixed excited triplet states, depends on the symmetrical MO (molecular orbital) of the admixed excited triplet. If there exists a line of nodes pressing through the methyl group or ring protons in the excited triplets no coupling is observed.

An MO study is being carried out for toluene, the xylenes, mesitylene, and durene in order to substantiate the group theoretical conclusions reached above.

\section{NMR STUDIES OF HYDROGEN BONDING}

Jefferson C. Davis, Jr.

This work has been completed and a report has been prepared: Jefferson Clark Davis, Jr。, Nuclear-Magnetic-Resonance Studies of Hydrogen Bonding (Thesis), UCRL-8909, Oct. 1959.

\section{HYDROGEN FLUORIDE SYSTEMS}

\author{
Edward A. Cohen and Kenneth S. Pitzer
}

Some acid-base systems in hydrogen fluoride are being studied by NMR. In addition, studies will be made of some halogen fluoride ions in $\mathrm{HF}$ solution.

NMR: KNIGHT SHIFT IN SOLUTIONS OF CALCIUM IN LIQUID AMMONIA Judith C. Brown and Kenneth S. Pitzer

A method has been devised for conversion of $\mathrm{Ca}^{43} \mathrm{CO}_{3}$, obtained from Oak Ridge, to calcium metal. It is found that if the reaction

$$
\mathrm{CaCl}_{2}+2 \mathrm{~K}=2 \mathrm{KCl}+\mathrm{Ca}
$$

is carried out in a thoria crucible the products separate physically, yielding the desired metal.

However, preliminary NMR studies of the nitrogen and proton resonances in dilute solutions of calcium-40 metal in liquid ammonia have indicated that there is no detectable Knight shift. Electron-spin-resonance 
studies of the same solutions reveal that there are definitely paramagnetic species in solution, therefore work is being carried out at present on a determination of the absolute number of unpaired electrons.

\section{ELECTRON-SPIN RESONANCE: PARAMAGNETIC RESONANCE}

Rollie J. Myers, Jr., Norman M. Edelstein, Larry R. Doyle, and Robert G. Hayes

Work is continuing on calcite. A sample of natural calcite was found to have a strong well-resolved quartet hyperfine structure. The spectrum is due to natural (perhaps radiation-induced) $F$ centers. The hyperfine interaction may be due to an associated interstitial ion, perhaps sodium. Further work will be done on these centers. Resonance work has also been started on $\mathrm{ClO}_{3}$ and $\mathrm{HCO}$.

\section{ULTRAVIOLET: MATRIX-ISOLATION STUDIES OF CARBON VAPOR}

Kenneth S. Pitzer and Raymond W. McNamee, Jr.

A device for detection of polyatomic species of carbon in carbon vapor by means of a matrix-isolation technique has been designed and constructed. Imperfections in the vacuum design have been corrected. 
Statistical Thermodynamics

\section{SECOND VIRIAL COEFFICIENT}

Fortunato Danon and Kenneth S. Pitzer

Studies are being made on the second virial coefficient of fluids using the equation obtained by Pitzer et al. in terms of the acentric factor, $\omega .1$

A theoretical basis for this empirical equation is being sought in connection. with the core model of molecules in gases as developed by T. Kihara. 2

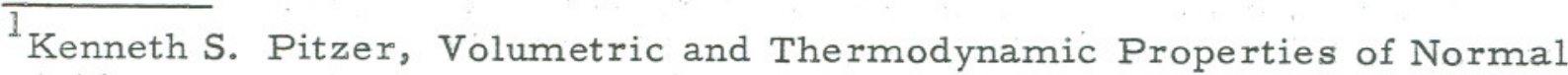
Fluids, UCRL-8093, Jan. 1958.

${ }^{2}$ T. Kihara, Revs. Modern Phys. 25, 831 (1953).
} 
Solid-State and Low-Temperature

Thermodynamics

\title{
INTERACTIONS BETWEEN MOLECULES ADSORBED ON A SURFACE
}

Oktay Sinanoglu and Kenneth S. Pitzer

This work has been reported in detail by these authors in a paper of this title, UCRL-8835, Aug. 1959.

\section{STUDIES IN THE SOLID-STATE CHEMISTRY OF SILVER OXIDE}

\author{
Kenneth S. Pitzer and Lawrence V. Gregor
}

The heat capacity of annealed $\mathrm{Ag}_{2} \mathrm{O}$ has been measured from $15^{\circ}$ to $90^{\circ} \mathrm{K}$. A rather sharp anomaly has been found at about $25^{\circ}$ if the sample is supercooled to 120 . However, this high heat capacity is not observed if the sample is cooled only to the anomalous region, i. e., 200. The entropy associated with this anomaly is about $0.3 \mathrm{cal} / \mathrm{deg} \mathrm{mole}$.

The surface areas of samples of $\mathrm{Ag}_{2} \mathrm{O}$ have been determined by the BET method to determine the effect of annealing on the surface. The surface area is markedly decreased by annealing, and an attempt is being made to correlate the decrease in surface area with the size and temperature region of the heat capacity anomaly at $25^{\circ} \mathrm{K}$.

\section{HEAT CAPACITY OF SOLID HYDROGEN UNDER PRESSURE}

\author{
William Orttung, Guenter Ahlers, and Kenneth S. Pitzer
}

Construction of the apparatus is almost completed and tests are in progress (see UCRL-8618, p. 105). The pressure and thermal parts are being tested separately. Apparatus for gas preparation is also being as sembled.

\section{HEAT CAPACITY OF BISMUTH}

\section{Norman E. Phillips}

The heat-capacity measurements on $\mathrm{Bi}$ between $0.1^{\circ}$ and $2.0^{\circ} \mathrm{K}$ have been analyzed in order to separate the contributions of conduction electrons, lattice vibrations, and nuclear alighment. The results have been submitted for publication. The value for the qudrupole coupling constant is $25 \mathrm{Mc}$, the Debye temperature $120.4^{\circ} \mathrm{K}$, and the effective mass ratio of the "holes" 0.90 . 


\section{HEAT CAPACITY OF THE ALKALI METALS AT TEMPERATURES BELOW $1^{\circ} \mathrm{K}$}

Measurements on the heat capacity of sodium and potassium have been made between 0.1 and $1.20 \mathrm{~K}$. The sodium sample does not show the previously reported anomaly near $10 \mathrm{~K}$. In both cases the effective mass of the electrons is greater than that predicted theoretically. The results have been submitted for publication.

\section{HEAT CAPACITY OF GALLIUM}

Norman E. Phillips

The heat capacity of gallium has been measured between 0.1 and $1.2^{\circ} \mathrm{K}$. The nuclear quadrupole contribution to the heat capacity becomes important below $0.2^{\circ} \mathrm{K}$. In this case the quadrupole resonance frequency is known and the calorimetric results agree well with the spectroscopic measurements, thus giving additional support to the temperature measurements in this region. The superconducting-state behavior is similar to that observed in aluminum and zinc.

\section{HEAT CAPACITY OF SMALL PARTICLES OF MgO}

William H. Lien and Norman E. Phillips

The measurements at helium temperatures have been extended to $\mathrm{MgO}$ particles of about $1000 \mathrm{~A}$ diameter. The heat capacity is appreciably smaller than that of the 100-A particles measured previously, and is of the order of magnitude of that expected from the internal degrees of freedom.

\section{TEMPERATURE SCALE BELOW $1^{\circ} \mathrm{K}$}

\section{Harry R. O'Neal and Norman E. Phillips}

Temperatures below $1^{\circ} \mathrm{K}$ are usually obtained by measurements of the magnetic susceptibility of a paramagnetic salt. Both ac and dc methods are in common use. In many cases of practical interest it is necessary to have metal present in the paramagnetic salt pill, and the resulting losses in the ac method can, in principle, change the calculated temperature. Apparatus has been constructed for an experimental investigation of this effect, with the object of evaluating the corrections that must be applied to the measured temperatures. 


\section{HEAT CAPACITY OF La-Gd ALLOYS}

\section{Norman E. Phillips}

It is possible that certain alloys of the La-Gd system may show ferromagnetism and superconductivity in the same sample. ${ }^{1}$. In order to investigate this point three series of heat-capacity measurements covering the temperature range 0.25 to $4.2 \circ \mathrm{K}$ have been made on a sample containing $0.7 \% \mathrm{Gd}$. The thermal behavior is complicated and shows hysteresis in some features, but a reproducible heat-capacity anomaly is observed at the expected ferromagnetic Curie temperature. The usual change of heat capacity associated with the transition from superconducting to normal is also observed.

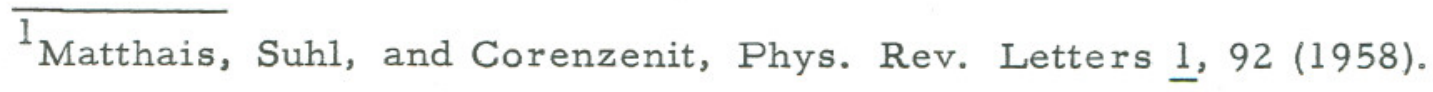


Inorganic Chemistry

\section{BIARSINE}

Leon Burright and William L. Jolly

This work has been completed and a report is bieing written.

\section{STIBINE}

Ladislav H. Berka and William L. Jolly

This work has been completed and reported: Ladislav Henry Berka, The Chemistry of Stibine (M. S. Thesis), UCRL-8781, June 1959.

\section{HYDROL YSIS OF POTASSIUM BOROHYDRIDE}

\section{Robert Mesmer and William L. Jolly}

The kinetics of the hydrolysis of $\mathrm{KBH}_{4}$ in basic solutions is being studied. The rate law determined by following the rate of disappearance of borohydride by means of a Redox titration is

$$
\frac{-\mathrm{d}\left(\mathrm{BH}_{4}^{-}\right)}{\mathrm{dt}}=\mathrm{k}_{1}\left(\mathrm{H}^{+}\right)\left(\mathrm{BH}_{4}^{-}\right)+\mathrm{k}_{2}\left(\mathrm{BH}_{4}^{-}\right) \text {. }
$$

Tentative values for the thermodynamic quantities, $\Delta H^{\dagger}$ and $\Delta S \dagger$, for both terms in the rate law were calculated from data covering the range of $25^{\circ}$ to $50^{\circ} \mathrm{C}$. This range will be extended to $10^{\circ} \mathrm{C}$. Work is in progress to learn some details about the mechanism of this reaction by using the deuterium isotope effect.

\section{SPECTRA OF METAL-AMMONIA SOLUTIONS}

\section{Marvin Gold and William L. Jolly}

Work is in progress for obtaining infrared spectra of solutions of alkali metals in liquid ammonia. A cell of light path $0.05 \mathrm{~mm}$ is maintained by circulating cold nitrogen around the cell. Pure sodium is obtained by decomposing sodium azide directly in the cell. With this very short light path, it will be possible to study the absorption peak for concentrations as high as $0.02 \mathrm{M}$, whereas previously the peak has been studied only for concentrations less than $0.002 \mathrm{M}$. 


\title{
SPECIES IN REFLUXED CHROMIC PERCHLORATE SOLUTIONS
}

James Finholt and Robert E. Connick

This work has been completed and a report is being written.

\section{RUTHENIUM STUDIES}

\author{
Dwight A. Fine and Robert E. Connick
}

The investigation of ruthenium(III) in chloride complexes has been completed. The separation and identification of two isomers of $\mathrm{RuCl}_{2}{ }^{+}$ and two isomers of $\mathrm{RuCl}_{3}$ were reported previously (in the preceding semiannual report, UCRL-8867). Two anionic complexes have been separated and identified as isomers of $\mathrm{RuCl}_{4}{ }^{-}$; identification was accomplished by study of equilibria involving the complexes. The species $\mathrm{RuCl}_{5}=$ and $\mathrm{RuCl}_{6}=$ have been characterized by spectrophotometric studies. Studies of absorption spectra and equilibria in solutions of $\mathrm{K}_{2} \mathrm{RuCl}_{5} \cdot \mathrm{H}_{2} \mathrm{O}$ have yielded information regarding the configurations of the various pairs of isomers and the compositions at equilibrium of solutions of Ru(III) in $\mathrm{HCl}$.

\section{THE EFFECT OF SALTS ON THE NUCLEAR MAGNETIC RESONANCE OF F ${ }^{19}$}

Edward E. Genser and Robert E. Connick

The earlier observations by Connick and Poulson on the chemical shift of the resonance of $F^{19}$ arising from changes in concentration of $\mathrm{NaF}$ and KF solutions have been extended to rubidium and cesium solutions. Qualitatively, the same trend appears to extend to these higher members of the series. Attempts to measure the effect in LiF solutions have so far been unsuccessful because of the low solubility of LiF.

\section{NMR STUDIES OF THE RATE OF EXCHANGE OF WATER MOLECULES IN THE FIRST COORDINATION SPHERE OF METAL IONS WITH BULK WATER MOLECULES}

\section{Diane Stover and Robert E. Connick}

\footnotetext{
Measurements of $\mathrm{T}_{2}$ values for aqueous solutions of $\mathrm{Mn}^{++}, \mathrm{Fe}^{+3}$, $\mathrm{CO}^{+2}, \mathrm{Cr}^{+3}, \mathrm{Ni}^{+2}$, and $\mathrm{Cu}^{+2}$ have been completed and the work is being written up. As was to be expected, $T_{2}$ is a linear function of the concentration of the paramagnetic ion. The data are in reasonable agreement with the earlier results of Poulson and Connick except for ferric ion, for which the present data indicate a considerably longer transverse relaxation lifetime than observed before. Measurements were made with water enriched in $\mathrm{O}^{17}$. The signals were detected by a side-band technique rather than the usual derivative method.
} 


\title{
MECHANISM OF ELECTRODE REACTIONS
}

\author{
Wayne D. Mathews and Edwin F. Orlemann
}

As part of a general program of study of the mechanism of electrode reactions the analysis of certain current-voltage curves offers particular promise in regard to identification and partial characterization of shortlived intermediate oxidation states. The current-voltage curves of interest are those obtained by the application of triangular and square wave pulses of variable frequency to a hanging-mercury-drop electrode system. An apparatus for such measurements has now been designed and assembled and should be in operation by January 1, 1960. 
Molecular-Beam Studies

STUDY OF REACTIVE COLLISIONS IN CROSSED MOLECULAR BEAMS

Dudley R. Herschbach, George H. Kwei, and James A. Norris

Much of the apparatus has been designed and the high-vacuum chamber, cold shields and traps, and pumping system are now under construction. The vacuum chamber is simply a box sitting on very fast pumps, with liquid-nitrogen-cooled shields hiding all the walls. Several kinds of experiments may be set up by mounting various auxiliary units on portholes. A special feature is a lid which rotates on ball bearings while maintaining a vacuum seal.

In the first experiments it is planned to study the reactions of alkali atoms with halogen-containing molecules. These reactions will have a high collision yield and the alkali halide formed can be detected with high sensitivity, and distinguished from the unreacted alkali, by means of surface ionization techniques. ${ }^{1}$ The beams will be formed by effusion from ovens mounted on the lid, which will be rotated to sweep the angular dis tribution of the scattered molecules past a fixed detector. The two ovens can be moved relative to each other to vary the angle of intersection of the beams. The vertical positioning of the ovens is also variable, so that the angular distribution of both the in-plane: and out-of-plane scattering can be measured.

The principal units of auxiliary apparatus now being designed are

(a) A toothed-wheel velocity analyzer, to be mounted at a second detector station;

(b) A small mass spectrometer, to be used first to enhance the sensitivity of the surface ionization detector and later to form a "universal detector" in conjunction with an electron bombardment ionizer. ${ }^{2}$

An IBM 704 computer program has been prepared for the analysis of angular-distribution data by a stochastic method.

IE. H. Taylor and S. Datz, J. Chem. Phys. 23, 1711 (1955).

${ }^{2}$ G. Fricke, Z. Physik 141, 166 (1955). 
High-Pressure Studies

\section{PRESSURE SINTERING OF INORGANIC OXIDES}

George Jura and Peter Montgomery

Experiments on sintering of oxides are continuing. Among the oxides that have been rendered transparent by pressure are $\mathrm{Gd}_{2} \mathrm{O}_{3}, n-\mathrm{Al}_{2} \mathrm{O}_{3}$, and $\mathrm{MgO}$. X-ray studies of the effect of pressure and subsequent annealing are now in progress. The data are as yet too insufficient to draw any firm conclusions. In general the line width of the sintered samples is greater, indicating a decrease in particle size.

\section{PHASE DIAGRAM OF PU AND Np}

Peter W. Montgomery, Denis McWhan, B. B. Cunningham, and George Jura

The $\mathrm{P}-\mathrm{T}$ phase diagram of $\mathrm{Pu}$ and $\mathrm{Np}$ are under investigation. The a $-\beta$ transition in $P u$ has been determined to 9,000 atm.

\section{THE GAP IN IODINE}

George Jura and Juozas R. Vaisnys

The gap between the valence band and the conduction band in iodine was measured at zero pressure and then from 30,000 to 200,000 atm. The gap at $1 \mathrm{~atm}$ is $1.5 \pm 0.2 \mathrm{v}$ and decreases to $0.18 \mathrm{v}$ at $200,000 \mathrm{~atm}$. The preexponential factor increases by three powers of 10 from 30,000 to 150,000 atm. The exact explanation of this is not as yet known.

The preliminary value for $\Delta H$ for the $\alpha-\beta$ transition is $1500 \mathrm{cal} \mathrm{mole} e^{-1}$. Further work may indicate a higher value.

\section{A PRESSURE SCALE TO 400,000 atm \\ George Jura and Juozas R. Vaisnys}

Radiographs were taken of the Bridgeman-type anvils to a loading pressure of 400,000 atm. The experiments were performed on Kennemetal K-96 and General Electric Carboloy 999 inserts. The area of contact was measured as the load increased. The softer K-96 deforms so greatly that it is useless at loads above 200,000 atm. At this load the computed pressure is 188,000 atm. The Carboloy 999 will be useful to loads over 400,000 atm. At this load, the computed pressure from the total deformation is 350,000 atm. 


\section{CHEMICAL ENGINEERING (PROCESS CHEMISTRY)}

\section{FRACTIONAL CRYSTALLIZATION FROM MELTS \\ William R. Wilcox and C. R. Wilke}

The vertical zone-melting runs have been completed. Qualitatively, the separation is greater when the rod of material is pulled up through the heater than when it is pulled down. This is believed due to the nature of the free convection currents generated in the zone. Only a few hörizontal runs remain in the zone-melting experimental program.

Currently, the heat- and mass-transfer data are being worked up.

Several physical properties of the systems used (paphthalene-benzoic acid and naphthalene-beta-naphthol) have been determined.

The cooled-drum apparatus has effected separations at fair production rates. Caution must be observed with the systems employed here, however, to maintain the liquid level well above the bottom of the drum. If this is not done the high volatility of the systems causes distillation to take place (condensing and subsequent freezing on the drum). Experiments will now be performed with salt water, in which the vapor pressure at melting is quite low.

\section{SETTLING CHARACTERISTICS OF AN IMMISCIBLE-LIQUID SYSTEM}

Victor L. Ledesma and C. R. Wilke

A study of the settling characteristics of a mixture of two immiscible liquids in a horizontal settler is being completed.

The different aspects of the problem considered are the effects on separation brought about by variation in temperature, liquid feed ratio, residence time, fluid velocity, holdup, presence of coalescing bed, and depth of coalescing bed. 


\title{
PARTIAL COALESCENCE OF A LIQUID DROP AT A LIQUID-LIQUID INTERFACE
}

Sidney B. Lang and C. R. Wilke

\begin{abstract}
A literature search and some preliminary experimental work have been completed on the problem of partial coalescence of a liquid drop at a liquid-liquid interface. A drop intitially surrounded by a second immiscible liquid phase, rather than coalescing completely in a single stage, coalesces in a series of discrete stages producing a succession of daughter drops. An experimental program based upon high-speed motion pictures is being planned to study the phenomena. A camera and cell-mounting table have been constructed for use in the motion picture studies.
\end{abstract}

\section{FORCED-CONVECTION BOILING IN TUBES}

Roger M. Wright, Robert L. Sani, and Leo A. Bromley

A report on the forced-convection boiling of degassed distilled water is being written. 1 Future investigations will cover the boiling of hydrocarbons and an extension of the present data on the boiling of water.

\section{LIQUID-LIQUID EXTRACTION AND AGITATION: PERFORMANCE OF PACKED EXTRACTION COLUMNS}

Norman $\mathrm{Li}$ and Theodore Vermeulen

Axial-mixing measurements have been made in the continuous phase (water) of a water-methyl-isobutyl-ketone system in countercurrent flow. The packings studied were 1/2-inch Raschig rings and 3/4-inch stoneware spheres. The Peclet numbers observed were somewhat lower, indicating greater mixing, than in previous runs on the water-kerosene system.

\section{COALESCENCE RATES IN AGITATED IMMISCIBLE MIXTUR ES}

James H. Vanderveen, Roger Cason, and Theodore Vermeulen

Numerical analysis of the drop-diameter profiles measured earlier has been undertaken. Although the correlations are not yet complete, it appears that the published data of Rodger, Trice, and Rushton can be reconciled with earlier data obtained in this project, on the basis of the coalescence behavior in their systems.

\footnotetext{
${ }^{1}$ Robert L. Sani, Downflow Boiling and Nonboiling Heat Transfer in a Uniformly Heated Tube (Thesis), UCRL-9023, Jan. 1960.
} 


\title{
RATE PROCESSES AT FLUID INTERFACES
}

\author{
Alphonse Hennico and Theodore Vermeulen
}

In connection with the distribution of a solute between two partially miscible solvents flowing countercurrently in an idealized "piston-flow" extraction column, calculations have been begun (using the IBM-650 computer) to determine the extent by which coexisting compositions in such a column may possibly deviate from the mutual-solubility curve.

\section{LIQUID DIFFUSION}

J. Holmes, C. R. Wilke, and Donald R. Olander

Twelve horizontal-diaphragm diffusion cells have been calibrated with $0.2 \mathrm{~N}$ hydrochloric acid.

The problem of a mass-transfer resistance outside the diaphragm was investigated. The external mass-transfer coefficients were measured by means of limiting-current experiments in a special electrochemical cell which has the same geometry as the diffusion cell. It was found that the external resistance is small and of the same order of magnitude for all liquids under study (including the calibration solution) at stirring speeds of 300 to $400 \mathrm{rpm}$. Free-convection data showed that density-stirred cells would give large errors (5 to $10 \%$ ) for a measurement on a very dilute solution after calibration with $0.2 \mathrm{~N}$ hydrochloric acid.

Work is being started on measuring the diffusion coefficients of toluene in mixed normal hydrocarbon solvents.

\section{LONGITUDINAL DISPERSION IN BEDS OF FINELY DIVIDED SOLIDS}

Jerry M. Robinson, C. R. Wilke, and Andreas Acrivos

The effect of the boundary conditions used in solving the differential equation describing either interdispersion of two gases or the gas-liquid partition chromatography process has been studied. It was found that a bed of particles of finite length $L$ may be considered to be the same as a portion of length $L$ of an infinite bed.

Peclet numbers for a column packed with glass spheres have been measured by using an experimental technique involving the use of a pulsed input to the column. At present the experimental technique is being checked by using a step-function input to the column. If the technique is found to be acceptable, the data will lead to the determination of Peclet number as a function of Reynolds number.

Information Division 
This report was prepared as an account of Government sponsored work. Neither the United States, nor the Commission, nor any person acting on behalf of the Commission:

A. Makes any warranty or representation, expressed or implied, with respect to the accuracy, completeness, or usefulness of the information contained in this report, or that the use of any information, apparatus, method, or process disclosed in this report may not infringe privately owned rights; or

B. Assumes any liabilities with respect to the use of, or for damages resulting from the use of any information, apparatus, method, or process disclosed in this report.

As used in the above, "person acting on behalf of the Commission" includes any employee or contractor of the Commission, or employee of such contractor, to the extent that such employee or contractor of the Commission, or employee of such contractor prepares, disseminates, or provides access to, any information pursuant to his employment or contract with the Commission, or his employment with such contractor. 